\title{
Phosphate Glasses
}

\author{
Francisco Muñoz ${ }^{1}$, Jean Rocherullé ${ }^{2}$, Ifty Ahmed ${ }^{3}$, Lili Hu ${ }^{4}$ \\ ${ }^{1}$ Institute of Ceramics and Glass (CSIC), Madrid, Spain \\ ${ }^{2}$ University of Rennes I, Rennes, France \\ ${ }^{3}$ University of Nottingham, $U K$ \\ ${ }^{4}$ Shanghai Institute of Optics and Fine Mechanics (CAS), Shanghai, China
}

\begin{abstract}
This chapter is dedicated to the studies on phosphate glasses, from their fundamental aspects to their most relevant applications of today. $\mathrm{P}_{2} \mathrm{O}_{5}$-based glasses have experienced a continuously increasing number of published works in the last decades and still they possess a bright potential. Their sometimes intricate structure has made its study a quite relevant field for the Glass Science community which attracts more and more researchers. And, on the other hand, the associated difficulties in their preparation on a large scale have led to the development of specific methods, such as those used for the melting of Nd-laser glasses. They are particularly known to have a low chemical durability, though the progress in the optimization of their composition demonstrates that can be very competitive and, in this respect, we will also pay attention to the improvement of their properties as a result of their nitridation. The structure and main physico-chemical properties of phosphate glasses will be reviewed, highlighting the most relevant and well-known applications existing nowadays, such as sealing and laser glasses, biomedical, as solid electrolytes or for the storage of wastes.
\end{abstract}


Table of Contents

1.1 Introduction

1.1.1 Phosphorus and Glass Formation

1.1.2 Research and Uses of Phosphate Glasses

1.2 The Structure of Phosphate Glasses

1.2.1 Vibrational Spectroscopies

1.2.2 Nuclear Magnetic Resonance

1.2.3 X-Ray and Neutron Diffraction Techniques

Computational Modelling

1.3 Properties and Applications

1.3.1 Chemical Properties

Oxynitride Phosphate Glasses

1.3.2 Thermal Properties

Low-Temperature Sealing Applications

1.3.3 Optical Properties

Neodymium Phosphate Laser Glass

1.3.4 Biomedical Applications

1.3.5 Electrical Properties

Solid electrolytes for battery applications

1.3.6 Phosphate Glasses for Waste Storage 


\subsection{Introduction}

The study of phosphate melts and glasses dates back to the time when Otto Schott (18511935) was devoted to the investigation of salt melts. Among them, he observed that phosphate salts formed homogeneous melts as chlorides, fluorides, sulfates or carbonates do [1]. Then, from 1881, after he started working together with Ernst Abbe in Jena on the production of new glasses and the study of their optical properties, Abbe wrote to Schott "The versatility of phosphoric acid is fabulous" [1]. However, due to the technical impediments in melting large numbers of batches at the time, they soon realized of the difficulties to attain big, homogenous and crystals-free phosphate glasses. Furthermore, in trying to produce mixtures of $\mathrm{SiO}_{2}, \mathrm{~B}_{2} \mathrm{O}_{3}$ and $\mathrm{P}_{2} \mathrm{O}_{5}$ Schott stated that phosphorus oxide exhibited a hostile behavior causing opalescence melts. Nowadays, everyone knows, and has to be aware, of the troubles associated to the melting of phosphate glasses, not to mention their sometimes extremely high dissolution rate in aqueous media.

\subsubsection{Phosphorus and Glass Formation}

Phosphorus has an unquestionable role in both Inorganic Chemistry and Biochemistry thanks to the great number of different bonding configurations that it can adopt, similar to $\mathrm{S}$ [2]. The ground state electronic configuration of $\mathrm{P}$ is $[\mathrm{Ne}] 3 \mathrm{~s}^{2} 3 \mathrm{p}^{3}$ and it is predominantly present in oxidation states III and V. Phosphorus itself exists in many allotropic forms and, when combined with oxygen, may give rise to some six oxide structures among which $\mathrm{P}_{4} \mathrm{O}_{10}$, the so-called phosphorus pentoxide is the most important. $\mathrm{P}_{4} \mathrm{O}_{10}$ is as so defined because it forms molecular structures of four $\mathrm{PO}_{4}$ units in a ring arrangement, where three of the oxygens on each phosphorous are bonded to neighboring $\mathrm{P}$ atoms, the fourth being doubly bonded to phosphorus. A similar arrangement is found in glassy $\mathrm{P}_{4} \mathrm{O}_{10}$, described as 
a three-dimensional network of linked $\mathrm{PO}_{4}$ tetrahedra [2]. Figure 1.1 shows a drawing of a 3D network of fully connected $\mathrm{PO}_{4}$ tetrahedra of $\mathrm{P}_{2} \mathrm{O}_{5}$ glass.

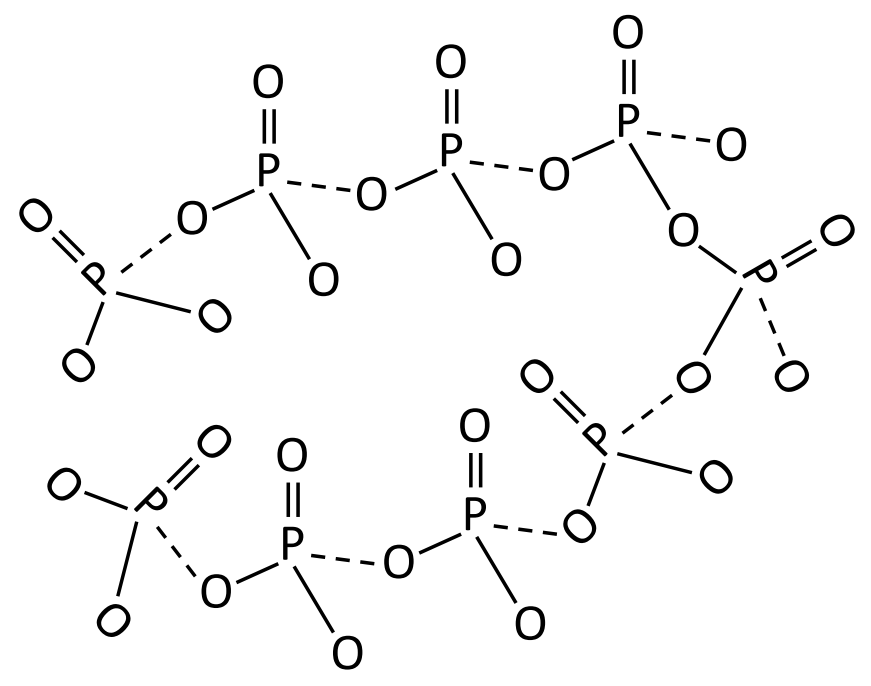

Figure 1.1: Cartoon of a network of $\mathrm{P}_{2} \mathrm{O}_{5}$ glass based on $\mathrm{PO}_{4}$ tetrahedra that are connected to neighboring groups through P-O-P bridges.

Meanwhile, compounds of phosphorus $\mathrm{V}$ are stable against oxidation state +3 , through the formation of a $\mathrm{P}=\mathrm{O}$ bond, polymeric forms of $\mathrm{P}_{4} \mathrm{O}_{10}$ hydrolyze easily to form $\mathrm{H}_{3} \mathrm{PO}_{4}$, and from here derives the extremely high dissolution tendency of phosphate glasses in water. According to the rule of Goldschmidt [3], by which a ratio of the ionic radii of cation and anion between 0.2 and 0.4 allows for glass formation, $\mathrm{P}_{2} \mathrm{O}_{5}$ is among the oxides that fulfils this condition, and thanks to its four-fold coordination to oxygens $\mathrm{P}$ was classified as a network-former element by Zachariasen [4], having the highest value of ionic field strength (2.1) as from Dietzel [5]. The higher difference between the field strength of phosphorus with those of silicon and boron make the formation of glass from mixtures of $\mathrm{P}_{2} \mathrm{O}_{5}$ with $\mathrm{SiO}_{2}$ as well as $\mathrm{B}_{2} \mathrm{O}_{3}$ particularly difficult. However, when modifier oxides are added to $\mathrm{P}_{2} \mathrm{O}_{5}$, a quite broad glass forming range can be attained in most combinations; in $\mathrm{MgO}-$ 
$\mathrm{P}_{2} \mathrm{O}_{5}$ system, for instance, the modifier oxide amount may reach $60 \mathrm{~mol} \%$ while in $\mathrm{ZnO}-$ $\mathrm{P}_{2} \mathrm{O}_{5}$ and $\mathrm{BeO}-\mathrm{P}_{2} \mathrm{O}_{5}$ can be as high as 64.8 and 67.9 mol \%, respectively [1]. After addition of a modifier oxide to the network of $\mathrm{P}_{2} \mathrm{O}_{5}$, P-O-P bonds break up and form negatively charged single bonded oxygens $\left(\mathrm{P}_{-} \mathrm{O}^{-}\right)$, whose charges are compensated with the modifier cations, and Thilo classified phosphate compositions in ultraphosphates $(\mathrm{O} / \mathrm{P}$ ratio<3), polyphosphates $(\mathrm{O} / \mathrm{P}>3)$ and metaphosphate for the case with $\mathrm{O} / \mathrm{P}=3[6]$.

When in solution, phosphate ions tend to form stable long chain structures, and being highly charged anions they will strongly associate with cations through covalent bonds, which is thought to be due to the resonance of the $\pi$-bond in the $\mathrm{PO}_{4}$ tetrahedra [7]. Similarly, it is very common in phosphate glasses to consider the double bonded oxygen as equivalent to the rest of non-bridging oxygens of the $\mathrm{PO}_{4}$ tetrahedra and in fact they become undistinguishable as in X-ray Photoelectron Spectroscopy data [8]. It is also thought that the resonance of the $\pi$-bond among all P-O bonds stabilizes the structure, most particularly for the metaphosphate compositions. As it will be seen in detail below in the section devoted to the atomic structure of the glasses, it is known following Hoppe [9], that modifier oxide additions to vitreous $\mathrm{P}_{2} \mathrm{O}_{5}$ help stabilize the network through formation of Me-O-P bonds that counteracts the de-polymerization caused by the decreasing number of P-O-P bonds.

\subsubsection{Research and Uses of Phosphate Glasses}

The most practical known use of phosphate glasses is the one water softener during washing glassware in the form of sodium hexametaphosphate $\left(\mathrm{NaPO}_{3}\right)$ or Calgon ${ }^{\circledR}$ that helps avoiding deposits of calcium. However, phosphate glasses have remained one of the 
type of glasses that have based their development on fundamental research. According to Scopus database, while the number of original publications dealing with phosphate glasses was below 10 per year from 1950 until the beginning of the 70's, it has increased exponentially over the last forty years. Due to their much lower chemical resistance than ordinary silicate glasses, phosphates have met with reticence when looking for new application fields. However, they also possess some unique properties that allow them to be employed in fields where no other glass type can achieve the same performance. It is worth mentioning that there have been two fields of application where phosphates have made extraordinary achievements, as bioglasses or glass-ceramics $[10,11]$ and laser host materials [12]. Phosphate based glasses can be formulated to have a chemical composition similar to that of mineral bone [13] and their biocompatible and bioresorbable properties make them extremely promising candidates for biomedical applications [14]. They have mainly been investigated as bioresorbable implant materials for targeted tissue repair applications, with the main advantages of having easily controllable degradation profiles coupled with ion release rates and cytocompatibility $[13,15,16]$. These tunable properties are usually controlled by varying their compositions but can also be controlled to some extent via surface area modifications [17].

Regarding their application as laser hosts, they have the advantage of having a high capacity to dissolve rare-earth elements, and thanks to their more open structure may allow the incorporation of relatively big amounts without significant clustering effects. They also have large emission cross-section and low non-linear refractive indices, which are ideal for their application as solid state matrices for the emission of laser radiation [18, 19]. However, the use of glasses as laser hosts requires the production of generally large dimensions with a very high optical homogeneity and high quantum efficiencies. Even so, 
neodymium containing phosphate glasses have been successfully applied for the production of high energy laser radiation in several projects, such as the National Ignition Facility (NIF) at the Lawrence Livermore Laboratory, in USA, the Gekko-XII in Osaka, Japan, and the Shenguang projects in China.

Another issue that has experienced a noticeable interest in the last years is related to the use of femtosecond laser irradiation to produce high refractive index waveguides [20,21] or even the three-dimensional patterning of metallic nanoparticles [22]. However, the most well-known, and useful, property that differentiates phosphate glasses is their low to very low melting temperatures, which makes the melting of phosphates less energy and time consuming. Nonetheless, the use of elevated temperatures must at the same time limited due to the ease of volatilization of phosphorus that may cause large losses from the melts as well as from alkali oxides [23]. On the other hand, their preparation often requires the use of crucible materials other than platinum-based, at least in a first stage if several melting steps are needed, due to the corrosion that phosphate glass batches usually cause. In parallel, it is found that the glass transition temperature is usually in the range of 300$500^{\circ} \mathrm{C}$, and can even fall below $200^{\circ} \mathrm{C}$ in certain cases if only alkalis are used as modifiers and the glasses are formulated with fluorides. Furthermore, the coefficient of thermal expansion can also be very high $\left(10-20 \cdot 10^{-6} \mathrm{~K}^{-1}\right)$, thus resulting in the less novel but, perhaps, the most studied field of application of phosphate glasses is for the sealing of low temperature components, e.g. tin and zinc-bearing phosphates [24]. In fact, the main objective in the search for new sealing glass compositions has been the improvement of the chemical durability of the glasses while maintaining adequate thermal characteristics for their use as sealants and, in this respect, the family of oxynitride glasses had its major 
progress as a consequence of the tremendous increase in the chemical durability of the glasses that can be achieved by substituting only a part of the oxygen of the glass by nitrogen [25]. Together with the adequate match of the thermal expansion of the sealant and those of the components to be sealed as well as a high chemical resistance, it is often required that the glasses had a very high electrical resistivity and so the formulation of phosphate-based compositions requires particular modifiers other than alkali oxides that, at the same time, may lower the viscosity of the undercooled liquid and do not produce an increase in the softening temperatures, which might become quite challenging as well.

On the contrary, the study of phosphate glasses with high, or relatively high, electrical conductivity has also been very prolific. In particular, lithium-bearing phosphate based glasses have been much studied in the last years for their potential applications as solid electrolytes for rechargeable batteries, due to the numerous advantages they may provide with respect to the use of dissolved salts in organic solvents [26]. Other studies on conducting phosphates have dealt with glasses showing protonic conductivity that can be used as solid electrolytes in intermediate temperature fuel cells [27,28] or because when containing transition metal elements such as Fe, may present mixed ionic-electronic conduction and work as electrode materials in rechargeable batteries [29]. Lithium phosphate glasses generally have higher conductivities than their crystalline counterparts and can be compatible with most of the electrode materials in use. In particular, lithium or sodium containing phosphates have been researched as they might be used as solid electrolytes in secondary batteries and, as it will be seen below, the highest importance of lithium phosphates as solid electrolytes derives from their relationships with the development of LiPON electrolytes for lithium micro-batteries [30]. Furthermore, it has been common in the recent years to study phosphate-based glass-ceramics in which the 
crystallizing phases are related to the NASICON (Na SuperIonic CONductor) structural type, which account with the highest electrical conductivity among all solid electrolytes to date [31].

The other characteristic that has make phosphate glasses attractive as an alternative to silicate and borosilicates is the degree of flexibility of their networks that allows for the solubility of very high amounts of heavy metal oxides without appearance of phase separation or devitrification phenomena that could deteriorate their properties. Furthermore, when those do also contain high amounts of iron oxides the chemical durability increases up to values that can be even better than silicates [32].

Due to the thoughtful fundamental investigation that has always been carried out previous to any applicative development, all properties of phosphate glasses have always been closely related to their atomic structure. As in other glass systems, this has been addressed by all different existing techniques but there is no doubt that NMR has been a particularly powerful method to get into the local, or short-range, and the medium-range order structure of phosphate glasses, facilitated by the high relative sensitivity of the ${ }^{31} \mathrm{P}$ nucleus as compared to ${ }^{29} \mathrm{Si}$.

In this chapter, we will make a review of the main structural features of phosphate glasses, as studied through vibrational spectroscopies, nuclear magnetic resonance as well as X-ray and neutrons diffraction, and survey all major physico-chemical glass properties paying special attention to their applications, such as solid electrolytes, laser or sealing materials, glasses in biomedicine or their use for wastes storage.

\subsection{The Structure of Phosphate Glasses}


It is known since Zachariasen work that the network of phosphate glasses is built up of $\mathrm{PO}_{4}$ units, where at least one of the oxygens forms a non-bridging point with neighboring tetrahedra that leads to important differences with the structure and properties of silicate or borosilicate glasses. Then, Van Wazer was one of the first in establishing a tentative description of the short- and medium-range order structure of phosphates based on the polymerization degree of their building units depending on the ratio between the concentrations of modifier and phosphorus oxide [33]. In any case, the interpretation of the structure in phosphate glasses has always followed the same nomenclature as the one used in silicates and introduced by Lippmaa [34], which takes into account the number of bridging oxygens per tetrahedron and gives rise to the well-known $\mathrm{Q}^{\mathrm{n}}$ terminology. Thus, the structure of phosphate glasses may be constituted of different arrangements of the tetrahedra shown in Figure 1.2.

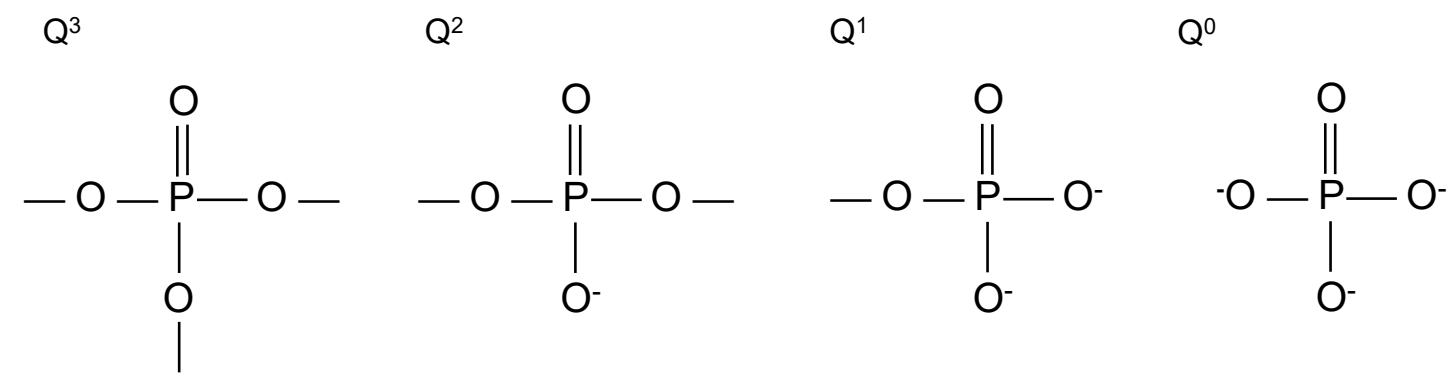

Figure 1.2: $\mathrm{Q}^{\mathrm{n}}$ structural types in phosphate glasses.

Vitreous $\mathrm{P}_{2} \mathrm{O}_{5}$ is formed by $\mathrm{Q}^{3}$ groups where the $\mathrm{P}=\mathrm{O}$ bond establish disruption points thus making a weaker network, which at the same time are highly hydrophilic, this being the reason for the high retention of water in the form of $\mathrm{P}-\mathrm{OH}$ bonds of phosphorus pentoxide 
as well as ultraphosphate glasses. When introducing modifier oxides, the P-O-P bonds break up and form P-NBO bonds where terminal oxygens are linked to modifier cations and once the metaphosphate composition, for which the $\mathrm{O} / \mathrm{P}$ ratio equals $3\left(\mathrm{MPO}_{3}\right.$ ( $\mathrm{M}=$ modifier), is reached only chains or rings of $\mathrm{Q}^{2}$-type groups remain. Upon further additions of a modifier, the $\mathrm{Q}^{2}$ convert to $\mathrm{Q}^{1}$ and depolymerize the structure until orthophosphate $\left(\mathrm{PO}_{4}{ }^{3-}\right)$ species appear that, due to their high crystallization tendency with cations, originate the limit of glass formation in the polyphosphate region.

The structure of phosphate glasses has been tackled by all different analytical techniques, though Raman and FTIR spectroscopies have been those mostly used. These two complementary techniques have always allowed for an easy identification of the main anionic species found in the glasses and how they are affected by the different modifier cations nearby. Later on, with the advent of the superconducting magnets, the use of NMR became more widespread and it can honestly be said that solid state NMR of ${ }^{31} \mathrm{P}$ nuclei now constitutes one of the most common ways of approaching the structure of phosphate glasses, which, at the same time, is a truly quantitative technique. On the other hand, X-ray and neutrons diffraction methods have proven to be very valuable for the study of the coordination numbers and distances at both the short- and medium-range orders.

In the attempt to clarify the structure of phosphate glasses at both the short and medium range orders, perhaps the studies of Hoppe concerning his specific model for phosphate glasses have been of greatest importance for the scientific community [9] and, from a general perspective, the most complete and cited review on the structure of phosphate glasses may be the one by Brow [35], which accounts for a full set of experimental techniques and explores all important factors that affect the structure of the glasses. 


\subsubsection{Vibrational Spectroscopies}

Raman and FTIR spectroscopies allow for distinguishing the characteristic vibrational modes of the phosphorus atoms in different configurations with bridging and non-bridging oxygens, typically vibrations involving $\mathrm{P}-\mathrm{O}-\mathrm{P}$ bonds of neighboring tetrahedra and the ones corresponding to the O-P-O bonds in the different species, metaphosphate, $\left(\mathrm{PO}_{3}\right)^{-}$, pyrophosphate, $\left(\mathrm{P}_{2} \mathrm{O}_{7}\right)^{4-}$, and orthophosphate groups $\left(\mathrm{PO}_{4}\right)^{3-}$. Furthermore, the mode of $\mathrm{P}=\mathrm{O}$ bonds in ultraphosphate glasses is also active in both FTIR and Raman spectra. As an example, in Figure 1.3 the FTIR spectra of $\mathrm{ZnO}$ and $\mathrm{BaO}$ containing metaphosphate glasses are shown.

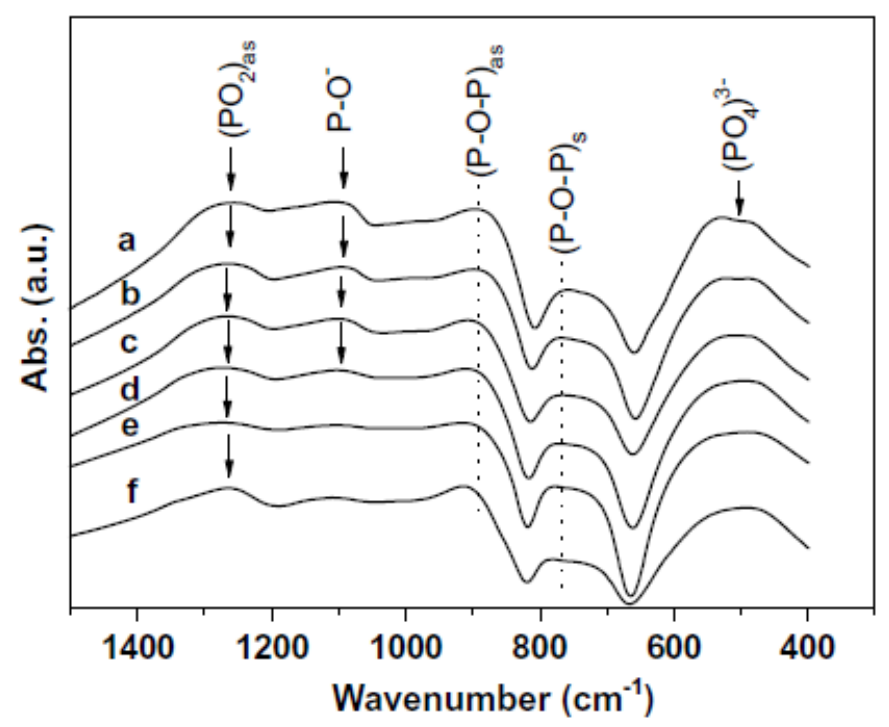

Figure 1.3: FTIR spectra of metaphosphate glasses of the system $\mathrm{xZnO}-(50-\mathrm{x}) \mathrm{BaO}-50 \mathrm{P}_{2} \mathrm{O}_{5}$ ( $\mathrm{x}=10,20,30,40$ and $50 \mathrm{~mol} \%$, from top to down, respectively). Reprinted from reference [36], Copyright (2005), with permission from Elsevier. 
The main peaks of infrared absorption observed correspond to the $\mathrm{P}=\mathrm{O}$ bonds ca. $1300 \mathrm{~cm}^{-}$ ${ }^{1}$, the P-NBO bonds at 1000 and $11150 \mathrm{~cm}^{-1}$ and the active modes of the vibrations involving P-O-P bonds at $950-850 \mathrm{~cm}^{-1}$ and $790-690 \mathrm{~cm}^{-1}$, for the asymmetric and symmetric modes, respectively [36].

FTIR spectra generally suffer of poor resolution due to the broadness of the peaks attributed to each active mode, which unfortunately results in very small differences when analyzing compositional variations. However, Raman spectroscopy can be used to elucidate frequency changes and variations with composition in a more refined way. Furthermore, the Raman spectra generally show narrower and more intense peaks in phosphate glasses, where one can easily observe subtle differences for small changes in composition. As it can be seen in Figure 1.4, the Raman spectra of a series of metaphosphate glasses of monovalent and bivalent modifier cations clearly show peaks attributed to the symmetric stretching mode vibration of the bonds involving bridging oxygens $(\mathrm{P}-\mathrm{O}-\mathrm{P})$ at ca. $700 \mathrm{~cm}^{-1}$ Raman shift, and those of the phosphorus with two non-bridging oxygens $(\mathrm{O}-\mathrm{P}-\mathrm{O})$ in $\mathrm{Q}^{2}$ type $\mathrm{PO}_{4}$ tetrahedra of the metaphosphate polymeric structure at ca. $1200 \mathrm{~cm}^{-1}$. 


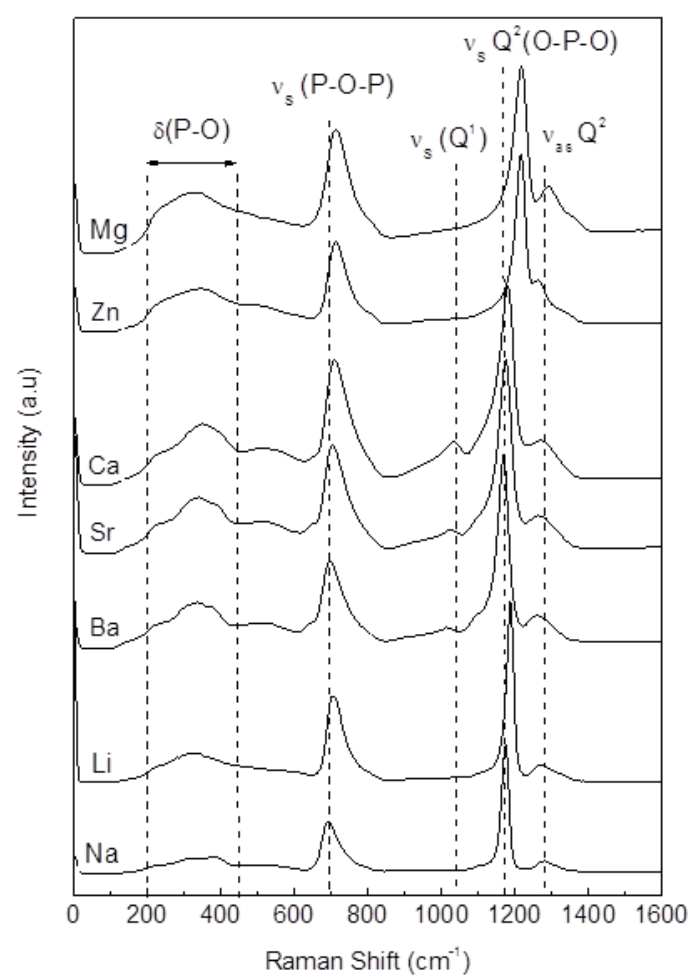

Figure 1.4: Raman spectra of metaphosphate glasses $50 \mathrm{M}_{2} \mathrm{O} / \mathrm{M}^{\prime} \mathrm{O}-50 \mathrm{P}_{2} \mathrm{O}_{5}(\mathrm{M}=\mathrm{Li}, \mathrm{Na}$;

$\left.\mathrm{M}^{\prime}=\mathrm{Ba}, \mathrm{Sr}, \mathrm{Ca}, \mathrm{Mg}, \mathrm{Zn}\right)$. Reprinted from reference [37], Copyright (2014), with permission

from Elsevier.

At ca. $1000 \mathrm{~cm}^{-1}$ a small but in some cases noticeable peak contribution can also be observed in the spectra of the metaphosphate glasses, which in this case is attributed to the stretching vibration of the $\mathrm{NBO}$ in $\mathrm{Q}^{1}$ terminal groups or pyrophosphate species, appearing when there is slight deviation of the metaphosphate compositions.

It is generally accepted that $\mathrm{Q}^{2}$ groups in metaphosphate glasses are in the form of long, also said infinite, chains. However, it must be recognized that ring configurations of tricyclophosphate units $\left(\mathrm{PO}_{3}\right)_{3}{ }^{3-}$ do also appear and they can be easily identified by Raman as described in Mamedov [38]. As also shown recently by Muñoz-Senovilla et al. in the alkali and alkaline-earth metaphosphate series [37], the ratio between the intensity of the 
symmetric stretching mode of P-NBO bonds and the sum of those attributed to the same mode in both chains and rings provides an approximation of the proportion of rings $v s$ chains in the network that depends of the type of modifier.

Raman spectroscopy can then be used to follow the structure of phosphate glasses through the ultraphosphate to polyphosphate regions of composition. The Raman spectra of glasses with composition $x \mathrm{xi}_{2} \mathrm{O}-(1-\mathrm{x}) \mathrm{P}_{2} \mathrm{O}_{5}$ can be seen in Figure 1.5. Vitreous $\mathrm{P}_{2} \mathrm{O}_{5}$ is clearly represented by the $\mathrm{P}=\mathrm{O}\left(1350 \mathrm{~cm}^{-1}\right)$ bond and the one of the bridging oxygens between phosphorus, P-O-P $\left(700 \mathrm{~cm}^{-1}\right)$. With the addition of $\mathrm{Li}_{2} \mathrm{O}$, the network depolymerizes and peaks associated to O-P-O bonds appear below $1200 \mathrm{~cm}^{-1}$, and the one of P-O-P shifts to higher Raman shifts.

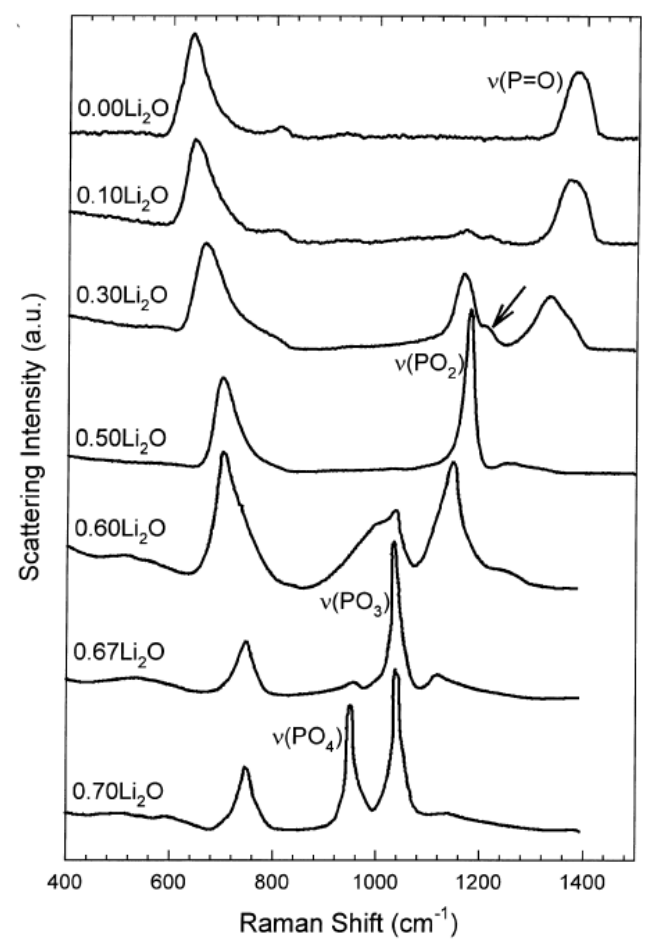

Figure 1.5: Raman spectra of lithium phosphate glasses $\mathrm{xLi}_{2} \mathrm{O}-(1-\mathrm{x}) \mathrm{P}_{2} \mathrm{O}_{5}(\mathrm{x}=0-0.7 \mathrm{~mol} \%)$. Reprinted from reference [35], Copyright (2000), with permission from Elsevier. 
At the metaphosphate composition, the active mode of the non-bridging oxygens in $\mathrm{Q}^{2}$-type groups $\left(\mathrm{PO}_{2}\right)$ is represented by a narrow and intense peak at $1190 \mathrm{~cm}^{-1}$, which upon further additions of modifier vanishes to form peaks of pyrophosphate or terminal $\mathrm{Q}^{1}$ units $\left(\mathrm{PO}_{3}\right)$, $1050 \mathrm{~cm}^{-1}$, and orthophosphate species $\left(\mathrm{PO}_{4}\right)$ at $950 \mathrm{~cm}^{-1}$.

\subsubsection{Nuclear Magnetic Resonance}

The isotope of ${ }^{31} \mathrm{P}$ is $100 \%$ naturally abundant and has a high absolute sensitivity with respect to ${ }^{1} \mathrm{H}$ of $6.65 \cdot 10^{-2}$, which makes NMR spectroscopy under magic angle spinning (MAS) particularly useful for the study of the structure of phosphate glasses. Furthermore, the ${ }^{31} \mathrm{P}$ is an $\mathrm{I}=1 / 2$ nucleus, giving then rise to broad but isotropic signals that in most cases allow for an easy quantification of all the phosphorus species in the network with much better resolution than for silicates. Today, ${ }^{31} \mathrm{P}$ MAS NMR is widely used for the determination of the structural environment of phosphorus nuclei and to obtain the polymerization degree of the network. In the work by Kirkpatrick et al. [39], the ${ }^{31} \mathrm{P}$ spectra of glasses with composition $\mathrm{xNa}_{2} \mathrm{O}-(100-\mathrm{x}) \mathrm{P}_{2} \mathrm{O}_{5}$ show the distinct structural arrangements that phosphorus atoms may take depending on the polymerization degree, as it can be seen in Figure 1.6. 


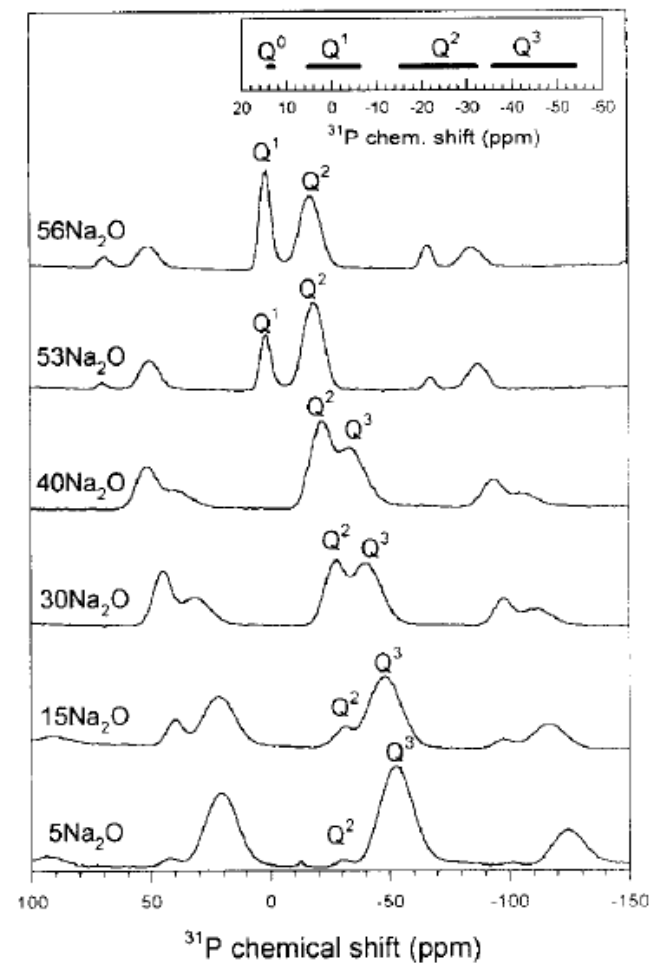

Figure 1.6: ${ }^{31} \mathrm{P}$ MAS NMR spectra of glasses of the system $x \mathrm{Na}_{2} \mathrm{O}-(100-\mathrm{x}) \mathrm{P}_{2} \mathrm{O}_{5}$. Reprinted from reference [39], Copyright (2005), with permission from Elsevier.

A main resonance at ca. -50 ppm attributed to the $Q^{3}$-type tetrahedra can be seen in a 5 mol $\% \mathrm{Na}_{2} \mathrm{O}$ containing glass with the presence of a minor one at $-30 \mathrm{ppm}$ that corresponds to $\mathrm{Q}^{2}$ middle-chain groups. It can be appreciated that with further additions of $\mathrm{Na}_{2} \mathrm{O}$, the isotropic chemical shift of the resonances moves downfield at the same time that the $\mathrm{Q}^{3}$ peak intensity decreases and the intensity of the $\mathrm{Q}^{2}$ one increases. Then, a single resonance of $\mathrm{Q}^{2}$-type units should be observed at the metaphosphate composition $\left(50 \mathrm{~mol} \% \mathrm{Na}_{2} \mathrm{O}\right.$ ). Above this sodium content, the polymeric structure breaks up and forms $\mathrm{Q}^{1}$ with a new resonance appearing near $0 \mathrm{ppm}$. Therefore, knowing the proportions of the structural $\mathrm{PO}_{4}$ groups present in the glass one can calculate the modifier and former contents or vice-versa 
through well-known equations [35,39]. However, in some cases disproportionation reactions may occur of the type shown below in equations (1) and (2) [35].

$$
\begin{aligned}
& \mathrm{Q}^{2} \rightarrow \mathrm{Q}^{1}+\mathrm{Q}^{3} \\
& \mathrm{Q}^{1} \rightarrow \mathrm{Q}^{0}+\mathrm{Q}^{2}
\end{aligned}
$$

These reactions are mostly typical of polyphosphate glasses, such as in zinc pyrophosphate glasses [40].

In phosphate glasses, the chemical shift of the ${ }^{31} \mathrm{P}$ nuclei is very sensitive to the type of modifier cations that are bonded to non-bridging oxygens. As it has been reported in several works, the chemical shift of phosphorus decreases linearly with the increase of the modifier's cationic potential in binary metaphosphate glasses $[37,39]$. Due to the particular structure of the $\mathrm{PO}_{4}$ tetrahedra, the phosphorus atoms become more shielded as the bond between modifier and oxygens gets stronger. Moreover, if several modifier cations are present, it has also been proved that the chemical shift varies in a linear way according to a homogeneous distribution of all modifier types with the structural building units of the network, as seen for example in glasses with composition $(25-\mathrm{x} / 2) \mathrm{Li}_{2} \mathrm{O}-(25-\mathrm{x} / 2) \mathrm{Na}_{2} \mathrm{O}-$ $\mathrm{xPbO}-50 \mathrm{P}_{2} \mathrm{O}_{5}[41]$

Another interesting picture that NMR can offer on the structure phosphate glasses is question of whether $\mathrm{PO}_{4}$ tetrahedra are arranged in the form of chains or rings. However, it is not possible to say, or quantify, how much of the phosphorus belong to either of the forms. Broadly speaking, one can derive a glass network composed of a higher or lower proportion of rings, which can be approximated through the analysis of the chemical shift anisotropy values of ${ }^{31} \mathrm{P}$ resonance [42]. However, this is an issue that has not received 
much attention but it might be of the highest interest for the medium-range order structure determination.

Beyond the speciation of the building units of the phosphate glass network, it is also possible to study their connectivity through dipolar correlation techniques, such as the Double-Quantum (DQ) MAS NMR experiments. These techniques work by selectively introducing dipolar interactions between ${ }^{31} \mathrm{P}$ nuclei and depending on their spatial proximity signals associated to homo- and hetero-nuclear correlations can be observed in a 2D plot [43]. In a polyphosphate glass composition, for instance, homo-nuclear correlation between $\mathrm{Q}^{2}$ and $\mathrm{Q}^{2}$ middle-chain groups can be seen, as well as those between $\mathrm{Q}^{1}$ and $\mathrm{Q}^{1}$ of pyrophosphate molecular species. And in the same plot, hetero-nuclear proximity between $\mathrm{Q}^{2}$ and $\mathrm{Q}^{1}$ groups can also be detected. In Figure 1.7, the $2 \mathrm{D}{ }^{31} \mathrm{P}$ DQ-SQ NMR plot is shown for a glass with composition of zinc pyrophosphate [44].

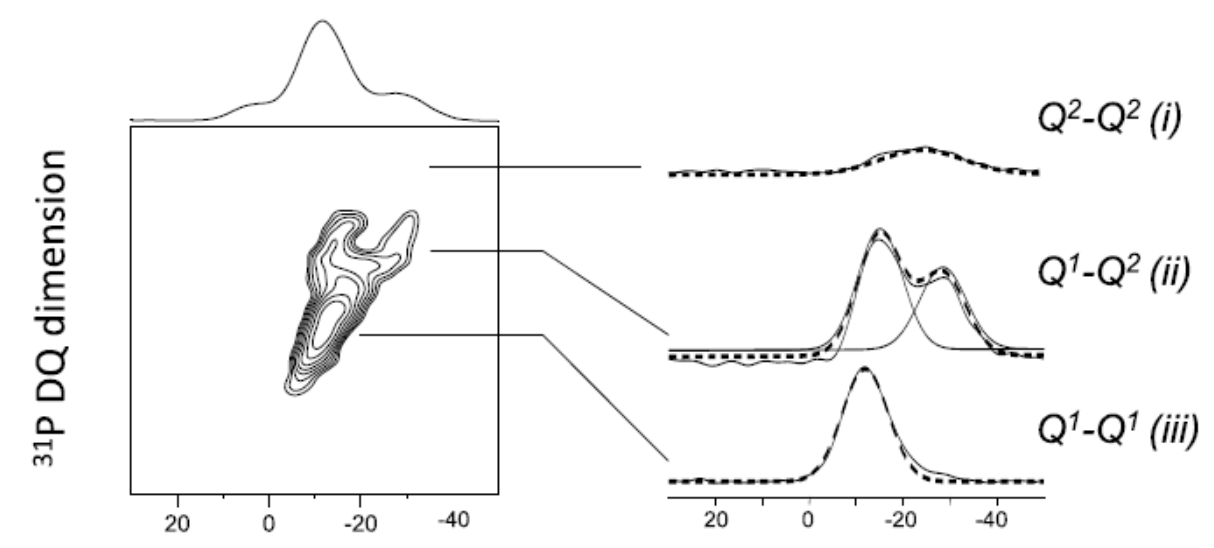

Figure 1.7: ${ }^{31} \mathrm{P}$ DQ-SQ MAS NMR spectrum of a zinc pyrophosphate glass. The right-hand side of the picture shows the $1 \mathrm{D}$ projection of the $\mathrm{Q}^{2}-\mathrm{Q}^{2}, \mathrm{Q}^{1}-\mathrm{Q}^{2}$ and $\mathrm{Q}^{1}-\mathrm{Q}^{1}$ correlations. Reprinted from reference [44], Copyright (2015), with permission from Elsevier. 
The $\mathrm{Q}^{1}-\mathrm{Q}^{1}$ correlation signals are typical of $\left(\mathrm{P}_{2} \mathrm{O}_{7}\right)^{4-}$ cluster species in pyrophosphate compositions, though for the glass shown in Figure 1.7 a small proportion of $\mathrm{Q}^{2}-\mathrm{Q}^{2}$ can also be seen, thought to come from small chains remaining in the network. Furthermore, if an adequate combination of sequences is used and the proportions of the signals associated to the appearing correlations are known, DQ NMR experiments can help to determine the length of the phosphate chains in the glass structure, in the form of diphosphate, triphosphate and polyphosphate or rings arrangements [45].

A more advanced 2D plot of correlations between phosphorus nuclei in phosphate glasses is the one developed by Fayon et al. and based on refocused INADEQUATE(Incredible natural-abundance double-quantum transfer experiment) pulse sequences to study the P-OP through-bond connectivity $[46,47]$. The method allows for the determination of direct bonds between phosphate species by using the $\mathrm{J}$ coupling. Even though, in solids, the $\mathrm{J}$ coupling is much smaller than dipolar interactions, the INADEQUATE sequences may promote polarization transfer through $\mathrm{J}$ coupling while avoiding recoupling of dipolar interactions [46]. Figure 1.8 represents the through-bond SQ-DQ spectrum of a glass with composition $0.59 \mathrm{PbO}-0.61 \mathrm{P}_{2} \mathrm{O}_{5}$ in which autocorrelation signals of $\mathrm{Q}^{2}-\mathrm{Q}^{2}$, at $-24 \mathrm{ppm}$ in the SQ dimension, and $\mathrm{Q}^{1}-\mathrm{Q}^{1}$, at $-8 \mathrm{ppm}$, tetrahedra can be clearly identified together with some amount of $\mathrm{Q}^{1}-\mathrm{Q}^{2}$, or $\mathrm{Q}^{2}-\mathrm{Q}^{1}$ cross-correlation signals in the off-diagonal, as seen in reference [47]. 


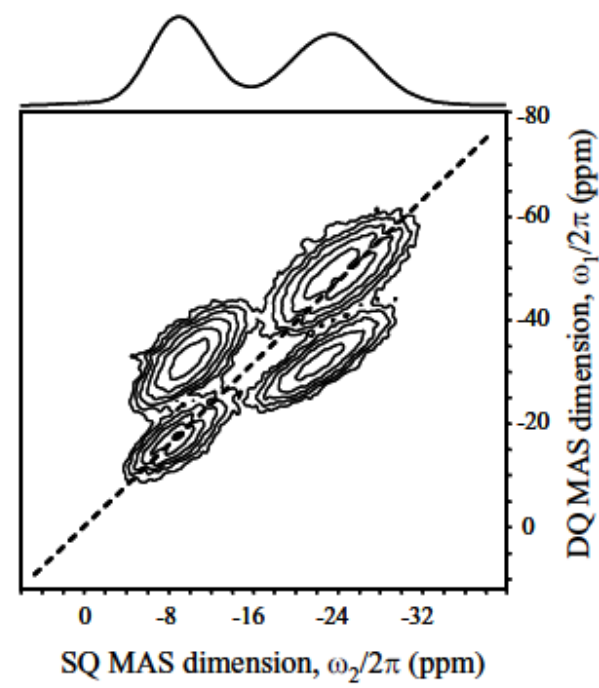

Figure 1.8: Through-bond SQ-DQ spectrum of the $0.59 \mathrm{PbO}-0.61 \mathrm{P}_{2} \mathrm{O}_{5}$ glass. Reprinted from reference [47], Copyright (2004), with permission from Elsevier.

Meanwhile the $\mathrm{Q}^{1}-\mathrm{Q}^{1}$ connectivity indicates the presence of $\mathrm{P}_{2} \mathrm{O}_{7}{ }^{4-}$ molecular species as said above, the fact that $\mathrm{Q}^{1}-\mathrm{Q}^{2}$ cross-correlation signals can be observed provides information on the chain length distribution in the glass network. Nevertheless the most important information that can be obtained through these spectra is the one related to the direct bonds between the phosphate species by means of the analysis of the chemical shift values in both the single and double-quantum dimensions of the spectra.

More recently, a new method called DQ-DRENAR (Double-Quantum Dipolar Recoupling Effects Nuclear Alignment Reduction) has also been tested for the analysis of the structure in phosphate glasses by Ren et al. [48]. The method, which is based on the REDOR (Rotational Echo Double Resonance) technique, can also be used for the study of the connectivity between phosphorus nuclei and the determination of internuclear distances, and it can be especially useful in combination with refocused INADEQUATE pulse 
sequence in the case of glasses that have a second glass former or intermediate oxide, for which the differentiation of the $\mathrm{Q}^{\mathrm{n}}$ groups gets quite complicated as they tend to overlap having similar chemical shifts $[49,50]$.

It is well known that the chemical durability of phosphate glasses can be greatly improved with the addition of aluminum, which may behave as either former or modifier due to its intermediate character, a role that depends on the particular composition of each glass. In this respect the study of the structural environment of $\mathrm{Al}^{3+}$ cations has always been of importance for the structure-properties relationships. Furthermore, ${ }^{27} \mathrm{Al}$ is a quite accessible nucleus with a high relative sensitivity and thanks to its quadrupolar character any changes occurring in the aluminum polyhedra can be easily studied by NMR. These can be in the form of 4-, 5- and 6-fold coordinated $\mathrm{AlO}_{\mathrm{n}}$ species, and the $\mathrm{AlO}_{6}$ ones are the most abundant when a high amount of modifier is present in the composition [51]. Furthermore, aluminum polyhedra appear to be bonded to phosphate tetrahedra through $\mathrm{P}-\mathrm{O}-\mathrm{Al}$ bonds, though the number of different species can be very high and the ${ }^{31} \mathrm{P}$ MAS NMR spectra does not usually offer good resolution to completely characterize and quantify all of them. In such a case, new advanced methodologies have been proved to be extremely precise for the separation of the specific P-O- $\left(\mathrm{AlO}_{\mathrm{n}}\right)$ links, as it has been shown by Van Wüllen et al. using a combination of MQ (Multiple Quantum)-MAS and heteronuclear correlation experiments (HETCOR) in the study of $\mathrm{K}_{2} \mathrm{O}-\mathrm{Al}_{2} \mathrm{O}_{3}-\mathrm{P}_{2} \mathrm{O}_{5}$ glasses [52]. Figure 1.9 shows a representation of the structural model for the potassium alumino-phosphate glasses with the basic structural units that have been determined through NMR. 


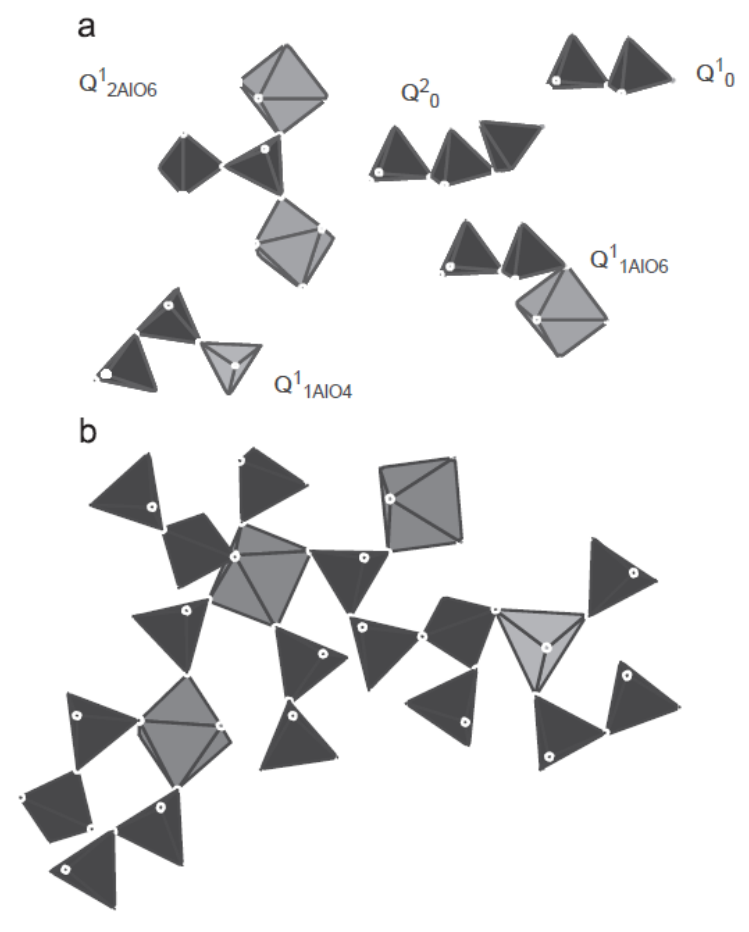

Figure 1.9: a) Structural units of the network in a $50 \mathrm{~K}_{2} \mathrm{O}-10 \mathrm{Al}_{2} \mathrm{O}_{3}-40 \mathrm{P}_{2} \mathrm{O}_{5}$ glass, and b) representation of the network arrangements. Reprinted from reference [52] Copyright (2007), with permission from Elsevier.

It is also well known that the properties of the phosphate glasses may also be improved through the addition of secondary glass former elements, like boron. For example, the ionic conductivity in alkali borophosphate glasses directly depends on the proportions of the three-fold and four-fold coordinated species of boron, the so-called $\mathrm{BO}_{3}$ and $\mathrm{BO}_{4}$ groups, respectively, being maximum for the highest content of $\mathrm{BO}_{4}[53]$.

Finally, the study of the structure of phosphate glasses through NMR may become even more challenging if one attempts the analysis of the anionic network through ${ }^{17} \mathrm{O}$ NMR. Even though oxygen accounts for the majority of the nuclei in the glass composition of oxide glasses, the very low abundance of the ${ }^{17} \mathrm{O}$ isotope and strong quadrupolar moment 
force to perform the materials synthesis under ${ }^{17} \mathrm{O}$ enrichment. This has been demonstrated that it can be done efficiently by two methods, the most extended one consisting in the hydrolysis of $\mathrm{PCl}_{5}$ with ${ }^{17} \mathrm{O}$-enriched water to form $\mathrm{H}_{3} \mathrm{PO}_{4}$ that later is reacted with the stoichiometric amount of modifier to give a glass [54]; or as shown by Flambard et al. through the remelting of a $\mathrm{NaPO}_{3}$ glass under 17O-enriched water vapor [55]. However, very few studies of ${ }^{17} \mathrm{O}$ NMR have been carried out in phosphate glasses to date, but it has been possible to perform proper quantification of the $\mathrm{BO}$ and NBO proportions as well as getting very useful information on the P-O-P bond angle from the ${ }^{17} \mathrm{O}$ MQ-MAS spectral analysis of $\mathrm{NaPO}_{3}$ glasses [54]. In more complex systems, the use of ${ }^{17} \mathrm{O}$ MAS and MQMAS spectroscopy may also allow for the determination of the amount of non-bridging oxygens bonded to either of the modifier cations in the composition or even the distinction of clustering of the modifier oxides, as shown in $\mathrm{Na}_{2} \mathrm{O}-\mathrm{Nb}_{2} \mathrm{O}_{5}-\mathrm{P}_{2} \mathrm{O}_{5}$ glasses [56].

The solid-state NMR approach to the elucidation of the structure of glasses, and phosphate glasses in particular, is continuously evolving and the experience has shown that the appropriate combination of pulse sequences and methodologies is leading the understanding of the structure-properties relationships.

\subsubsection{X-Ray and Neutron Diffraction Techniques}

The materials studied for their interesting technological or scientific properties are often complex. Typically they are made of multiple elements and do not present an infinite periodicity. Nevertheless powder diffraction is an important method for the characterization of these materials but it requires going beyond the phenomenon of diffraction with the maximum intensities corresponding to the Bragg equation and to favor a total scattering approach including both the Bragg and diffuse scattering on an equal basis [57] 
Powder diffraction data are collected first, then explicit corrections are made and the measured intensity is finally normalized by the incident flux. The coherent and normalized scattered intensity $S(Q)$ is a function of the magnitude of the scattering vector given by equation (3):

$$
Q=\frac{4 \pi \sin \theta}{\lambda_{0}}
$$

In practice, the $S(Q)$, determined for total scattering studies, is measured over a wide range of $Q$-values, however the coherent intensity dies out with increasing $Q$. Beyond a $Q$-value of about $500 \mathrm{~nm}^{-1}$, there are no more features for $S(Q)$. Using laboratory sources, the maximum $Q$ attainable is around $80 \mathrm{~nm}^{-1}$ from a $\mathrm{Cu} \mathrm{K} \alpha$ tube and $220 \mathrm{~nm}^{-1}$ from a $\mathrm{Ag}$ tube. As a consequence, for a better spatial resolution, synchrotron radiation or spallation neutron sources with short wavelength epithermal neutrons are required. Total scattering data are Fourier transform to obtain the pair distribution function (PDF) which is fit to give structural information.

Diffraction methods make it possible to obtain structural information from a radial distribution of pair distances in which the areas of the peaks are associated with the number of atoms in the coordination spheres [58]. It has been well established that the first resolved peak at $0.155 \mathrm{~nm}$ is attributed to the $\mathrm{P}-\mathrm{O}$ bond with a coordination number, $\mathrm{N}_{\mathrm{PO}}$, of four. This number is in perfect agreement with the firmly-established rule that the basic unit of the network of phosphate glasses is the $\mathrm{PO}_{4}$ tetrahedra.

Similarly, additional information such as the number of metal-oxygen coordination, $\mathrm{N}_{\mathrm{MeO}}$, can be obtained when structural assumptions are made about the adjacent peaks.

Efforts have been made to measure total scattering with high accuracy to extract more information from the experimental data. Even though these measurements have basically 
the same requirements than that of any powder diffraction measurements, they have additional requirements for high quality data. This includes that data must be measured over a wide Q-range by combining the diffraction data of neutron and synchrotron radiations. This allows separating the distance peaks of unlike pairs of atoms [60] as well as the O-O contribution due to edges of the $\mathrm{PO}_{4}$ units, which is separated from the Me-O distance peak [61]. Thus, using the anomalous dispersion of the X-ray scattering amplitudes $[62,63]$ and the isotopic change of the neutron scattering lengths [64] several studies of glassy phosphate materials have been performed. Extensive studies have been carried out by Hoppe and coworkers on phosphates doped with various ions including La [65], Ga [66], Fe [67], $\mathrm{Pb}$ [68], $\mathrm{Zn}$ [69], and $\mathrm{Ti}$ [70]. Hoppe et al. developed a set of rules for network changes upon the addition of modifying atoms to describe the disruption of P-O-P bonding units as a function of $\mathrm{P}_{2} \mathrm{O}_{5}$ content.

Likewise, the truncation of the Fourier integral results in the broadening of the peaks of the real-space correlation functions $T(r)$. The use of epithermal neutrons $(\sim 1 \mathrm{eV})$ from spallation sources [71] and of hard X-ray photons (>40 keV) from synchrotron sources [72], by increasing the maximum $\mathrm{Q}$ attainable $\left(Q_{\max }\right)$ at almost $500 \mathrm{~nm}^{-1}$, have considerably reduce this broadening effect.

The effect of $Q_{\max }$ on the real-space resolution for vitreous $\mathrm{P}_{2} \mathrm{O}_{5}$ is illustrated in the following figure. 


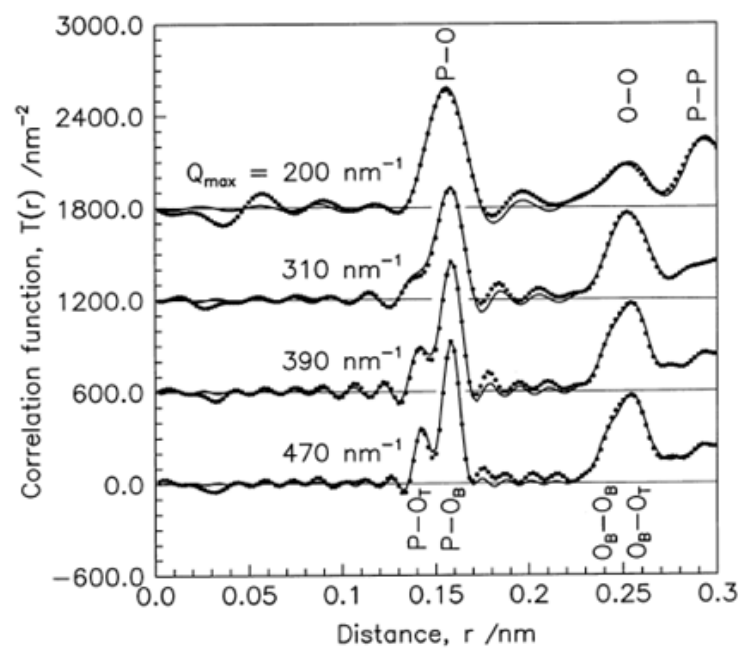

Figure 1.10: Illustration of the $Q_{\max }$ influence in vitreous $\mathrm{P}_{2} \mathrm{O}_{5}$ [58]. The upper function results from XRD data [73] $\left(\lambda_{0}=0.0561 \mathrm{Ag} \mathrm{K}\right)$. The three lower functions are obtained from ND data with varying $Q_{\max }[10](\lambda>0.022 \mathrm{~nm})$. Solid lines functions are calculated using the parameters of the Gaussian functions which model the nearest neighbor peaks of the vitreous $\mathrm{P}_{2} \mathrm{O}_{5}$ structure. Reprinted from reference [58], Copyright (2000), with permission from Elsevier.

A splitting of the P-O distance peak is clearly observed when $Q_{\max }$ exceeds $400 \mathrm{~nm}^{-1}$. Two types of bonding should be considered for phosphorous, one to a terminal oxygen atom $\left(\mathrm{O}_{\mathrm{T}}\right)$ and another to a bridging oxygen atom $\left(\mathrm{O}_{\mathrm{B}}\right)$ [72]. In addition, from neutron diffraction data for which $Q_{\max }$ is 390 and $470 \mathrm{~nm}^{-1}$, the O-O peak displays a shoulder denoting two different O-O distances. If a P-P distance of $295 \mathrm{pm}$ can be determined from XRD data, the use of ND data with variable $\mathrm{Q}_{\max }$ does not make it possible to get the exact value of the $\mathrm{P}$ $\mathrm{P}$ coordination number. The explanation is the presence of $\mathrm{P}-\mathrm{O}$ and $\mathrm{O}-\mathrm{O}$ second neighbor contributions in the P-P peak range. 
The presence of two first-neighbor peaks of P-O distances is always observed when using $\mathrm{ND}$ of great resolving power and this result may be compared to that of $\mathrm{O}_{1 \mathrm{~s}}$ XPS (X-ray Photoelectron Spectroscopy) experiments. Such spectra always display two peaks and as a result two $\mathrm{O}$ atoms species are present in phosphate glasses. Similarly to the analysis of the total scattering data, the mole fractions of the $\mathrm{O}_{\mathrm{T}}$ and $\mathrm{O}_{\mathrm{B}}$ atoms are related to the corresponding peak areas. Likewise, the ratio of the two oxygen species constitutes a measure of a continuous depolymerization phenomenon affecting the phosphate network when adding modifier cations $[8,74,75]$.

In a phosphorous pentoxide glass, only threefold corner-linked $\mathrm{PO}_{4}$ tetrahedra have to be considered. The addition of a modifier cation results in an increase of the number of $\mathrm{O}_{\mathrm{T}}$ atoms which constitutes the coordination polyhedra of this cation. Thus, a polymer-like structure is obtained for a metaphosphate glass composition $[75,76]$, the chains and/or rings of the vitreous network being interconnected [77].

Furthermore, the following figure illustrates the influence of the $\mathrm{M}^{\mathrm{II}} \mathrm{O}$ oxide content, expressed as the $\mathrm{MO} / \mathrm{P}_{2} \mathrm{O}_{5}$ molar ratio, on the positions and magnitudes of the $\mathrm{P}-\mathrm{O}_{\mathrm{T}}$ and $\mathrm{P}$ $\mathrm{O}_{\mathrm{B}}$ correlations which can be expressed as the P-NBO (non-bridging oxygen) and P-BO (bridging oxygen) respectively. Another way to best describe the tetrahedral units is the $\mathrm{Q} n$ notation, where $n$ is the number of BOs per unit. 


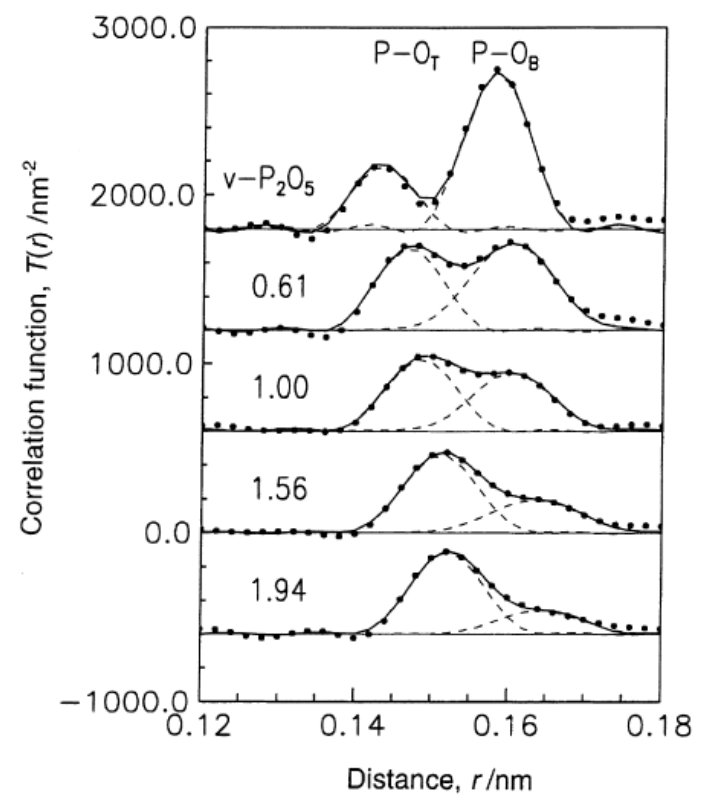

Figure 1.11: Influence of the modifier oxide to phosphorous pentoxide molar ratio (y) on the lengths of the $\mathrm{P}-\mathrm{O}$ bonds ( $\mathrm{ND}, Q_{\max }=470 \mathrm{~nm}^{-1}$ ). The modifier oxides are $\mathrm{ZnO}$ for $\mathrm{y}=0.61, \mathrm{PbO}$ for $\mathrm{y}=1.0$ and 1.56 and a mixture of $\mathrm{ZnO}$ and $\mathrm{PbO}$ for $\mathrm{y}=1.94$. Reprinted from reference [58], Copyright (2000), with permission from Elsevier.

In vitreous $\mathrm{P}_{2} \mathrm{O}_{5}$, each unit possesses one short $\mathrm{P}-\mathrm{O}_{\mathrm{T}}$ bond and three long $\mathrm{P}-\mathrm{O}_{\mathrm{B}}$ bonds and is connected to three others via bridging oxygen (BO) atoms. As described above, the $\mathrm{M}^{\mathrm{II}} \mathrm{O}$ addition disrupts the network and creates NBOs. For the metaphosphate composition there is an equal proportion of $\mathrm{P}-\mathrm{O}_{\mathrm{T}}$ and $\mathrm{P}-\mathrm{O}_{\mathrm{B}}$ corresponding to two NBOs and two BOs per unit. Further increasing the $\mathrm{M}^{\mathrm{II}} \mathrm{O}$ content results in an increase of the NBOs and for a pyrophosphate glass composition one obtains three $\mathrm{P}-\mathrm{NBO}$ and one $\mathrm{P}-\mathrm{BO}$. It is also observed that such an increase leads to a longer P-NBO distance. The network becomes less connected and the NBOs are less strongly bonded to phosphorous.

Hoppe et al. [58] also report on the effect of various modifying cations on the lengths of the $\mathrm{P}-\mathrm{O}$ bonds in the case of metaphosphate glass composition. As illustrated by Figure 1.12, 
the $\mathrm{P}-\mathrm{O}_{\mathrm{T}}$ and $\mathrm{P}-\mathrm{O}_{\mathrm{B}}$ peaks can be differentiated in the case of $\mathrm{KPO}_{3}$ while the splitting is significantly reduced in $\mathrm{AlP}_{3} \mathrm{O}_{9}$. This can be explained, in part, by the cation field strength which can shift the local electron density away from the BOs. Nevertheless, this effect is not fully related to the cationic field strength as illustrated by the lowest split of the $\mathrm{PbP}_{2} \mathrm{O}_{6}$ glass when compared to that of the $\mathrm{LaP}_{3} \mathrm{O}_{9}$ glass, even though the field strength of $\mathrm{La}^{3+}$ is greater than that of the $\mathrm{Pb}^{2+}$ cation.

Indeed, the change in the metaphosphate behavior, displayed in Fig. 11.2, is the consequence of both the differences in the P-O lengths and of the widths of the $\mathrm{P}-\mathrm{O}_{\mathrm{T}}$ and $\mathrm{P}-$ $\mathrm{O}_{\mathrm{B}}$ peaks. The shift of the electron density, affected by the electric field of the neighboring cation [78, 79] can explain the change in bond length. Ab initio molecular orbital calculations performed on a series of alkali metaphosphate clusters [80] have shown the same effects.

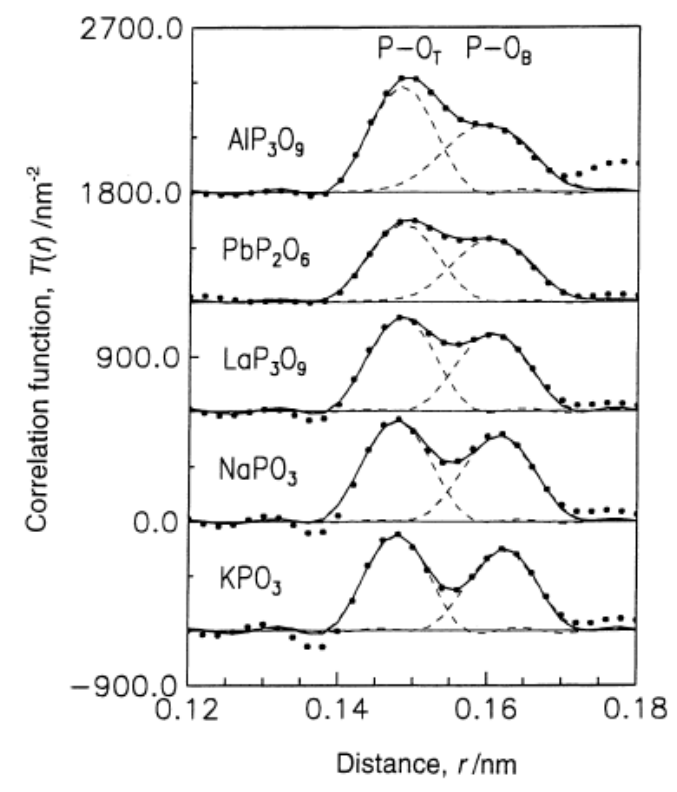


Figure 1.12: Influence of the modifier cation on the lengths of the P-O bonds for various metaphosphate glasses (ND, $Q_{\max }=470 \mathrm{~nm}^{-1}$ ). Reprinted from reference [58], Copyright (2000), with permission from Elsevier.

Considering the anionic phosphate skeleton, the doubly-bonded oxygen atoms do not participate to the stability of the structure but tend to coordinate a modifier cation [9]. XRD studies performed on divalent cation containing phosphate glasses indicate a change of the Me-O coordination number $[81,82]$.

This behavior is consistent with the variation of the packing densities of $\mathrm{Mg}, \mathrm{Zn}, \mathrm{Ca}$ and $\mathrm{Ba}$ phosphate glasses which present minima for different compositions [82]. At very low $\mathrm{MeO}$ content, one should observe the highest $\mathrm{N}_{\mathrm{Me}-\mathrm{O}}$ numbers. Experimentally, values of 10 for $\mathrm{Ba}, 8$ for $\mathrm{Ca}$, and 6 for $\mathrm{Mg}$ and $\mathrm{Zn}$ are found. The $\mathrm{Me}-\mathrm{O}$ coordination number must be lowered when adding further $\mathrm{MeO}$, the experiment confirm that limits of 8 for $\mathrm{Ba}, 6$ for $\mathrm{Ca}$ and 4 for $\mathrm{Mg}$ and $\mathrm{Zn}$ are reached. The corresponding compositions can be calculated considering that for the formation of the Me-O-P bridges, the number of NBO per $\mathrm{Me}$ ion has to be equal to the Me-O coordination number. Similarly, the transition temperatures of alkali phosphate glasses present a minimum at $20 \mathrm{~mol} \% \mathrm{MeO}$ content [83, 84].

As can be seen, the Me-O coordination number plays a decisive role. Nevertheless, this number is not as well-defined as that for $\mathrm{N}_{\mathrm{PO}}$ and the uncertainty in the determination of $\mathrm{N}_{\mathrm{MeO}}$ limits the exactitude of the model predictions. The best accuracy is achieved when the Me-O distances are in the range between the $\mathrm{P}-\mathrm{O}$ and $\mathrm{O}-\mathrm{O}$ distances at 1.55 and $2.52 \mathrm{~nm}$, respectively, and do not interfere with the $\mathrm{P}-\mathrm{O}$ or $\mathrm{O}-\mathrm{O}$ peaks. A few examples of the coordination number and of the interatomic distance are given below in table I.

In this table, the $\mathrm{N}_{\mathrm{MeO}}$ values have been determined from the peak of the correlation function in closest distance and do not take into account any asymmetry in the coordination 
polyhedral. Consequently, these values are not necessarily agreeing with the number of oxygens in a usual $\mathrm{MeO}_{\mathrm{n}}$ polyhedron.

Table I: Coordination numbers and distance of some atomic pairs.

\begin{tabular}{|l|l|l|l|}
\hline $\begin{array}{l}\text { Atom } \\
\text { pair }\end{array}$ & coordination & Distance & Reference \\
\hline Al-O & $6.0 \pm 0.3$ & $1.89 \pm 0.03$ & 61 \\
\hline Al-O & $7.1 \pm 0.8$ & $1.89 \pm 0.02$ & 78 \\
\hline La-O & $7.1 \pm 0.5$ & $2.46 \pm 0.02$ & 85 \\
\hline $\mathrm{Ca}-\mathrm{O}$ & $7.0 \pm 0.4$ & $2.39 \pm 0.03$ & 61 \\
\hline $\mathrm{Sr}-\mathrm{O}$ & $6.0 \pm 0.2$ & $2.55 \pm 0.03$ & 86 \\
\hline $\mathrm{Ba}-\mathrm{O}$ & $8.0 \pm 0.5$ & $2.79 \pm 0.04$ & 61 \\
\hline $\mathrm{Pb}-\mathrm{O}$ & $5.0 \pm 0.4$ & $2.48 \pm 0.01$ & 87 \\
\hline $\mathrm{K}-\mathrm{O}$ & $3.0 \pm 0.5$ & $2.63 \pm 0.03$ & 79 \\
\hline & $3.8 \pm 0.3$ & $3.02 \pm 0.01$ & \\
\hline $\mathrm{Na}-\mathrm{O}$ & $5.0 \pm 0.4$ & $2.38 \pm 0.03$ & 61 \\
\hline & $5.0 \pm 0.2$ & $2.47 \pm 0.03$ & 86 \\
\hline & & $2.89 \pm 0.03$ & \\
\hline & & & \\
\hline & & & \\
\hline & & & \\
\hline & & & \\
\hline & & & \\
\hline & & & \\
\hline
\end{tabular}

The knowledge of the medium range order, in other words the reciprocal order of the largest structural units is limited to diffraction data related to the first peaks [88-90]. As a result, the specific changes, in relation to structural features, have been described as functions of the $\mathrm{P}_{2} \mathrm{O}_{5}$ content and/or the nature of the modifier cation [91, 92]. Structural 
features in the neutron structure factors, $S(Q)$, characteristic of intermediate-range $\left(Q \leq 3 \AA^{-}\right.$ ${ }^{1}$ ) order were identified. The addition of an alkali metal such as $\mathrm{Na}$ has an effect on the intermediate-range structure due to destruction of the $\mathrm{PO}_{4}$ network structure. Around the metaphosphate glass composition a new peak appears at lower $Q$ than the intermediaterange order peak, which is found in the $S(Q)$ 's of all alkali metaphosphate glasses $(\mathrm{M}=\mathrm{Li}$, $\mathrm{Na}, \mathrm{K}, \mathrm{Rb}$ and $\mathrm{Cs}$ ), which may be associated with extended-range order. The length scales of the extended range order increases with the size of $\mathrm{M}^{+}$. These phenomena can be explained by the effects of oxygen atoms, i.e. $\mathrm{PO}_{4}$ chain-like units, ordering around the $\mathrm{M}^{+}$. The short- and intermediate-range order of $\mathrm{M}^{\mathrm{II}} \mathrm{O}-\mathrm{P}_{2} \mathrm{O}_{5}(\mathrm{M}=\mathrm{Mg}, \mathrm{Zn})$ glasses with compositions around that of the metaphosphate have been studied by neutron diffraction $[93,94]$. If the $\mathrm{Mg}-\mathrm{O}$ coordination number is 6 and almost independent of $\mathrm{MgO}$ content, the average $\mathrm{Zn}-\mathrm{O}$ coordination number is 5 . Both $\mathrm{M}-\mathrm{O}$ distances increase slightly with the M-O content from 50 to $60 \mathrm{~mol} \%$ and the distributions of the distances broaden with the MO content from 40 to $50 \mathrm{~mol} \%$.

In comparison with the structures of zinc phosphate crystals, the distorted five-coordination of $\mathrm{Zn}-\mathrm{O}$ may be regarded as the mixture of $\mathrm{ZnO}_{4}$ tetrahedra and $\mathrm{ZnO}_{5}$ polyhedra. As a consequence, $\mathrm{Zn}$ plays a typical dual role as a network-modifier in the process of the depolymerization of the $\mathrm{PO}_{4}$ tetrahedral network and it acts as a network-former for forming the linkage of $\mathrm{ZnO}_{4}$ and $\mathrm{PO}_{4}$ tetrahedra. The presence of the two kinds of network is revealed by the characterization of the intermediate-range order peak and shoulder at around $\mathrm{Q}=1.6 \AA^{-1}$ and $1.1-1.2 \AA^{-1}$, corresponding to $\mathrm{ZnO}_{4}-\mathrm{PO}_{4}$ and $\mathrm{PO}_{4}-\mathrm{PO}_{4}$ topological connections, respectively. 
Likewise, both the average $\mathrm{Zn}-\mathrm{O}$ distances of the distorted $\mathrm{ZnO} 5$ polyhedron and of the $\mathrm{Zn}$ $\mathrm{O}$ coordination number increase slightly when increasing the $\mathrm{ZnO}$ content from 59.3 to $69.7 \mathrm{~mol} \%$.

These small changes in the short- and intermediate-range order associated with the chemical ordering of $\mathrm{PO}_{4}$ and $\mathrm{ZnO}_{4}$ tetrahedra and $\mathrm{ZnO}_{5}$ distorted polyhedra probably explain the anomalous changes in physical properties such as the increasing $\mathrm{T}_{\mathrm{g}}$ behavior at $\mathrm{ZnO}$ concentrations above $60 \mathrm{~mol} \%$. As it was mentioned in section 1.2.2, zinc phosphate glasses can also develop disproportionation reactions at around the pyrophosphate composition, giving rise to out of the trend changes in the properties that could be explained through the phosphate groups speciation as well as the change in the coordination number of zinc.

\section{Computational Modelling}

Various methodologies can be used to fit the data from crystalline compounds. The most familiar is the Rietveld refinement [95] which can be operated to both X-ray and neutron diffraction data. Nevertheless, fitting diffraction data related to glassy materials is more questionable and different processes have been conceived. These models are usually generated by Reverse Monte Carlo (RMC) [96,97], Molecular Dynamics (MD) [98,99] or, more recently, by Empirical Potential Structure Refinement (EPSR) [100,101].

However, these methods are computationally intensive and the calculations are limited to a maximum of a few hundred atoms, and by consequence their agreement with experiment can be poor in the low- $q$ region of the data. In addition, even $a b$ initio techniques still require some choice in terms of, for example, the density-functional, and this can affect the results. 
Considering the $\mathrm{Ca}\left(\mathrm{PO}_{3}\right)_{2}$ metaphosphate glass, the short range structure has been investigated using both X-ray and neutron diffraction and then modelled using the reverse Monte Carlo method [102]. This approach of combining computer simulations with more than one set of experimental data avoids to fail in interpreting correctly the experimental results and provides to obtain more robust and detailed structural information. Based on the geometry of the basic phosphate unit, a model has been refined to match the experimental diffraction data. Thus, six interatomic correlations have been differentiated and fitted to finally obtain two values of the Ca-O bond length, i.e. 2.35 and $2.86 \AA$, and a calcium coordination number of 6.9. This latter value is coherent with distorted polyhedral units such as capped octahedral or capped trigonal prisms. In comparison, calcium metaphosphate crystals present a capped trigonal prism structure. In addition, it appears that most of the non-bridging oxygen atoms are bonded to two calcium atoms, creating $\mathrm{Ca}$ clusters with a $\mathrm{Ca}-\mathrm{Ca}$ correlation distance which is a function of the sharing mode between two adjacent $\mathrm{Ca}$ coordination polyhedra, i.e. edge-sharing or corner-sharing. Nevertheless, there is no quantitative way to describe the Ca clusters in terms of their shape.

It should be noticed that the main advantage of the RMC method is that it is comparatively easy to use and the program is readily and freely available. In addition, data sets from different techniques (e.g. diffraction, EXAFS, NMR, etc.) can be 'fitted' simultaneously while respecting quantitatively their different experimental errors. Furthermore it is relatively easy to build extra constraints into the refined model by, for example, adding coordination number constraints obtained from, e.g. NMR methods, or requiring the model to have agreement with local atomic arrangements known from, e.g. EXAFS measurements. A disadvantage is that it is difficult to build in molecular structure to the 
model apart from using rather crude constraints that risk trapping the simulation in local minima.

In the past ten years, the application of molecular dynamics simulations in the field of bioactive glasses has improved both the identification of structural features and the fundamental understanding of composition-bioactivity relationships in these materials [103]. If most of the work has focused on biosilicate glasses, several investigations have been carried out on the effects of incorporating fluorine on the structure, and hence the bioactivity, of fluorinated phosphate based glasses [104,105]. From these studies, it has been established that atomistic simulations have revealed details of bulk structural features which affect the glass dissolution and thus its bioactivity, such as the connectivity network and the tendency to form chains, rings and clusters. The replacement of an oxygen atom in a PO4 tetrahedron by a non-bridging fluorine atom causes a slight reduction in the glass network connectivity, which is likely to increase the bioactivity. A second effect, namely the segregation of the glass network into modifier-rich and network-rich regions with an attendant decrease in bioactivity, is likely to be insignificant due to the sizable amount of PF bonding observed. As a result, fluorinated phosphate-based glasses do not suffer the same decrease in bioactivity as fluorinated silicate-based glasses, and can be considered as strong candidates for biomaterials.

\subsection{Properties and Applications}

In the following section we will put our main interest in the most important applications that phosphate glasses have nowadays with relationship to their properties, such as chemical, thermal and mechanical, electrical or optical. Phosphate glasses can be used for a variety of applications within very diverse fields, though in most cases a suitable 
combination of several of their properties is needed and which can be found through the formulation of complex compositions. Nevertheless, due to the intrinsic importance of the atomic structure on the interpretation of the variation of properties with composition, most relevant studies on properties are always based on simple systems.

\subsubsection{Chemical Properties}

Discussing chemical properties of phosphate glasses, researchers have always focused on their dissolution behavior in aqueous media. This has been a recurrent topic when studying the properties of phosphate glasses and remains as the long-standing issue to be resolved during the design of new compositions for any application. The origin of their ease for dissolution resides in the highly hygroscopic nature of the phosphate units forming the glass network, especially to protonated species, and likely related to the high stability of phosphate compounds into solution [106]. While, in most cases one looks for the highest chemical durability, there are fields where a strict control of the dissolution rate of the glasses must be imposed independently of whether high or low, such as in biomedical applications, resorbable materials, controlled drug release, etc.

Comparatively speaking, phosphate glasses are more soluble than silicates, but the mechanisms of dissolution are similar in both, and when studying dissolution rates the same important factors are taken into account: composition, surface area, temperature, $\mathrm{pH}$ and time. Furthermore, the most common way to study the dissolution kinetics has been through the weight loss of a bulk glass sample against time, normalized to its surface area and keeping constant conditions of the ratio between the surface of the sample and the volume of solution [107]. Sometimes, convenient agitation of the media can be used, but for simplicity static condition are normally employed. On the other hand, while most of the 
studies carry out the tests at room temperature, especially those indicated for biomedical studies in simulated body fluid solutions, it has also been usual to perform kinetics at different temperatures even up to $90-100{ }^{\circ} \mathrm{C}$ either in static or dynamic conditions, if extreme environments need to be reproduced in a short period of time [108]. Other methods include the standardized dissolution tests that simulate the corrosion of nuclear waste glasses and are described in the ASTM C-1285-94 specifications, or the so-called Product Consistency Test (PCT), to follow the dissolution of powdered glasses at $90{ }^{\circ} \mathrm{C}$.

It is generally observed that the dissolution of phosphate glasses takes place congruently into two separated stages when studying the weight loss against time: first, a period that depends on $\mathrm{t}^{1 / 2}$ and is attributed to the diffusion of water through the glass surface; second, a constant loss stage depending linearly on $\mathrm{t}$ [109]. However, as numerous factors are involved in the whole process of dissolution (composition, temperature, $\mathrm{pH}$, etc.) any change in one of them may affect the duration of each of these stages. Bunker et al. proposed a mechanism by which only until the polymeric phosphate chains are completely hydrated (stage $\mathrm{t}^{1 / 2}$ ) the dissolution of the whole chains may take place ( $\mathrm{t}$-dependent stage). This was proposed as in agreement with the amount of acid that the dissolution of the phosphate glasses needed to keep a constant solution $\mathrm{pH}$, which at the same time allowed for a calculation of the length of the dissolved chains, being around 40 units [109]. Other authors, however, have proposed that after the hydration of the glass surface, with exchange of protonated species by modifier ions $\left(\mathrm{Li}^{+}\right.$or $\left.\mathrm{Na}^{+}\right)$, there must be a breakage of the P-O-P bonds of the hydrated layer that results in the dissolution of the glass [110]. Similarly, Döhler et al. stated that the hydrolysis step follows the hydration of phosphate groups and, furthermore, that the contribution of the hydrolysis of P-O-P bonds in the mechanism depends on the phosphate content after studying the dissolution of glasses with 
compositions $\mathrm{xP}_{2} \mathrm{O}_{5}-(100-\mathrm{x}) / 2 \mathrm{CaO}-(100-\mathrm{x}) / 2 \mathrm{Na}_{2} \mathrm{O}(\mathrm{x}=35-55 \mathrm{~mol} \%)$, for which the higher the amount of $\mathrm{P}_{2} \mathrm{O}_{5}$ the higher the extent of hydrolysis is [111]. In their work, Döhler et al. observed that the solubility of the glasses, as studied from powdered glasses $(125-315 \mu \mathrm{m})$ in $\mathrm{pH}=7.4$ tris-buffered solutions at $37^{\circ} \mathrm{C}$, decreases with the decrease of the phosphate content in the glasses, and they suggested that shorter chains would be less hydrolysable. This situation is completely different to what has been seen in sodium or lithium binary phosphate systems, where the opposite trend occurs $[112,113]$, in which a decrease of the solubility results with the increase of the $\mathrm{P}_{2} \mathrm{O}_{5}$ content. Therefore, it is clear that both type and content of modifiers, as well the ratio between phosphate and modifiers, give rise to a different behavior and likely variations in the mechanism. What seems to be clear is that, concerning the nature of the modifiers, the chemical durability of the glasses will increase with the higher ionic field strength of the cations and that the overall solubility will not only depend on the hydrolysis step of the P-O-P bonds but also on the strength of the metal to oxygen bonds.

Delahaye et al. also point out to another influencing factor on the $\mathrm{t}^{1 / 2}$ first stage of dissolution related to the ionic strength of the solution [107]. The authors have also concluded that a diffusion controlled step occurs for short times of dissolution; however, they argued that this would happen as a result of the increase in the ionic strength of the solution that limits the rate of dissolution of the glasses until it keeps constant for longer durations. Furthermore, one should also take into account if an alteration of the surface of the glass takes place through formation of hydrated layers or precipitation of crystalline compounds that may be forcing changes in the mechanism of dissolution. For example, the dissolution behavior of $\mathrm{ZnO}-\mathrm{P}_{2} \mathrm{O}_{5}$ bulk glasses in distilled water at temperatures of 30 to 90 
${ }^{\circ} \mathrm{C}$ for $72 \mathrm{~h}$ was classified according to the precipitated products appeared in solution or onto the sample surface after the leaching tests, which showed decreased solubility with the decrease of $\mathrm{P}_{2} \mathrm{O}_{5}$ content, and even lower solubility for the highest temperatures [114]. In the highest phosphate containing glasses the formation of a corrosion layer onto the surface dramatically decreases the dissolution rate of the glasses.

\section{Oxynitride Phosphate Glasses}

If there has been one way by which phosphate glasses have achieved a considerable increase of their chemical durability it is clearly their nitridation. The nitridation of phosphate glasses, or the partial substitution of oxygen by nitrogen, was originally develop by Marchand at the University of Rennes 1 by thermal ammonolysis of a phosphate base glass under an $\mathrm{NH}_{3}$ flow [115], in an attempt to establish a comparison with the already known oxynitride silicate liquids (SiAlON) that play an important role in the joining of silicon nitride ceramics and related phases [116]. The literature on oxynitride phosphate glasses is not as extensive as that of their silicate counterparts because silicon oxynitride glasses have always been of great interest not only for glass scientist but also for ceramists. However, phosphate melts possess the advantage that they can be nitrided at much lower temperatures and, under adequate conditions, produce glasses with much better homogeneity and transparency, which may expand their possibilities of application. Actually, in principle all considered applications for phosphate glasses can also be considered for oxynitride phosphates, with higher chemical durability.

The first nitrided phosphate glass by Marchand was a $\mathrm{NaPO}_{3}$ composition at $700{ }^{\circ} \mathrm{C}$ for 100 $\mathrm{h}$ in order to achieve the maximum allowed nitrogen content in the glass, reaching nearly 10 wt. \% that corresponds to a glass with composition $\mathrm{NaPO}_{2.01} \mathrm{~N}_{0.66}$ [115]. Thus, the 
substitution of nitrogen for oxygen takes place in a stoichiometric way through the exchange of $2 \mathrm{~N}^{3-}$ anions by $3 \mathrm{O}^{2-}$, resulting in the following reaction, given by the reaction below:

$$
\mathrm{NaPO}_{3}+x \mathrm{NH}_{3} \rightarrow \mathrm{NaPO}_{3-3 \mathrm{x} / 2} \mathrm{~N}_{\mathrm{x}}+\mathrm{H}_{2} \mathrm{O}
$$

The reaction must take place at temperatures higher than $600^{\circ} \mathrm{C}$, above which decomposition of $\mathrm{NH}_{3}$ may proceed in order to react with the melt; however, it has to be realized that temperature is another limiting factor due to the fact that this cannot surpass $800^{\circ} \mathrm{C}$ because phosphorus can be easily reduced and form colored inhomogeneous glasses. In any case, to be able to achieve high nitrogen contents in a short period of time the temperature should be as high as possible, which is related to a low melt viscosity [117]. The first remarkable observation by Marchand was the increase of $T_{g}$ of the glasses after nitrogen incorporation, which was of more than $100^{\circ} \mathrm{C}$ with respect to that of the sodium metaphosphate glass. This change of $\mathrm{T}_{\mathrm{g}}$ was already explained through the increased crosslink density and covalent character introduced by the two nitrogen species that may appear in the oxynitride glasses, the dicoordinated nitrogen, $\mathrm{P}-\mathrm{N}=\mathrm{P}\left(\mathrm{N}_{\mathrm{d}}\right)$, and the tricoordinated one, $\mathrm{P}-\mathrm{N}<(\mathrm{P})_{2}\left(\mathrm{~N}_{\mathrm{t}}\right)$, as seen later by X-ray Photoelectron Spectroscopy [118].

Soon after the experiments of Marchand, the study of oxynitride phosphate glasses became an interesting topic of research within the field of phosphates due to the interesting modifications of both their structure and properties. The first studies of the dissolution of oxynitride phosphate glasses were performed by Day and coworkers at the University of Missouri and showed that the dissolution of the oxynitrides was up to 10000 times slower than that of the oxide parent glasses, as shown by Bunker et al. in glasses of the system $\mathrm{Na}_{2} \mathrm{O}-\mathrm{BaO}-\mathrm{Al}_{2} \mathrm{O}_{3}-\mathrm{P}_{2} \mathrm{O}_{5}$ [119]. They observed a linear decrease of the dissolution rate at 
temperatures between 30 and $70^{\circ} \mathrm{C}$ with the nitrogen content, that decreases to almost that of soda-lime glasses for the highest nitrogen contents, and interpreted the results as a consequence of a much slower diffusion of water throughout the glass surface and a mechanism involving direct hydrolysis of the P-N bonds. In such a case, the dissolution rate changes from a mechanism controlled through the square root of reaction time to another depending directly on $t$. Furthermore, they concluded that the dissolution of the oxynitride compositions is less sensitive to $\mathrm{pH}$ changes, thus leading to glasses that can resist better in a wider range of conditions.

Further studies demonstrated the impact of nitrogen on several other properties, such a decrease of the coefficient of thermal expansion and increases in density, refractive index and hardness [120-122], and all results can be explained on the basis of the increased crosslinking of the glass network through the new bonds created. The effect on viscosity was also studied, showing an increase with the content of nitrogen [121]. Despite the observed trend, authors determined lower activation energies for the viscous flow in the oxynitride sodium metaphosphate glasses; however, this issue was not much researched in detail at the beginning. More recently, Paraschiv et al. have started a systematic study of the thermodynamics and kinetic fragility study in nitrided phosphates with interesting results that show a decreasing fragility of the glasses with nitrogen content that might be related to an inhomogeneous microstructure composed of regions with different rigidities [123]. Another way of incorporating nitrogen into the glasses was attained through the addition of metal nitrides during the melting of a sodium phosphate glass [124]. The results showed the same modification of properties of oxynitride glasses though in this case further changes in composition of the glasses takes place as secondary metals are being added to the glass, such as $\mathrm{Mg}$ or $\mathrm{Al}$, and due to the higher melting temperatures needed to dissolve the 
nitrides inhomogeneities may often result and therefore this method has not been much explored.

The studies on the structure of oxynitride phosphate glasses through XPS of the $\mathrm{O}_{1 \mathrm{~s}}$ and $\mathrm{N}_{1 \mathrm{~s}}$ energy levels allowed for the determination of the reaction mechanisms of ammonolysis. Both $\mathrm{BO}$ and NBO oxygens decreased their amount as the nitrogen content is increased in the glasses; however, the ratio between them, BO/NBO showed a linear decrease in all cases though with slight varying rates depending on glass composition [125]. Brow et al. concluded that the nitrogen for oxygen substitution takes place on both $\mathrm{BO}$ and NBO simultaneously, without preference for a substitution in either of the oxygen types in the network. At the same time, Marchand et al. defined the two substitution rules that constitute the basis for the nitridation: 1) $2 \mathrm{~N}_{\mathrm{t}}=3 \mathrm{BO}$ and 2) $2 \mathrm{~N}_{\mathrm{d}}=2 \mathrm{NBO}+\mathrm{BO}$ [118]. As shown above, $\mathrm{N}_{\mathrm{t}}$ and $\mathrm{N}_{\mathrm{d}}$ refer to the tri-coordinated and di-coordinated nitrogen atoms, respectively. From the analysis of the $\mathrm{N}_{1 \mathrm{~s}}$ XPS spectra of the $\mathrm{N}_{\mathrm{t}}$ and $\mathrm{N}_{\mathrm{d}}$ relative proportions, one may calculate the expected values of the $\mathrm{BO} / \mathrm{NBO}$ ratio assuming the above rules and following equation (4):

$$
\mathrm{BO} / \mathrm{NBO}=(\mathrm{BO} / \mathrm{NBO})_{0}-\left[1.5 \cdot \mathrm{N}_{\mathrm{t}} /\left(2-\mathrm{N}_{\mathrm{d}}\right)\right]
$$

where $(\mathrm{BO} / \mathrm{NBO})_{0}$ represents the initial $\mathrm{BO} / \mathrm{NBO}$ ratio in the parent glass [118]. Using the above rules, Le Sauze et al. showed a good correlation when studying mixed alkali oxynitride metaphosphate glasses with composition $\mathrm{Li}_{0.5} \mathrm{Na}_{0.5} \mathrm{PO}_{3-3 \mathrm{x} / 2} \mathrm{~N}_{\mathrm{x}}$ glasses. Figure 1.13 shows the experimental BO/NBO ratio as determined by XPS, black squares, and the calculated values, dotted line, following Marchand's rules [126]. 


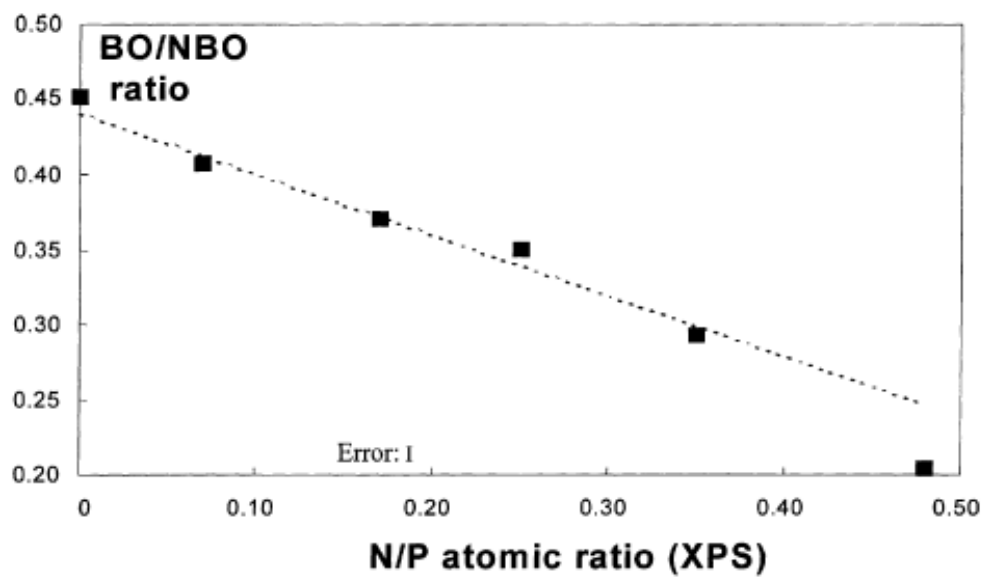

Figure 1.13: Calculated $v s$ experimental $\mathrm{BO} / \mathrm{NBO}$ ratio in $\mathrm{Li}_{0.5} \mathrm{Na}_{0.5} \mathrm{PO}_{3-3 \mathrm{x} / 2} \mathrm{~N}_{\mathrm{x}}$ glasses.

Reprinted from reference [126], Copyright (2000), with permission from Elsevier.

Furthermore, $\mathrm{N}_{1 \mathrm{~s}}$ XPS results generally show a higher amount of $\mathrm{N}_{\mathrm{t}}$ bonds at the first stages of nitridation, i.e. low nitrogen contents, which might be related to an initial preference for the substitution of the bridging oxygens alone, contrary to that proposed before by Brow et al. [125]. As the nitrogen content increases, both $\mathrm{N}_{\mathrm{t}}$ and $\mathrm{N}_{\mathrm{d}}$ proportions become similar and it may also happen that $\mathrm{N}_{\mathrm{d}}$ surpasses the content of $\mathrm{N}_{\mathrm{t}}$. As it was shown by Muñoz et al. comparing alkali ('NaPON'), mixed alkali ('LiNaPON') and mixed-alkali lead metaphosphate glasses ('LiNaPbPON'), the variation of the $\mathrm{N}_{\mathrm{t}} / \mathrm{N}_{\mathrm{d}}$ ratio does also depend on the glass composition, showing higher $\mathrm{N}_{\mathrm{t}}$ values for the sodium metaphosphate system [127].

The glass network structure has been also well characterized by ${ }^{31} \mathrm{P} \mathrm{NMR}$, which may also contribute to a precise determination of the reaction mechanisms. It is known that $\mathrm{PO}_{4}$ groups transform into $\mathrm{PO}_{3} \mathrm{~N}$ and $\mathrm{PO}_{2} \mathrm{~N}_{2}$ units after nitridation and in their work, Le Sauze et al. showed the complete evolution of these structural species as a function of the nitrogen content [126]. Based on their results and the analysis done by ${ }^{31} \mathrm{P}$ DQ MAS NMR, they 
proposed that the nitridation first proceeds by the substitution of nitrogen for oxygen to form $\mathrm{PO}_{3} \mathrm{~N}$ groups, homogeneously distributed in the glass network, and then, continues by the formation of $\mathrm{PO}_{2} \mathrm{~N}_{2}$ on the previously existing $\mathrm{PO}_{3} \mathrm{~N}-\mathrm{PO}_{4}$ links [126]. Thus, the authors concluded that the mechanism assumes that oxynitride regions grow at the expense of the oxide ones, which was further verified in LiNaPbPON glasses by Muñoz et al. [128,129].

Figure 1.14 shows the evolution of the $\mathrm{P}(\mathrm{O}, \mathrm{N})_{4}$ tetrahedra as a function of the nitrogen content in $\mathrm{Li}_{0.25} \mathrm{Na}_{0.25} \mathrm{~Pb}_{0.25} \mathrm{PO}_{3-3 \mathrm{x} / 2} \mathrm{~N}_{\mathrm{x}}$ glasses [128].

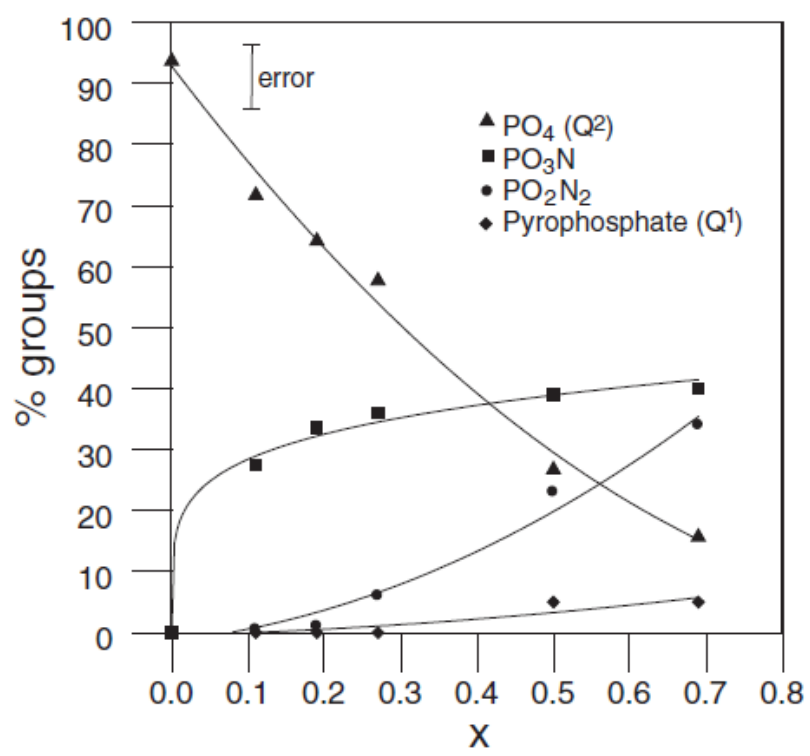

Figure 1.14: Evolution of the proportions of $\mathrm{P}(\mathrm{O}, \mathrm{N})_{4}$ tetrahedra with nitrogen content $(\mathrm{x})$ in oxynitride glasses with composition $\mathrm{Li}_{0.25} \mathrm{Na}_{0.25} \mathrm{~Pb}_{0.25} \mathrm{PO}_{3-3 \mathrm{x} / 2} \mathrm{~N}_{\mathrm{x}}$. Reprinted from reference [128], Copyright (2003), with permission from Elsevier.

While the proportion of $\mathrm{PO}_{4}$ groups progressively decreases with $\mathrm{x}, \mathrm{PO}_{3} \mathrm{~N}$ and $\mathrm{PO}_{2} \mathrm{~N}_{2}$ increase with nitridation, though the one of $\mathrm{PO}_{3} \mathrm{~N}$ groups remains higher than that of $\mathrm{PO}_{2} \mathrm{~N}_{2}$ for all $\mathrm{x}$. These proportions vary similarly in all glass compositions but some differences 
can be found depending on the type of modifiers, particularly at high nitrogen contents [127]. Furthermore, the fact that for the highest nitrogen contents, a higher amount of $\mathrm{N}_{\mathrm{d}}$ type bonds is found and indicates that $\mathrm{PO}_{2} \mathrm{~N}_{2}$ tetrahedra will host a higher amount of dicoordinated nitrogen species, likely due to a higher stability forced by steric effects. The above data were also used to determine that the nitridation mechanism is constituted by a system composed of two pseudo-first-order consecutive reactions as shown by Muñoz in [130]. First, the reaction with $\mathrm{NH}_{3}$ gives rise to the formation of $\mathrm{PO}_{3} \mathrm{~N}$ from $\mathrm{PO}_{4}$ and then, $\mathrm{PO}_{2} \mathrm{~N}_{2}$ form from the substitution of nitrogen for oxygen in the $\mathrm{PO}_{3} \mathrm{~N}$ groups that are linked to neighboring $\mathrm{PO}_{4}$ with the subsequent formation of new $\mathrm{PO}_{3} \mathrm{~N}$. Both reaction steps were determined to have the same activation energy of ca. $150 \mathrm{~kJ} \cdot \mathrm{mol}^{-1}[130]$.

Finally, the last recent finding was also achieved by Muñoz et al. through the use of ${ }^{17} \mathrm{O}-$ enriched NaPON glasses [131]. In these glasses, the structure was studied by ${ }^{17} \mathrm{O}$ high-field MAS and MQ-MAS NMR and the authors were able to determine that two types of nonbridging oxygens are located on the $\mathrm{P}(\mathrm{O}, \mathrm{N})_{4}$ tetrahedra, while for the $\mathrm{NaPO}_{3}$ reference glass a single type of NBO is found. After the modeling of the 3Q-MAS spectra taken at 18.8 T, it was possible to determine of the NMR parameters of each site and quantify their population. The results revealed a second type of NBO whose amount increased with the nitrogen content in the $\mathrm{NaPO}_{3-3 \times / 2} \mathrm{~N}_{\mathrm{x}}$ studied glasses, being of ca. $80 \%$ of the total $\mathrm{NBO}$ content for the maximum N/P ratio of 0.68 . As the new non-bridging oxygen contribution would be that coming from the NBO located in the $\mathrm{PO}_{3} \mathrm{~N}$ and $\mathrm{PO}_{2} \mathrm{~N}_{2}$ groups formed during nitridation, the authors were able to calculate the proportion of those given the fractions of each of the structural units and assuming that $\mathrm{PO}_{3} \mathrm{~N}$ groups have two $\mathrm{NBO}$ and one $\mathrm{BO}$ while $\mathrm{PO}_{2} \mathrm{~N}_{2}$ have no $\mathrm{BO}$ left, obtaining a quite good agreement with the experimental quantification. 
The most extended studies of oxynitride phosphate glasses have dealt with their application as sealing glasses, not only for their high chemical durability but also due to their still adequate softening temperature and thermal expansion for the sealing of low melting point metals [132]. However, the fact that their dissolution rate can be controlled and adjusted as needed through the choice of the right composition and nitrogen content, let us think that oxynitride phosphates have a much bigger potential for present and future applications, such as in the field of bioresorbable phosphate glasses for medical applications [133]. Last but not least, it is worth mentioning here the studies on the electrical conductivity of lithium oxynitride phosphate glasses and their relationship with the LiPON electrolytes that are used in lithium microbatteries [30]. As it will be seen below, these amorphous thin-film electrolytes possess the same increase in ionic conductivity and chemical and mechanical resistance thanks to the partial substitution of oxygen by nitrogen as the lithium oxynitride phosphate glasses have [134].

\subsubsection{Thermal Properties}

The most important and studied thermal properties of phosphate glasses are glass transition temperature and thermal expansion behavior, as they have been of the major interest for their application as low temperature sealing glasses [135]. Other properties have received much less attention and have been studied for fundamental interest only, such as the heat capacity $[136,137]$. Thermal conductivity has normally been determined when being a key factor in the behavior of the glass under working conditions, such as in the case of the Nddoped phosphate laser glasses [19], where a large thermal conductivity contributes to an increased thermal shock resistance during laser operation as will be detailed below. 
Low glass transition temperatures are usually associated with high thermal expansion coefficients and have a clear relationship with the two main structural factors, the field strength of the modifier cations and the polymerization degree of the glass forming network. The less interconnected network in phosphate glasses resulting from the $\mathrm{P}=\mathrm{O}$ bond of the $\mathrm{PO}_{4}$ building units has a tremendous impact on the $\mathrm{T}_{\mathrm{g}}$ and simultaneously on the thermal expansion of the glass. Furthermore, even minor amounts of water can remain dissolved into the glass and affect $\mathrm{T}_{\mathrm{g}}$ with an additional substantial decrease. It is also wellknown in lithium and sodium phosphate glasses that $T_{g}$ first decreases with the addition of alkali oxide down to a minimum around $20 \mathrm{~mol} \%$, then continuously increases with further additions of modifier [138]. This was attributed to a re-distribution of the Li-O bonds depending on the alkali concentration rather than to an abrupt change in the coordination number of lithium cations that give rise to an increase of $T_{g}$ through the formation of crosslinks of O-Li-O polyhedra [139], being in agreement with the structural model of Hoppe [9]. Nevertheless, the glass transition temperature increase is always associated with the ionic field strength of the modifier cations, though there are exceptions like when using cations like $\mathrm{Zn}$ or $\mathrm{Pb}$. These elements are known to provide relatively high chemical durability values while maintaining low transition temperatures as well as high coefficients of thermal expansion. However, as it has been shown recently, a linear relationship appears between $\mathrm{T}_{\mathrm{g}}$ and the product of the cationic potential of the modifier and its coordination number in metaphosphate glasses, where now the $T_{g}$ of the zinc metaphosphate composition does not result abnormally low compared to the values in alkali and alkalineearth containing glasses [37].

As indicated above, the glass transition temperature of alkali phosphate glasses can be lower than $300^{\circ} \mathrm{C}$ although the chemical resistance of simple phosphate compositions, like 
those or even with some additions of alkaline-earth elements, is rather low. Zinc, lead and also bismuth can be used in combination with alkaline-earth elements to provide low $\mathrm{T}_{\mathrm{g}}$ and high thermal expansion at the same time that relatively good durability values.. However, these compositional changes do not normally meet the specific requirements for the application of phosphate glasses and so the most effective option is the formulation of glasses with $\mathrm{Al}_{2} \mathrm{O}_{3}$. This can greatly affect the thermal behavior of the glasses but undoubtedly will improve their chemical resistance. Furthermore, the incorporation of even minor amounts of alumina in the glass composition may help to reduce the crystallization tendency, being also advantageous for the control of the sealing process through maintaining adequate fluidity. In this sense, it is worth mentioning the important role of the viscosity of the glass, not only for their production, but also as a determinant factor that must be strictly controlled when the phosphate glasses needs working as a solder glass [140].

\section{Low-Temperature Sealing Applications}

Glasses are known to be suitable for the production of mechanically reliable and vacuumtight seals with metals and ceramics. The direct wettability of materials by glasses and the viscosity behavior of glasses are among the critical properties. The stability and mechanical strength of a glass seals must be ensured by limiting the mechanical stress in the glass component at temperatures met during production and use. In other words, the thermal contractions of the two sealing components should match each other below the transition temperature of the glass. In addition, glasses must very often fulfil other requirements such as possessing high electrical insulation, chemical resistance to the environment or specific optical properties. Glasses are generally classified according to their composition, such as 
silicates, borosilicates, alumino-borates, lead and zinc borates, antimonates, vanadates or phosphates. However, they can be also classified according to their thermal expansion and temperature characteristics into "hard" and "soft" glasses [141]. Hard glasses have low thermal expansion coefficients, i.e. $\alpha<5 \cdot 10^{-6} \mathrm{~K}^{-1}$, whereas soft glasses possess higher thermal expansions, i.e. $\alpha>8 \cdot 10^{-6} \mathrm{~K}^{-1}$. As a general rule, glasses of high expansion possess relatively low softening and working temperatures, while low-expansion glasses have higher softening points. Glasses with particularly low softening temperatures are referred to as "solder" glasses. This is because they are used to join glass to other glasses, ceramics, or metals without thermally damaging the materials to be joined. Soldering is generally carried out in the viscosity range of $\eta=10^{3}-10^{5} \mathrm{~Pa} \cdot \mathrm{s}$ of the solder glass, which corresponds to various temperature ranges, depending on the chemical compositions.

Among the various glass compositions which have been developed, the Pb-based sealing frits, such as $\mathrm{PbO}-\mathrm{B}_{2} \mathrm{O}_{3}-\mathrm{SiO}_{2}$ or $\mathrm{PbO}-\mathrm{ZnO}-\mathrm{B}_{2} \mathrm{O}_{3}$ glasses, are the materials of choice for most commercial sealing operations including, in late years, plasma display panel (PDP) or vacuum fluorescent displays (VFD). These materials offer the advantage of low viscosities for which the softening point is $\angle 400^{\circ} \mathrm{C}$, coefficient of thermal expansion in the range 9$10 \times 10^{-6} \mathrm{~K}^{-1}$ and flow over an extended period of time without simultaneous crystallization when fired as a fine powder $(10-40 \mu \mathrm{m})$ during the sealing process. However, they suffer from a severe drawback which is the high $\mathrm{PbO}$ content (typically more than 70 wt.\%), a component with deleterious health and environmental effects. For these reasons, a search has been conducted for glass compositions with the lowest possible $\mathrm{T}_{\mathrm{g}}$ as alternatives to $\mathrm{Pb}$ based frits. One such system is the $\mathrm{SnO}-\mathrm{ZnO}-\mathrm{P}_{2} \mathrm{O}_{5}$ (SZP) ternary [20]. Both the aqueous 
durability and crystallization of the SZP frits may be made comparable to that of Pb-based systems by adequate design of the composition.

The development of solder glasses with very low soldering temperatures is limited by the fact that reducing the temperature generally means increasing the coefficient of thermal expansion. This effect is less pronounced in devitrifying solder glasses and it can be also avoided by adding inert fillers with low or negative coefficients of thermal expansion (e.g. $\mathrm{ZrSiO}_{4}$ or $\beta$-eucryptite).

Vitreous solder glasses have to be distinguished from devitrifying solder glasses, according to their behavior during the soldering process. The properties of solder glasses do not change during soldering; upon reheating the solder joint, the temperature dependence of the softening is the same as in the preceding soldering process. Contrary to vitreous solder glasses, devitrifying solder glasses crystallize. They change into a ceramic-like polycrystalline material during soldering and the viscosity increases by several orders of magnitude during crystallization so that further flowing is suppressed.

Only limited attention has been devoted to the controlled crystallization of phosphate glasses to produce glass-ceramic materials. Much of this work has been aimed at the production of biomedical materials based on calcium phosphate for applications involving bone replacement and dental implants [141]. The crystallization behavior of a number of phosphate systems, including $\mathrm{Na}_{2} \mathrm{O}-\mathrm{CaO}-\mathrm{P}_{2} \mathrm{O}_{5}, \mathrm{Na}_{2} \mathrm{O}-\mathrm{BaO}-\mathrm{P}_{2} \mathrm{O}_{5}, \mathrm{Na} 2 \mathrm{O}-\mathrm{A}_{2} \mathrm{O}_{3}-\mathrm{P}_{2} \mathrm{O}_{5}$ and $\mathrm{Li}_{2} \mathrm{O}-\mathrm{BaO}-\mathrm{P}_{2} \mathrm{O}_{5}$, have been investigated likewise the effect of a number of potential nucleating species, such as $\mathrm{TiO}_{2}, \mathrm{ZrO}_{2}, \mathrm{Y}_{2} \mathrm{O}_{3}, \mathrm{La}_{2} \mathrm{O}_{3}, \mathrm{Ta}_{2} \mathrm{O}_{5}, \mathrm{WO}_{3}$ and platinum [142]. Among these additions, only platinum was found to be effective at promoting bulk crystallization. Relatively high thermal expansion coefficients in the range of 16.2 $22.5 \cdot 10^{-6} \mathrm{~K}^{-1}$ have been achieved. A devitrification study conducted on calcium phosphate 
glasses containing a number of oxide and fluoride additions have shown that $\mathrm{TiO}_{2}$, in conjunction with $\mathrm{A}_{2} \mathrm{O}_{3}$, may also be employed to promote bulk crystallization [143]. Thermal expansion data for a number of phosphate glasses and glass-ceramics are given in Table II, with their corresponding chemical compositions, which have been taken from references [141] and [144].

Apart from characteristic data, such as coefficient of thermal expansion (CTE), glass transition temperature or elastic properties, the importance of the design of the seal should not, however, be underestimated. A wrong design is usually associated with mismatch in coefficient of thermal expansion, producing tensile stresses in the glass. These usually manifest themselves as cracks, emanating from the interface into the bulk of the glass, although if the stresses are not high enough to cause cracking initially, time-dependent failure may occur due to the influence of static fatigue. A good design must take into consideration any possible mismatch in thermal expansion and seek to place the interface under compression [144].

A common feature of all compression seals can be illustrated by glass-to-metal seals which are used to provide electrical connections to components that must be hermetically sealed. In this typical application, electrical connectivity is provided through metallic pins arranged within an opening of a metallic shell that is sealed with a glass to insulate/isolate the pin from the housing. A single-pin, concentric glass-to-metal seal is depicted in Figure 1.15.

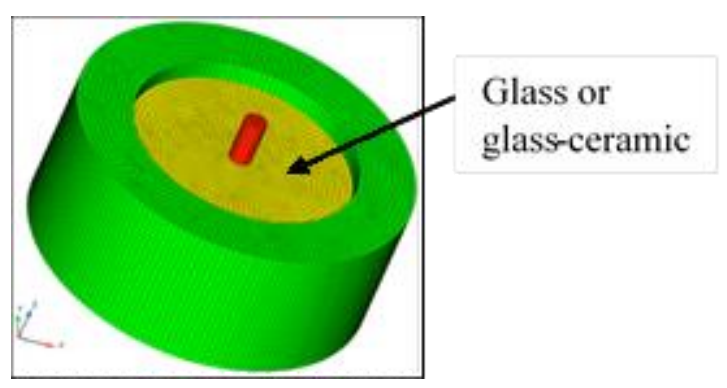


Figure 1.15: Schematic draw of a glass-to-metal compression seal.

The choice of materials is an important factor in reducing the risk of glass fracturing. Compression seals use an outer shell material with a CTE that is greater than the glass and the CTE of the pin that closely resembles or is lower than that of the glass. As such, the glass is subjected to nominal radial compression on cooling that tends to reduce the possibility of generating high tensile stresses. As a result, the glass body is kept under overall radial pressure after the sealing. This pre-stressing protects the glass body against dangerous mechanical loads and guarantees robust seals. Because the compressive stress of the glass is compensated by a tensile stress in the metallic shell, the wall must be sufficiently thick (at least $0.5 \mathrm{~mm}$ even for small seals) in order to be able to absorb such tensions permanently. Compression seals can be produced as hard glass or soft glass seals. If the difference between the thermal expansion of the metallic shell and that of the sealing glass is significantly higher than $5 \cdot 10^{-6} \mathrm{~K}^{-1}$, an additional pre-stressing of the glass body may result. 
Table II: Composition and characteristic temperatures of phosphate sealing glasses (Data selected from references [141] and [144]).

\begin{tabular}{|c|c|c|c|c|c|c|c|c|c|c|c|c|c|}
\hline \multirow[t]{2}{*}{ Code } & \multicolumn{10}{|c|}{ Composition (mol \%) } & \multirow{2}{*}{$\begin{array}{c}\text { Sealing } \\
\text { temperature } \\
\left({ }^{\circ} \mathrm{C}\right)\end{array}$} & \multirow{2}{*}{$\begin{array}{l}\text { Thermal } \\
\text { expansion } \\
\left(10^{-6} \mathrm{~K}^{-1}\right)\end{array}$} & \multirow{2}{*}{$\begin{array}{c}\text { Temperature } \\
\text { range }\left({ }^{\circ} \mathrm{C}\right)\end{array}$} \\
\hline & $\mathrm{Na}_{2} \mathrm{O}$ & $\mathrm{K}_{2} \mathrm{O}$ & $\mathrm{BaO}$ & $\mathrm{ZnO}$ & $\mathrm{B}_{2} \mathrm{O}_{3}$ & $\mathrm{Al}_{2} \mathrm{O}_{3}$ & $\mathrm{SiO}_{2}$ & $\mathrm{P}_{2} \mathrm{O}_{5}$ & $\mathrm{PbO}$ & Others & & & \\
\hline G1 & 25.00 & 25.00 & & & & & & 50.00 & & & 212 & 34.7 & $100-250$ \\
\hline G2 & 35.00 & 15.00 & & & & & & 50.00 & & & 221 & 30.0 & $100-250$ \\
\hline G3 & 15.00 & & & & & & & 50.00 & & $35 \mathrm{Ag}_{2} \mathrm{O}$ & 266 & 26.8 & $100-250$ \\
\hline G4 & & 38.00 & & & & 3.00 & & 56.00 & & $3 \mathrm{Fe}_{2} \mathrm{O}_{3}$ & 317 & 26.0 & $100-250$ \\
\hline G5 & & 38.00 & & & & & & 56.00 & & $6 \mathrm{Fe}_{2} \mathrm{O}_{3}$ & 303 & 25.6 & $100-250$ \\
\hline G6 & & 34.00 & & & & 8.00 & & 58.00 & & & 313 & 24.0 & $100-250$ \\
\hline G7 & & 34.00 & & & & 4.00 & & 58.00 & & $4 \mathrm{Fe}_{2} \mathrm{O}_{3}$ & 350 & 22.0 & $100-250$ \\
\hline G8 & & 30.00 & & & & 10.00 & & 60.00 & & & 374 & 20.0 & $100-250$ \\
\hline G9 & & & & & & & & 50.00 & 50.00 & & 310 & 17.1 & $100-200$ \\
\hline G10 & & & & & & & & 58.80 & 41.20 & & 255 & 15.3 & $100-200$ \\
\hline G11 & & & & 20.00 & & & & 40.00 & 40.00 & & 345 & 13.2 & $100-200$ \\
\hline G12 & & & & 20.00 & & & & 50.00 & 30.00 & & 325 & 12.1 & $100-200$ \\
\hline G13 & & & 26.47 & & 9.72 & 6.63 & & 57.18 & & & 450 & 11.6 & $20-400$ \\
\hline G14 & & & 8.11 & 30.57 & & & & 61.32 & & & 330 & 11.6 & $100-200$ \\
\hline G15 & & & & 30.00 & & & & 50.00 & 20.00 & & 305 & 11.0 & $20-200$ \\
\hline G16 & & & 15.78 & 29.74 & & 11.87 & & 42.61 & & & 460 & 9.6 & $20-400$ \\
\hline G17 & & & & & & 26.84 & & 32.88 & & $40.28 \mathrm{CuO}$ & 540 & 7.1 & $20-400$ \\
\hline G18 & & & & 40.42 & 7.87 & 5.38 & & 46.33 & & & 475 & 7.0 & $20-400$ \\
\hline G19 & & & 2.82 & 42.48 & & 4.77 & 8.08 & 41.85 & & & 500 & 6.4 & $20-400$ \\
\hline GC1 & 40.00 & & 10.00 & & & & & 50.00 & & & & 22.5 & $25-250$ \\
\hline GC2 & 20.00 & & 30.00 & & & & & 50.00 & & & & 16.2 & $25-250$ \\
\hline GC3 & & & & & & 7.40 & 7.80 & 39.10 & & $\begin{array}{l}40.30 \mathrm{CaO} \\
5.50 \mathrm{TiO}_{2}\end{array}$ & & 14.1 & $20-185$ \\
\hline
\end{tabular}

${ }^{*} \mathrm{G}=$ Glass $;{ }^{*} \mathrm{GC}=$ Glass-Ceramic 


\subsubsection{Optical Properties}

It is well known that phosphate glasses deviate from the "normal line" behavior that silicate glasses have in the representation of the relative partial dispersion and the Abbe number [1]. Due to their higher chemical and mechanical resistance, and the fact that they follow a predictive value of the partial dispersion $v s$ the Abbe number, silicates are the standard optical glasses. Phosphate glasses generally possess higher partial dispersions for the same Abbe number than silicate glasses and, together with borates, which have a negative contribution, can be used for the correction of the secondary spectrum of silicate glasses [1]. In the field of optical lenses, phosphate glasses have found application in Precision Glass Molding, where the use of low $\mathrm{T}_{\mathrm{g}}$ glasses helps in reducing the temperature and time of processing. In any case, the low chemical durability of phosphates to environmental moisture, again, limits their use and most of the works today remain searching for new compositions with adequate thermal and optical properties while having acceptable chemical durability [145]

An advantage of phosphate glasses is, however, their ability to be melted with fluorides for the production of fluorophosphates glasses. Particularly, high fluorine containing phosphate glasses are excellent for optical glasses with positive anomalous dispersion that can be used for the substitution of $\mathrm{CaF}_{2}$ single-crystals in the reduction of chromatic aberrations [1,146].

Phosphates and fluorophosphates in particular are good candidates as athermal glasses where near zero coefficient of refractive index $(\mathrm{dn} / \mathrm{dT})$ and low thermo-optical constants can be easily achieved, usually better than in silicate glasses. Furthermore, when glasses have a negative value of the index variation with temperature, phosphate can be used for the elimination of wave aberration due to temperature changes [1]. Negative values of $\mathrm{dn} / \mathrm{dT}$ can be attained in metaphosphate glasses of modifier cations with low ionic field 
strength, such as in $\mathrm{K}, \mathrm{Na}, \mathrm{Ba}$ or $\mathrm{Pb}$ metaphosphates due to their large thermal expansion coefficient [147]. In fact, potassium and barium are modifier elements generally used in the formulation of laser phosphate glasses as it will be seen below [12].

Other interesting features of phosphate glasses are their non-linear refractive index values $\left(\mathrm{n}_{2}\right)$ and fluorescence linewidths. Phosphates have moderate non-linear index and low linewidths while fluorophosphates glasses have even smaller $\mathrm{n}_{2}$ and linewidths, which in addition to their higher UV transparency and lower phonon energy makes them very appropriate for luminescence applications [148]. Nevertheless, phosphates are very prone to present water in their compositions and very few amounts of hydroxyl ions produce very drastic non-radiative fluorescence quenching that may limit their use if the glasses are not properly melted [149].

\section{Neodymium Phosphate Laser Glass}

Neodymium doped phosphate laser glass (simplified as Nd:phosphate glass) is widely used in high power laser facilities. There are two kinds of Nd:phosphate laser glasses: one is for high peak power laser application, another is for high average power application. Neodymium ions have eight absorption bands from UV to infrared range due to the $4 f^{3}$ electronic energy level transitions. According to the energy diagram, the $\mathrm{Nd}^{3+}$ ion is used mainly for $1 \mu \mathrm{m}$ laser application due to the transition between ${ }^{4} \mathrm{~F}_{3 / 2}$ and ${ }^{4} \mathrm{I}_{11 / 2}$ energy levels. This is a typical four energy level laser which has low laser threshold and laser efficiency is less sensitive to thermal effects. Phosphate glass is used as the matrix for $\mathrm{Nd}^{3+}$ ions as it has medium phonon energy, high solubility to rare earth ions, large damage threshold and superior spectroscopic properties compared with silicate glass matrix. Therefore, neodymium phosphate glass is a priority laser material 
of choice for $1 \mu \mathrm{m}$ laser facilities. In addition, platinum inclusions can be easily oxidized and dissolved as platinum ions in phosphate glasses, thus preventing the formation of Pt inclusions, which is a key parameter to prevent the laser damage for high power laser application [19].

The composition design for Nd:phosphate glass should consider first its application. For different application purpose, there will be different composition design.

The figure of merit (FOM) of high peak power Nd:phosphate laser glass is given in equation (5) [150].

$$
F O M_{\text {laser }}=\frac{\Delta \lambda_{a b s}\left(\tau_{0} Q\right) \sigma_{e m} \eta_{e x}}{n_{2}}
$$

Where $\Delta \lambda_{a b s}$ is the absorption bandwidth, $\sigma_{e m}$ is the stimulated emission cross section, $\eta_{e x}$ is energy extraction efficiency, $\mathrm{n}_{2}$ is the nonlinear refractive index, $Q$ is concentration quenching factor and $\tau_{0}$ is fluorescent lifetime at zero $\mathrm{Nd}^{3+}$ ion concentration.

The most important parameter of high peak power Nd:phosphate laser glass is the peak stimulated emission cross section $\sigma_{\mathrm{em}}$. It is calculated by J-O method [151,152]. Large peak stimulated emission cross section is preferred to achieve high gain efficiency. Another important parameter is nonlinear refractive index $\mathrm{n}_{2}$. To prevent the risk of nonlinear optical damage, smaller $\mathrm{n}_{2}$ is preferred for high peak power Nd:phosphate laser glass. The high peak power Nd:phosphate laser glass is usually a kind of metaphosphate glass $(\mathrm{P} / \mathrm{O}=3)$ [19]. The peak stimulated emission cross section of Nd:phosphate laser glass is sensitive to glass composition. The main composition of Nd:phosphate laser glass is $\mathrm{P}_{2} \mathrm{O}_{5}-\mathrm{Al}_{2} \mathrm{O}_{3}-\mathrm{M}_{2} \mathrm{O}-\mathrm{MO}$ [19]. $\mathrm{P}_{2} \mathrm{O}_{5}$ content in high peak power Nd:phosphate glass is about $55-65 \mathrm{~mol} \%$. The stimulated emission cross section 
of $\mathrm{Nd}^{3+}$ ion usually increases with $\mathrm{P}_{2} \mathrm{O}_{5}$ content from 45 to 70 mol $\% \mathrm{P}_{2} \mathrm{O}_{5}$ in phosphate glasses [19]. $\mathrm{M}_{2} \mathrm{O}$ can be $\mathrm{K}_{2} \mathrm{O}$ or a mixture of alkali oxides, while $\mathrm{MO}$ can be one alkaline oxide or a mixture of alkaline-earth oxides. Small cationic field strength such as those of $\mathrm{K}^{+}$and $\mathrm{Ba}^{2+}$ ions results in large stimulated emission cross section of $\mathrm{Nd}^{3+}$ ion in phosphate glass. $\mathrm{MgO}$ content is used to achieve lower nonlinear refractive index but it has larger cationic field strength and it decreases peak stimulated emission cross section of $\mathrm{Nd}^{3+}$ ion. $\mathrm{Al}_{2} \mathrm{O}_{3}$ content is used to improve the chemical durability and to control the thermal expansion coefficient of $\mathrm{Nd}$ :phosphate laser glass in reasonable range for fabrication. But it decreases the stimulated emission cross section of $\mathrm{Nd}^{3+}$ ion. In addition, small amounts of high valence oxides such as $\mathrm{Nb}_{2} \mathrm{O}_{5}, \mathrm{La}_{2} \mathrm{O}_{3}$ and $\mathrm{Y}_{2} \mathrm{O}_{3}$ are used in Nd:phosphate laser glass to improve the chemical durability and vitrification behavior of the glass.

Figure 1.16 presents compositions for both research and commercial Nd:phosphate laser glasses [19]. It is found that the commercial $\mathrm{Nd}$ :phosphate laser glass is usually metaphosphate glass with $\mathrm{O}: \mathrm{P}$ ratio of 3 .

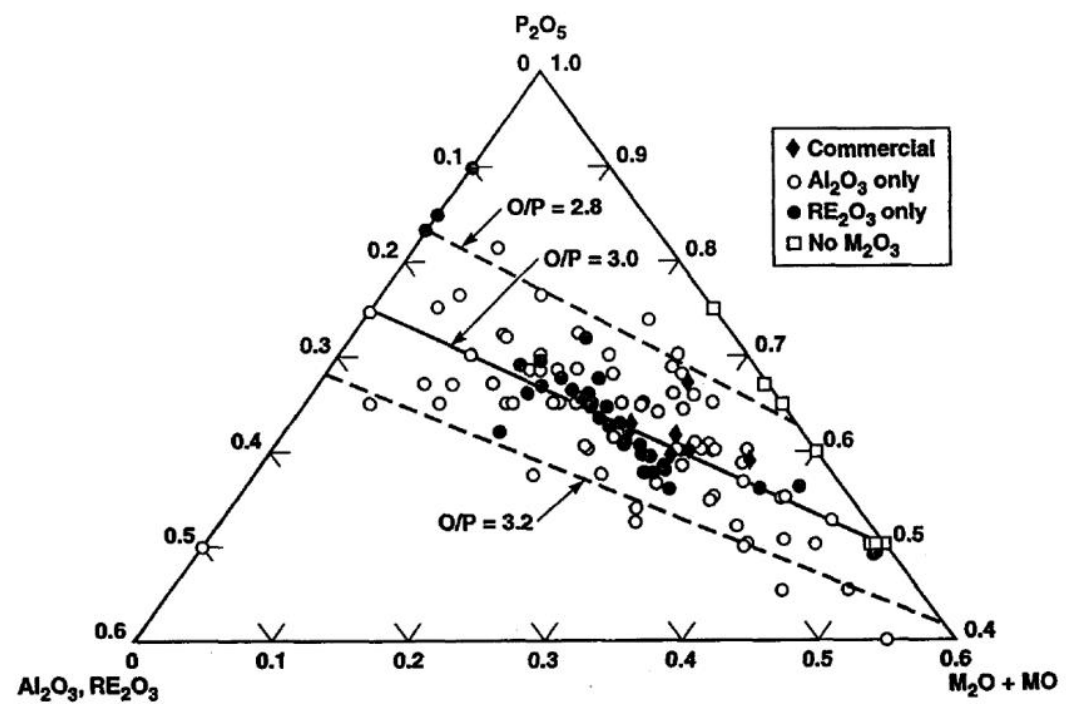


Figure 1.16: Composition range diagram of $\mathrm{Nd}$ :phosphate laser glasses. Reprinted from reference [19], Copyright (2000), with permission from Elsevier.

The figure of merit of high average power $\mathrm{Nd}$ :phosphate laser glass is shown in equation (6).

$$
F O M_{t m}=\frac{K_{1 c} K(1-v)}{\alpha E}
$$

Where $E$ is Young's modulus, $K_{l c}$ is the fracture toughness, $K$ is thermal conductivity, $v$ is Poisson's ratio and $\alpha$ is linear thermal expansion coefficient.

For high average power laser applications, the Nd:phosphate laser glass works in lower repetition rate such as $0.1-15 \mathrm{~Hz}$. It results in the accumulation of thermal gradients and may cause distortion of the laser beam and even the failure of the laser host. In such a case the thermo-mechanical properties of the glass should be optimized. The second goal is to get high gain coefficient. In order to optimize the thermal mechanical property, lower thermal expansion coefficient and large thermal conduction are preferred. The main high average power composition is $\mathrm{P}_{2} \mathrm{O}_{5}-\mathrm{Li}_{2} \mathrm{O}-\mathrm{Al}_{2} \mathrm{O}_{3}-\mathrm{SiO}_{2}$. A large amount of $\mathrm{Al}_{2} \mathrm{O}_{3}$ is contained in this glass in order to get lower thermal expansion coefficient. $\mathrm{Li}_{2} \mathrm{O}$ is used to increase the thermal conductivity of glass. As a result, high average power Nd:phosphate laser glass has a smaller stimulated emission cross section compared with high peak power Nd:phosphate laser glass.

Another important property of neodymium laser glass is the gain coefficient. It is expressed in equation (7),

$$
g=\Delta N \sigma(\lambda)-\alpha_{\text {loss }}
$$

where $\sigma(\lambda)$ is the emission cross section at laser wavelength $\lambda$. For Nd:phosphate glass, 
the maximum emission cross section in the near infrared region is around $1053 \mathrm{~nm} . \Delta N$ is $\mathrm{Nd}^{3+}$ inverted population density. It is determined by the fluorescent lifetime and fluorescence effective bandwidth of this state. $\alpha_{\text {loss }}$ is the attenuation at the laser wavelength. From eq.(7) it is known that in order to achieve high gain coefficient, large stimulated emission cross section, long fluorescent lifetime and lower attenuation are preferred. These three parameters are dependent not only on glass composition but also on the fabrication process.

The stimulated emission cross section of $\mathrm{Nd}^{3+}$ ion can be evaluated from the measurement of absorption and emission spectra of $\mathrm{Nd}^{3+}$ ion in glass by method reported by Krupke [153] and based on Judd-Ofelt (J-O) time [151,152].

$$
\begin{gathered}
A_{J J^{\prime}}=\frac{64 \pi^{2} e^{2} n}{3 h(2 J+1) \lambda^{3}} \times \frac{\left(n^{2}+2\right)^{2}}{9} \times S_{J J^{\prime}} \\
\Delta \lambda_{\text {eff }}=\int \frac{I(\lambda)}{I\left(\lambda_{p}\right)} d \lambda \\
\sigma=\frac{\lambda^{4}}{8 \pi c n^{2}} \times \frac{A_{J J^{\prime}}}{\Delta \lambda_{\text {eff }}}
\end{gathered}
$$

Equations (8) to (10) are used to calculated the stimulated emission cross section of $\mathrm{Nd}^{3+}$ ion. In equation (8), $\mathrm{A}_{\mathrm{JJ}}$, is probability for a transition from initial $\mathrm{J}$ manifold to terminal J' manifold, $\mathrm{n}$ is refractive index, $\lambda$ is wavelength, $\mathrm{h}$ is Plank constant, $\mathrm{J}$ is the total angular momentum of initial level, $\mathrm{J}$ ' is the total angular momentum of terminal level and $S_{J J}$, is line strength of an electric-dipole transition between initial $\mathrm{J}$ manifold to terminal J' manifold. In equation (9), $\Delta \lambda_{\text {eff }}$ is effective linewidth of fluorescent spectrum, $I\left(\lambda_{p}\right)$ is fluorescent intensity at peak position, $I(\lambda)$ is the fluorescent intensity at wavelength $\lambda$. And finally, $\sigma$ is the stimulated emission cross section with $\mathrm{c}$ as the speed of light, in equation (10). The radiative transition probability from $J$ state to $J$ ' 
state, $A_{J J}$, can be obtained from absorption spectrum with equation (8). The effective linewidth, $\Delta \lambda_{\text {eff }}$, can be calculated by equation (9) from emission spectrum. Stimulated emission cross section of $\mathrm{Nd}^{3+}$ ion can be calculated from equation (10). It is known that large $\mathrm{A}_{\mathrm{JJ}}$, and small $\Delta \lambda_{\text {eff }}$ will result in a large stimulated emission cross section.

Figure 1.16 indicates the effect of cationic field strength, $\mathrm{P}_{2} \mathrm{O}_{5}$ and $\mathrm{Al}_{2} \mathrm{O}_{3}$ contents on the spectroscopic parameters of $\mathrm{Nd}^{3+}$ ion in phosphate glasses. It is clearly shown that the contents of $\mathrm{Al}_{2} \mathrm{O}_{3}$, alkali oxide and alkaline oxide can affect the stimulated emission cross section effectively. For alkali oxide and alkaline oxide, the smaller the cation field strength, the larger the stimulated emission cross section of $\mathrm{Nd}^{3+}$ ion. $\mathrm{Al}_{2} \mathrm{O}_{3}$ content will decrease the stimulated emission cross section and increase the effective linewidth of emission. Radiative decay rate (that is radiative transition probability) changes in the same trend as the stimulated emission cross section with glass composition. The emission bandwidth increases with the increase of cation field strength from $\mathrm{K}^{+}$to $\mathrm{Li}^{+}$ and from $\mathrm{Ba}^{2+}$ to $\mathrm{Mg}^{2+}$ in Fig. 3. There is in generally increase trend of stimulated emission cross section with the increase of $\mathrm{P}_{2} \mathrm{O}_{5}$ content from $45 \mathrm{~mol} \%$ to $70 \mathrm{~mol} \%$ in Figure 1.17. 


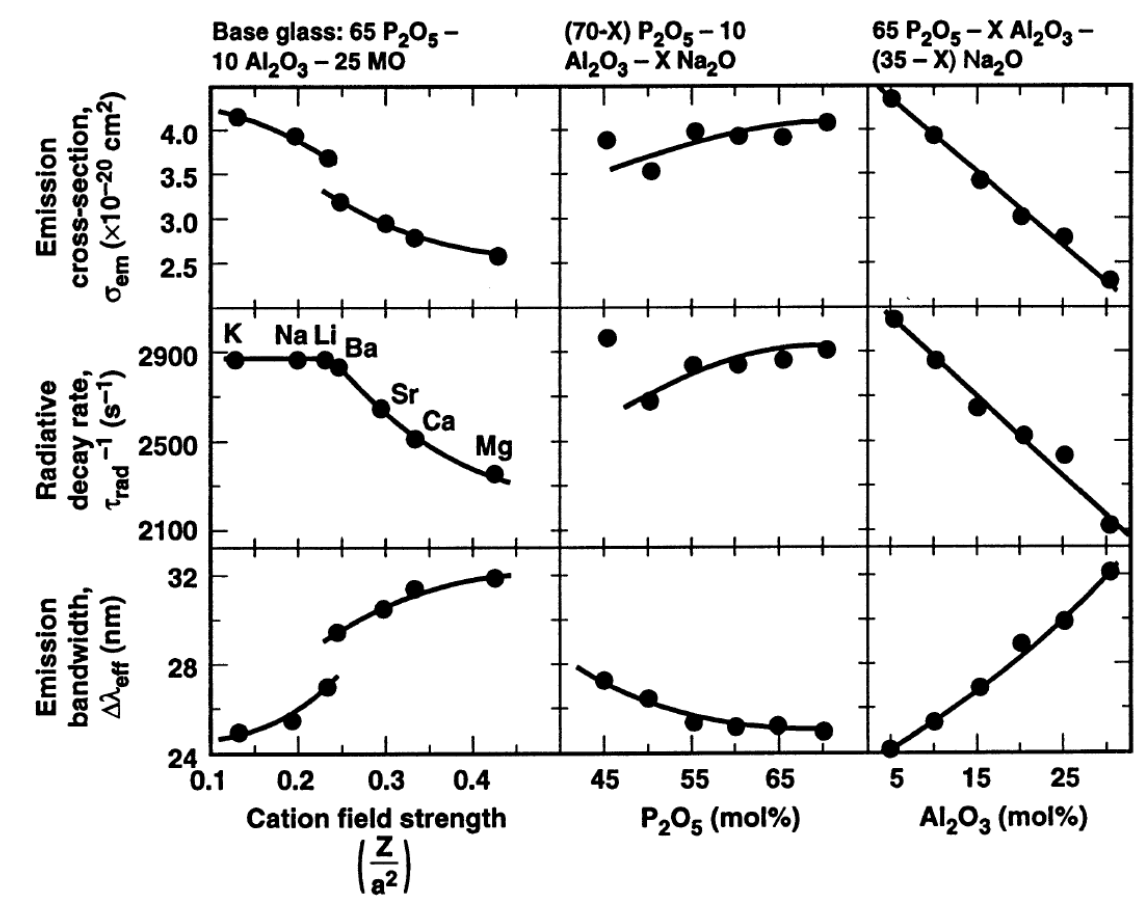

Figure 1.17: The effect of cationic field strength, $\mathrm{P}_{2} \mathrm{O}_{5}$ and $\mathrm{Al}_{2} \mathrm{O}_{3}$ contents on the spectroscopic parameters of $\mathrm{Nd}^{3+}$ ion in phosphate glasses. Reprinted from reference [19], Copyright (2000), with permission from Elsevier.

The fluorescent lifetime is related to radiative transition rate $\left(A_{\text {rad }}\right)$ and non-radiative transition rate $\left(\mathrm{W}_{\mathrm{nr}}\right)$. It is determined by glass composition, fabrication process, and the $\mathrm{Nd}^{3+}$ ion concentration. In equation (11) the non-radiative transition rate $\mathrm{W}_{\mathrm{nr}}$ is closely related to the fabrication process. The larger the non-radiative transition rate, the shorter the fluorescent lifetime. Radiative transition rate $\mathrm{A}_{\mathrm{rad}}$ is determined by composition of glass. Large $\mathrm{A}_{\mathrm{rad}}$ corresponds to short fluorescent lifetime. Radiative lifetime is the inverse of radiative transition rate in equation (12), which is determined by the glass composition. The fluorescent lifetime of $\mathrm{Nd}^{3+}$ ions is inversely related to $\mathrm{Nd}^{3+}$ ion concentration as express in eq. (13), where $\mathrm{N}$ is the $\mathrm{Nd}^{3+}$ ion concentration, $\mathrm{Q}$ is concentration quenching factor, which is physically equivalent to the $\mathrm{Nd}^{3+}$ ion 
concentration needed to reduce the fluorescent lifetime to one half of its zero concentration limit.

$$
\begin{gathered}
\tau=1 /\left(A_{r a d}+W_{n r}\right) \\
\tau_{r a d}=\frac{1}{A_{r a d}} \\
\tau=\frac{\tau_{0}}{1+(N / Q)^{2}}
\end{gathered}
$$

From equation (13) it is known that the fluorescent lifetime decreases with the increase of $\mathrm{Nd}^{3+}$ ion concentration. As the fabrication process of $\mathrm{Nd}$ :phosphate glass is highly moisture sensitive. Dehydroxylation process is necessary to remove hydroxyl groups in glass melt and to achieve long fluorescent lifetime of $\mathrm{Nd}^{3+}$ ion in phosphate glass matrix [154].

The attenuation at the lasing wavelength (1053 nm in Nd:phosphate glass) is determined by the impurity contamination, absorption of $\mathrm{Nd}^{3+}$ ion in infrared range, and scattering caused by bubbles or inclusions in glass. The ppm level of transition metal ions (such as $\mathrm{Cu}^{2+}, \mathrm{Fe}^{2+}$ ) and rare earth ion impurities ( attenuation at lasing wavelength. In order to get the attenuation as low as possible, the impurities in raw materials and impurity contamination during fabrication process should be controlled. The extinction coefficient of $\mathrm{Cu}^{2+}$ ion in Nd:phosphate laser glass is as large as $2.7 \times 10^{-3} \mathrm{~cm}^{-1}$ [155]. $\mathrm{Cu}^{2+}$ ion is most harmful transition metal ion to attenuation of $\mathrm{Nd}$ :phosphate laser glass of all impurities. Its content in glass should be controlled in ppb level. 
The contribution of $\mathrm{Nd}^{3+}$ ion itself to attenuation can be expressed in equation (14). At room temperature for $4.2 \times 10^{20} \mathrm{~cm}^{-3}$ of $\mathrm{Nd}^{3+}$ ions concentration, absorption coefficient of $\mathrm{Nd}^{3+}$ ion at $1053 \mathrm{~nm}$ is at the level of $7 \times 10^{-4} \mathrm{~cm}^{-1}[155]$.

$$
\alpha_{N d}(T)=1.03 \times 10^{-20}\left[N d^{3+}\right] \exp \left(\frac{-2576}{T}\right)
$$

Where $\alpha_{\mathrm{Nd}}(\mathrm{T})$ is the loss in $\mathrm{cm}^{-1},\left[\mathrm{Nd}^{3+}\right]$ the neodymium concentration and $\mathrm{T}$ the temperature in $\mathrm{K}$. Typical application of high peak power Nd:phosphate glass is for laser inertial confinement fusion facility, such as National Ignition Facility (NIF) in US, Laser Megajoule (LMJ) in France and Shen Guang facility in China. These facilities use commercial high peak power Nd:phosphate glasses. They are LHG-8 from Hoya Company, LG-770 from Schott Company, N21 and N31 from SIOM in China as well as KGSS-0180 from GOI in Russia. Table III lists the main parameters of 4 kinds of high peak power Nd:phosphate laser glasses. They are used in NIF in US, LMJ in France, Shen Guang facilities in China and high power laser facility in Russia, respectively. Table IV shows the high power laser facilities worldwide and the high peak power Nd:phosphate glasses used inside. More than 3000 pieces of large size Nd:phosphate laser glasses have been used in the largest laser facility-NIF in US.

Table III: Main parameters of high peak power neodymium phosphate laser glasses from Hoya [19], Schott [152], Russia (GOI) [156] and SIOM [157]. 


\begin{tabular}{|l|l|l|l|l|l|}
\hline parameters & $\mathrm{N} 21$ & $\mathrm{~N} 31$ & LHG-8 & LG-770 & KGSS-0180 \\
\hline$\sigma / 10^{-20} \mathrm{~cm}^{2}$ & 3.4 & 3.8 & 3.6 & 3.9 & 3.6 \\
\hline${ }^{*} \tau_{\text {rad }} / \mu \mathrm{sec}$ & & 348 & 365 & 351 & \\
\hline$\Delta \lambda_{\text {eff }} / \mathrm{nm}$ & 26.5 & 25.5 & 26.5 & 25.4 & \\
\hline${ }^{*} \mathrm{~d} / \mathrm{g} / \mathrm{cm}^{3}$ & 3.40 & 2.87 & 2.83 & 2.59 & \\
\hline${ }^{*} \mathrm{n}_{\mathrm{d}}$ & 1.5758 & 1.540 & 1.5296 & 1.5067 & 2.83 \\
\hline $\mathrm{n}_{1053 \mathrm{~nm}}$ & 1.5652 & 1.533 & 1.5201 & 1.4991 & \\
\hline $\mathrm{Abbe} \mathrm{number}$ & 65.2 & 65.8 & 66.5 & 68.4 & \\
\hline $\mathrm{n}_{2} / 10^{-13} \mathrm{esu}$ & 1.30 & 1.18 & 1.12 & 1.01 & \\
\hline $\mathrm{Tg} /{ }^{\circ} \mathrm{C}$ & 500 & 450 & 485 & 460 & 1.1 \\
\hline$\alpha / 10^{-7} / \mathrm{K}\left(20-100^{\circ} \mathrm{C}\right)$ & 110 & 115 & 115 & 116 & 460 \\
\hline $\mathrm{dn} / \mathrm{dT} / 10^{-7} / \mathrm{K}$ & -42 & -43 & -53 & -47 & 116 \\
\hline $\mathrm{dS} / \mathrm{dT} / 10^{-7} / \mathrm{K}$ & 19 & 14 & 6 & 11 & -40 \\
\hline $\mathrm{k} / \mathrm{W} / \mathrm{m} \cdot \mathrm{K}$ & 0.55 & 0.56 & 0.58 & 0.57 & \\
\hline $\mathrm{E} / \mathrm{GPa}$ & & 56.4 & 50.0 & 47 & \\
\hline
\end{tabular}

* parameters that vary with $\mathrm{Nd}_{2} \mathrm{O}_{3}$ concentration.

TableIV: Nd:phosphate glasses used in high power laser facilities 


\begin{tabular}{|c|c|c|c|}
\hline Laser facility & Nd:glass & Number of laser beam & Volume of glass \\
\hline Omega-EP in US & LHG-8 & 60 & $2.3 \mathrm{~L}$ \\
\hline Gekko- XII in Japan & LHG-8 & 12 & $2.7 \mathrm{~L}$ \\
\hline NIF in US & LHG-8, LG-770 & 192 & $15 \mathrm{~L}$ \\
\hline Shen Guang II & N21, N31 & $8+1$ & $3-7 \mathrm{~L}$ \\
\hline Shen Guang III prototype & N31 & 8 & $7.6 \mathrm{~L}$ \\
\hline Shen Guang II upgrade & N31 & 8 & $12 \mathrm{~L}$ \\
\hline Shen Guang III & N31 & 48 & $15 \mathrm{~L}$ \\
\hline LMJ in France & LHG-8, LG-770 & 240 & $15 \mathrm{~L}$ \\
\hline
\end{tabular}

Table $\mathrm{V}$ gives 5 kinds of high average power Nd:phosphate laser galsses. HAP-4 is from Hoya Company. APG-1 and APG-2 are from Schott Company. NAP-2 and NAP-4 are from SIOM. These glasses have relative smaller stimulated emission cross section but with lower thermal expansion coefficient and larger thermal conductivity compared with those of high peak power Nd:phosphate laser glasses in Table II.

The typical application of high average power $\mathrm{Nd}$ :phosphate laser glass is laser processing, such as laser peening [12]. In recent years, with the development of petawatt $\left(10^{15}\right.$ watt) high power laser, the $\mathrm{Nd}$ :phosphate glass laser is used as pumping source in the petawatt laser system. There is an increasing demand on high average power Nd:phosphate laser glass.

Table V: Main parameters of high average power neodymium phosphate laser glasses 
from Hoya [19], Schott [19] and SIOM [157]

\begin{tabular}{|l|l|l|l|l|l|}
\hline parameters & HAP-4 & APG-1 & APG-2 & NAP-2 & NAP-4 \\
\hline$\sigma / 10^{-20} \mathrm{~cm}^{2}$ & 3.6 & 3.4 & 2.4 & 3.7 & 3.2 \\
\hline${ }^{*} \tau_{\text {rad }} / \mu \mathrm{sec}$ & 350 & 385 & 464 & 380 & 400 \\
\hline$\Delta \lambda_{\text {eff }} / \mathrm{nm}$ & 27.0 & 27.8 & 31.5 & 27.0 & 29.0 \\
\hline${ }^{*} \mathrm{~d} / \mathrm{g} / \mathrm{cm}^{3}$ & 2.70 & 2.64 & 2.56 & 2.76 & 2.60 \\
\hline${ }^{*} \mathrm{n}_{\mathrm{d}}$ & 1.5433 & 1.5370 & 1.5127 & 1.542 & 1.530 \\
\hline $\mathrm{n}_{1053 \mathrm{~mm}}$ & 1.5331 & 1.5260 & 1.5032 & 1.536 & 1.523 \\
\hline $\mathrm{Abbe} \mathrm{number}$ & 64.6 & 67.7 & 66.9 & 67 & 66 \\
\hline $\mathrm{n}_{2} / 10^{-13} \mathrm{esu}$ & 1.21 & 1.13 & 1.06 & 1.22 & 1.10 \\
\hline $\mathrm{T}_{\mathrm{g}} /{ }^{\circ} \mathrm{C}$ & 486 & 450 & 549 & 478 & 545 \\
\hline$\alpha / 10^{-7} / \mathrm{K}\left(20-100^{\circ} \mathrm{C}\right)$ & 72 & 99.6 & 64 & 96 & 71 \\
\hline $\mathrm{dn} / \mathrm{dT} / 10^{-7} / \mathrm{K}$ & 18 & 12 & 34 & -8.7 & 19 \\
\hline $\mathrm{dS} / \mathrm{dT} / 10^{-7} / \mathrm{K}$ & 57 & 52 & 76 & 36 & 50 \\
\hline $\mathrm{k} / \mathrm{W} / \mathrm{m} \cdot \mathrm{K}$ & 1.02 & 0.78 & 0.84 & 0.76 & 0.86 \\
\hline $\mathrm{E} / \mathrm{GPa}$ & 70 & 71.0 & 64.0 & 58 & 67 \\
\hline & & & & & \\
\hline & & & & & \\
\hline
\end{tabular}

1.3.4 Biomedical Applications 
Due to the chemical instability of phosphate based glasses, various modifier oxides have been explored in order to make phosphate glasses compatible with applications in biomedicine, including metal oxides such as $\mathrm{Na}_{2} \mathrm{O}, \mathrm{CaO}, \mathrm{MgO}, \mathrm{Fe}_{2} \mathrm{O}_{3}, \mathrm{Sr}_{2} \mathrm{O}_{3}, \mathrm{Al}_{2} \mathrm{O}_{3}$, $\mathrm{CuO}$ and $\mathrm{TiO}_{2}$ [158]. Among them, $\mathrm{Fe}_{2} \mathrm{O}_{3}$ and $\mathrm{TiO}_{2}$ have been reported to have greater resistance to hydration due to their network strengthening capability via their crosslinking effect $[159,160]$. As such, these metal oxides have been explored quite widely in order to try and impart control over the glass dissolution rates [161]. Phosphate glasses have also been fabricated into continuous fibers (Phosphate Glass Fibers or PGFs) via both a melt and pre-form drawing process (see Figure 1.18). The melt drawing technique usually involves melting glass frits in a crucible containing bushing tips with small holes at the exit [17]. Molten glass is then allowed to flow gravitationally through the bushing tips and the fibers formed are then collected on a rotating drum in order to produce continuous fibers. The pre-form fiber drawing process is a two stage process which involves production of a glass pre-form rod followed by heating the pre-form rod in a furnace to above its $\mathrm{T}_{\mathrm{g}}$. At this temperature a molten gob forms at the end of the pre-form which falls away from the tip due to gravity producing a fibrous strand which is then collected onto a rotating drum [162].

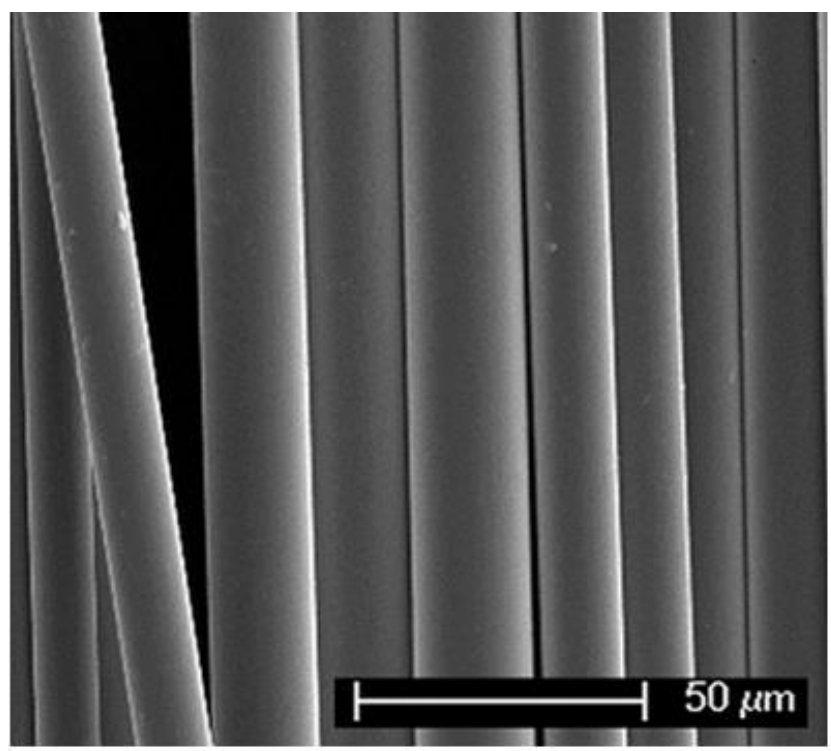


Figure 1.18: SEM image of melt drawn quaternary PGFs (fibers with composition of $50 \mathrm{P}_{2} \mathrm{O}_{5}-40 \mathrm{CaO}-16 \mathrm{Na}_{2} \mathrm{O}-5 \mathrm{Fe}_{2} \mathrm{O}_{3}$ in mol \%). Reprinted from reference [17], with permission from "Hot Topics in Biomaterials" as agreed by Future Medicine Ltd.

Successful production of continuous PGFs depends on several parameters such as melt temperature, melt viscosity, fragility index, oxygen/phosphorus ratio and drawing speed [163]. Proper selection of glass composition is essential so that the bonds present within the glass melt are of sufficient strength to withstand the stresses applied during the fiber drawing process. Additionally, further heat treatment (also known as annealing) of the fibers produced can be employed in order to relieve internal stresses present within the fibers, thus achieving a more stable configuration [164]. The process parameters of fiber production have also been found to play an influential role in varying the fiber mechanical and dissolution properties. For example, highly fragile glasses are manufactured into fiber via a melt drawing process where rapid cooling of the molten strand is essential. On the other hand comparatively less fragile glasses can be processed into continuous fiber via both the melt draw and solid pre-from fiber manufacturing routes [163].

PGFs have some advantageous features over their bulk form, such as excellent mechanical properties and higher surface area. These properties can also be varied by controlling the fiber dimensions via process variables such as the diameter of the bushing exit holes, melt temperature (hence viscosity of the glass), mass flow and drawing speed [163]. The dissolution rates for PGFs have been seen to increase with decreasing fiber diameter, due to the vast increase in surface area. For example, Ahmed et al. $[15,165]$ reported that degradation rates of phosphate glass fibers (within the 
ternary $\mathrm{P}_{2} \mathrm{O}_{5}-\mathrm{CaO}-\mathrm{Na}_{2} \mathrm{O}$ systems) increased significantly compared to bulk glass of the same composition. Furthermore, additions of metal ions (such as $\mathrm{Na}_{2} \mathrm{O}, \mathrm{CaO}, \mathrm{MgO}$ or $\mathrm{Fe}_{2} \mathrm{O}_{3}$ etc.) within the glass structure enabled further control over their dissolution rates. For example, addition of $\mathrm{Fe}_{2} \mathrm{O}_{3}$ content (from 1 to 5 mol \%) within the iron phosphate glass system $\left(\mathrm{P}_{2} \mathrm{O}_{5}-\mathrm{CaO}-\mathrm{Na}_{2} \mathrm{O}-\mathrm{Fe}_{2} \mathrm{O}_{3}\right)$ exhibited a significant reduction in the glass dissolution rates from $\sim 0.00045$ to $\sim 0.00004 \mathrm{mg} \cdot \mathrm{cm}^{-2} \cdot \mathrm{h}^{-1}[165]$.

More recently, core/clad resorbable PGFs with varying metal ions (such as $\mathrm{Ti}^{2+}$ and $\mathrm{Fe}^{3+}$ ) were successfully manufactured by Ahmed et al. [166]. This type of core/clad fiber was earlier limited to optical glass fibers only. The main advantage associated with core/clad fiber was the additional control conferred over their ion release profiles. It was also shown that hollow fibers could be produced if a comparatively faster degrading composition of the inner core glass was selected. The core/clad glass fiber production process involved the following steps: a) manufacture of glass billets with varying compositions (preferably with similar thermal expansion profiles), b) co-extrusion of the stacked glass billets by placing the cladding glass underneath the core glass (see Figure 1.19a), and c) the core/clad fibers (see Figure 1.19b) were then drawn from the core/clad pre-form via the previously mentioned pre-form drawing technique.

a)

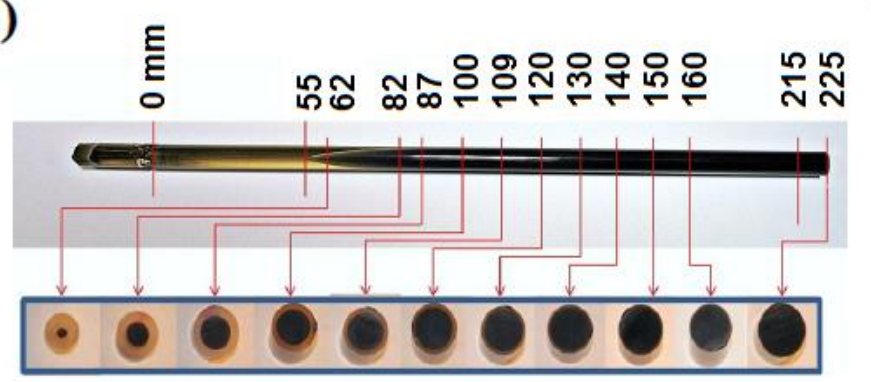

b)

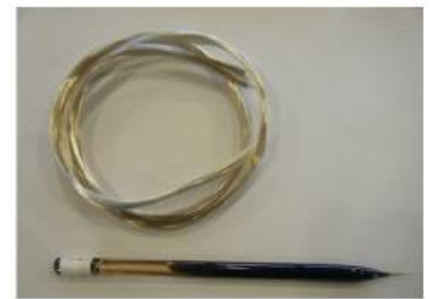

Figure 1.19: a) Cross-sections of an extruded core/clad preform (the values indicate the cut distance of the preform into discs) and b) an extruded core/clad preform and 
resultant fibers. Reprinted from reference [166], Copyright (2015), with permission from De Gruyter.

Mechanical properties of the glass fibers produced via any of the above mentioned techniques depend on the molecular orientation of the glass components along with the bonds created within the chemical compositions [167,168]. For example, the bulk glass consists of chemical bonds which are usually in isotropic form; whereas during glass fiber manufacture the network bonds are converted into anisotropic form as the $\mathrm{PO}_{4}$ tetrahedra align in the direction of the pull $[169,170]$.

PGFs have also been utilized to reinforce bioresorbable polymers to fabricate bioresorbable composites [171,172]. As the mechanical properties of PGFs can be varied by simply changing their diameter as well as their chemical compositions, a wide range of PGF-reinforced composites can be produced with tailored mechanical properties to match both cortical and cancellous bone [173,174]. For example, very recently PGFs with high mechanical properties (for example, tensile modulus $\sim 70 \mathrm{GPa}$ and tensile strength $\sim 1.2 \mathrm{GPa}$ ) were produced from boron doped PGFs (with the formulation $45 \mathrm{P}_{2} \mathrm{O}_{5}-16 \mathrm{CaO}-5 \mathrm{Na}_{2} \mathrm{O}-24 \mathrm{MgO}-10 \mathrm{~B}_{2} \mathrm{O}_{3}$ ) [175].

Furthermore, the orientation of PGFs within the composites can also have an influential role on their mechanical properties. For example, continuous unidirectional (UD) fiber reinforced composites produced superior mechanical properties than randomly (RM) oriented fiber reinforced composites (properties achieved from tensile modulus for RM and UD composites ranged between $\sim 6.7$ and $\sim 9 \mathrm{GPa}$, respectively) [176]. Other factors that also influenced the overall mechanical properties of PGF reinforced composites were fiber volume fraction, fiber length, distribution and strength of the fiber/matrix interface $[173,174]$. 
Phosphate based glasses in the form of powder, bulk, rod, and fiber containing varying modifier ions such as iron, zinc and copper have been explored for a range of biomedical and tissue engineering applications $[165,177,178]$. These metal ions have been found to be beneficial for promoting various biomedical functions. For example, iron ions are well known to promote cell attachment and differentiation as well as to participate in redox reactions for certain types of proteins (such as, cytochrome, myoglobin, etc.) $[165,177]$.

Similarly, Zinc ions were found to stimulate protein synthesis in osteoblast cells and also increase ATPase and ALP activity [179] and copper ions have been reported to have antibacterial properties, stimulate angiogenesis and proliferation of human endothelial cells [180]. As such, $\mathrm{Zn}$ doped PGFs in the form of 3D-scaffolds were investigated for the construction of muscle organoid units [177] and $\mathrm{Cu}$-doped PGFs were found to prevent bacterial colonization and reduce the number of viable bacteria in the local environment [178].

Researchers also investigated iron doped PGFs as potential cell delivery vehicles for cell transplantation purposes and utilized their morphology to orientate muscle precursor cells along the axes of the fibers to form myotubes (see Figure 1.20) [165]. 4$5 \mathrm{~mol} \% \mathrm{Fe}_{2} \mathrm{O}_{3}$ was reported to be most favorable for cell attachment and differentiation due to the enhanced chemical durability of the PGFs and controlled ion release profile [165]. 

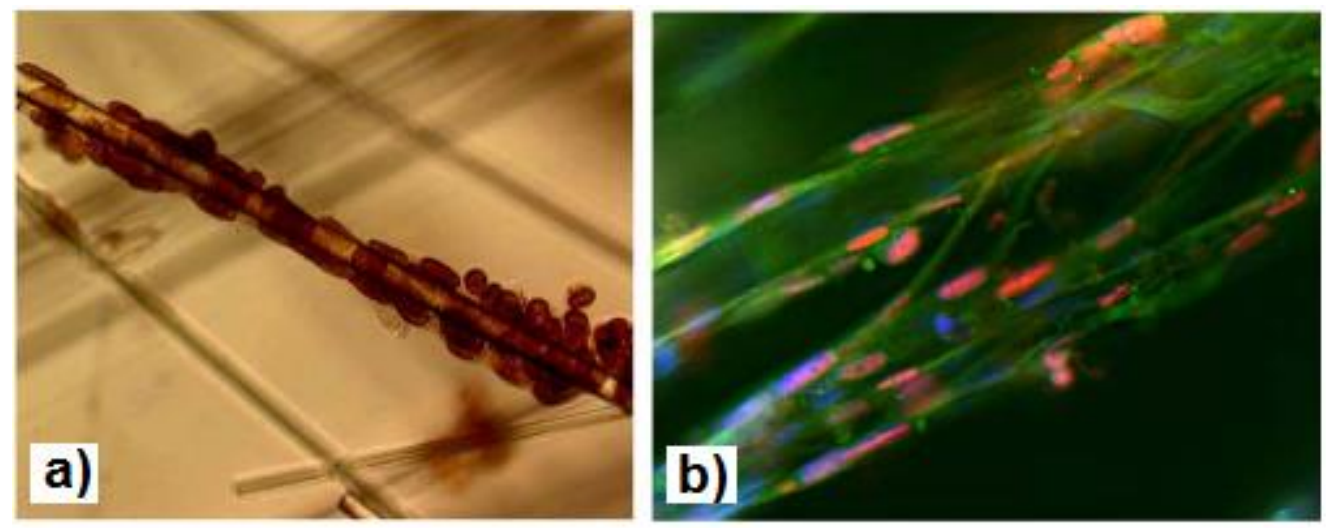

Figure 1.20: a) Attached muscle precursor cells (MPCs) on iron-phosphate glass fibers and b) MSCs differentiation on PBG fibers: Desmin (seen in green) is a cytoplasmic marker of all skeletal muscle cells. Myogenin (seen as Red) is a nuclear marker of differentiation. The Blue is DAPI(4,6-diamidino-2-phenylindole (which stains all nuclei)). Reprinted from reference [165], Copyright (2004), with permission from

Elsevier.

3D PGF constructs (with composition $62.9 \mathrm{P}_{2} \mathrm{O}_{5}-21.9 \mathrm{Al}_{2} \mathrm{O}_{3}-15.2 \mathrm{ZnO}$ in mol \% and average diameter of $6.5 \mu \mathrm{m}$ ) were investigated for the construction of muscle organoid units to resemble the structure of skeletal muscle cells [177]. PGF bundles were found to be surrounded by fibrous sheaths and increasing cell numbers were observed on the fiber construct due to the macro-topography of the 3D structure (see Figure 1.21). 

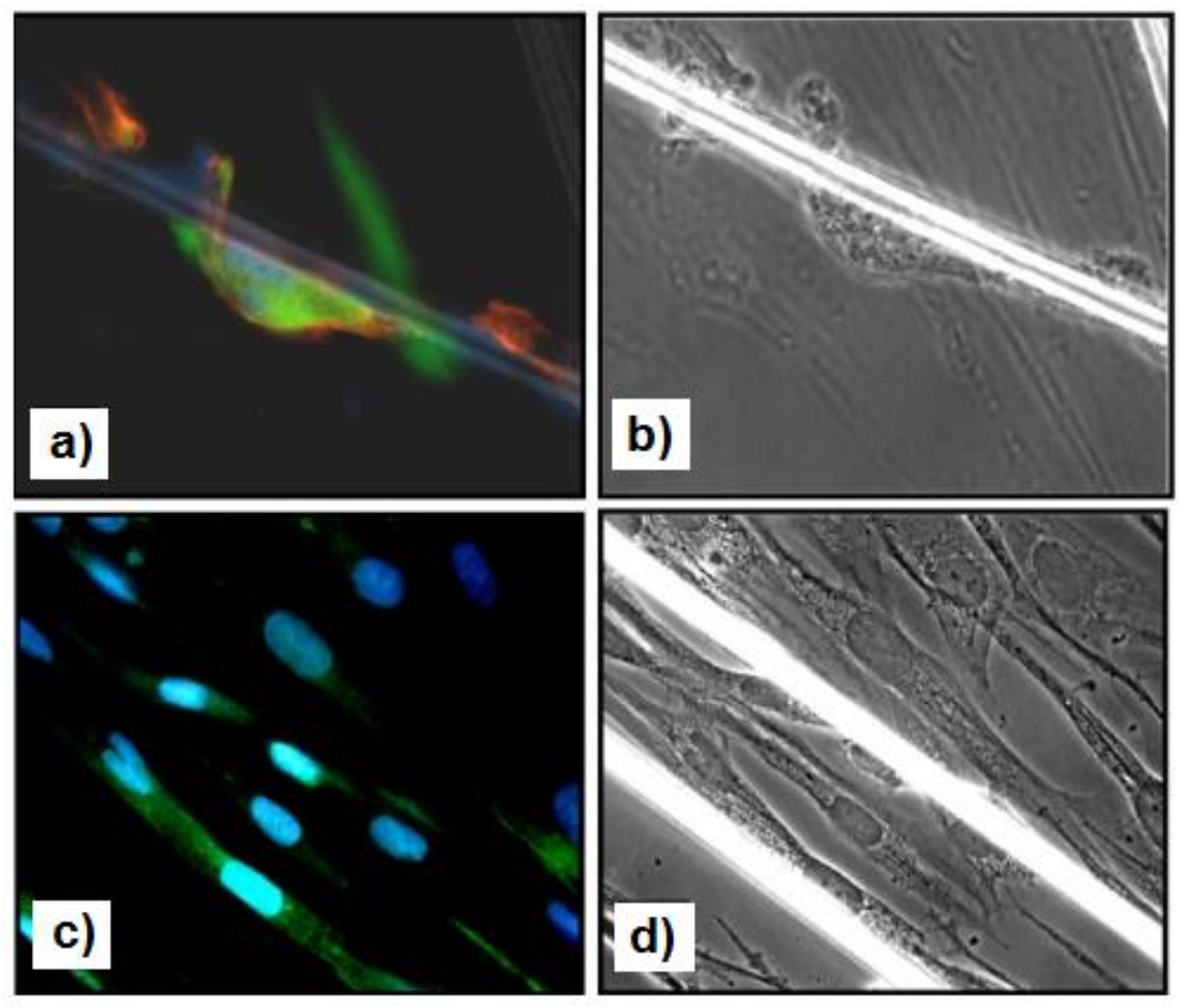

Figure 1.21: a) Immunostaining shows a multinucleated myotube, expressing desmin (green immunostaining) and sarcomeric actin (red immunostaining), attached to the mesh scaffold on day 7, b) phase contrast micrograph of the myotube and mesh scaffold, c) immunostaining demonstrating single myogenic desmin-positive cells alongside gelatin coated glass fibers, and d) phase contrast micrograph showing single cells parallel to the glass fibers. Reprinted from reference [177], Copyright (2005), with permission from Elsevier.

PGFs with composition $50 \mathrm{P}_{2} \mathrm{O}_{5}-30 \mathrm{CaO}-9 \mathrm{Na}_{2} \mathrm{O}-3 \mathrm{SiO}_{2}-3 \mathrm{MgO}-(5-x) \mathrm{K}_{2} \mathrm{O}-x \mathrm{TiO}_{2}$ mol $\%$ (where $x=0,2.5,5$, respectively) were investigated for their influential role in neuronal polarization and axonal growth direction by Vitale-Brovarone et al. [181]. It was reported that aligned PGFs provided the directional cue for growing Dorsal Root Ganglia (DRG) neuron cells along the fiber length (see Figure 1.22a). Additionally, the 
active proliferation of neonatal olfactory bulb ensheathing cells (NOBEC) on PGFs was seen to be extending along the fiber surface as shown in Figure 1.22b.
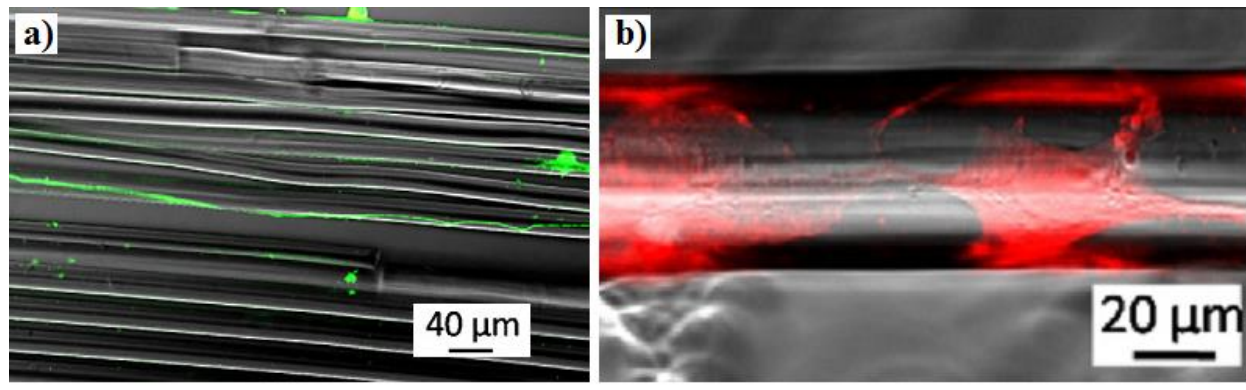

Figure 1.22: Confocal microscope images of a) DRG neurons on glass fibers presenting long neuritis extended along the fiber axis direction and b) NOBEC cells showing active proliferation on Phosphate glass fibers. Reprinted from reference [181], Copyright (2012), with permission from Elsevier.

Moreover, degradation of PGFs in composite materials could lead to the formation of micro-channels, which would play an important role in the perfusion and transportation of nutrients, oxygen and formation of blood vessels. For example, Nazhat et al. [182] investigated fomation of microchannels (30-40 $\mu \mathrm{m}$ diameter) within unidirectionally orientated PGF reinforced collagen scaffolds (Figure 1.23). These spiral collagen-PGF scaffolds were investigated as potential candidates for axonal outgrowth following spinal cord injuries [183]. It was also observed that cylindrical scaffolds implanted into transected spinal cords of rats exhibited better functional recovery compared to collagen alone and no inflammatory responses were observed for both groups. 

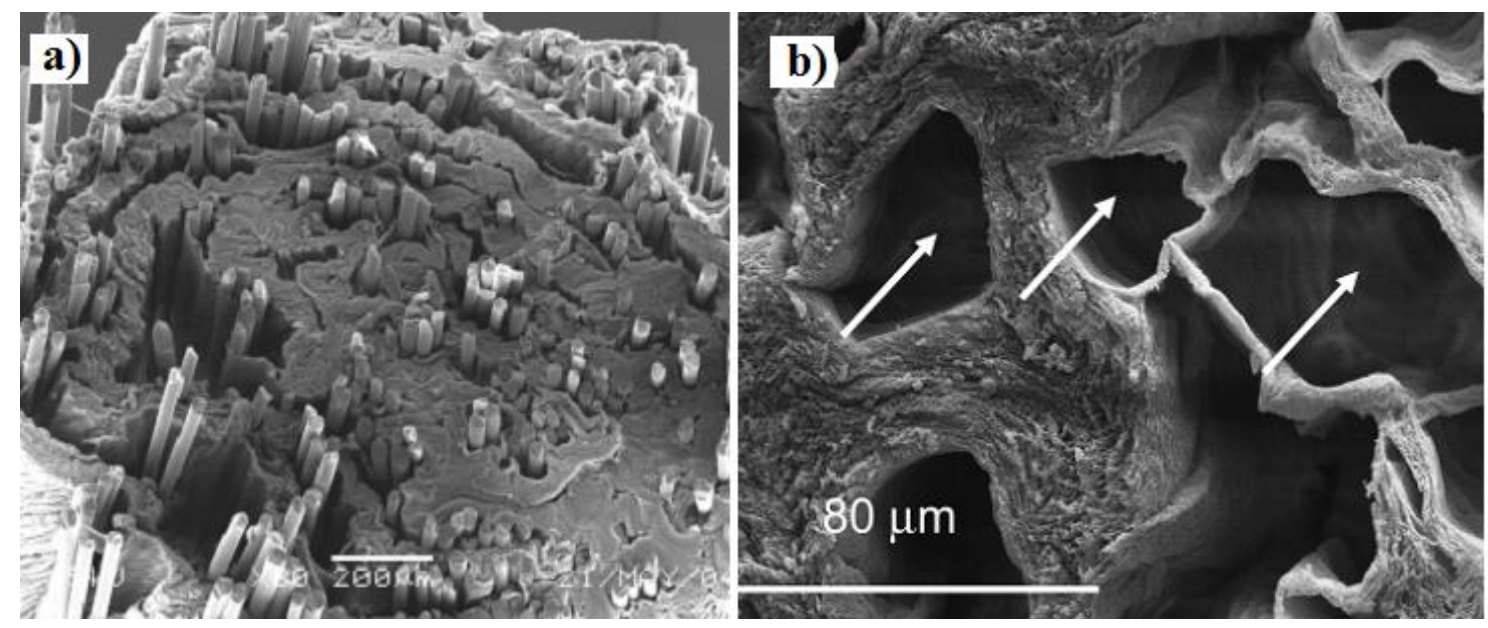

Figure 1.23: SEM images represent a) the cross-sectional PGF-collagen spiral constructs and $b$ ) the formation of microchannels (indicated by arrows) via degradation of the PGFs in within the ollagen spriral constructs. Reprinted with permission from reference [182]. Copyright (2007) American Chemical Society.

Recently, PGF reinforced composites have also been investigated as fully resorbable fracture fixation devices for load bearing applications [172]. Bioploymers (such as, polylactic acid or polycaprolactone) reinforced with various compositions of PGF have been fabricated in the form of rods (Figure 1.24a) and screws (Figure 1.24b) with mechanical properties similar or superior to that of cortical bone. For example, unidirectionally (UD) oriented PGF reinforced PLA composites exhibited an initial flexural strength of $130 \mathrm{MPa}$ and modulus of $11.5 \mathrm{GPa}$ for a $24 \%$ fiber volume fraction composite [172]. In comparison, the mechanical properties of the human femur, tibia and fibula were reported to have a modulus of elasticity and tensile strength in the range of 10-22 GPa and 67-140 MPa, respectively [184,185]. 

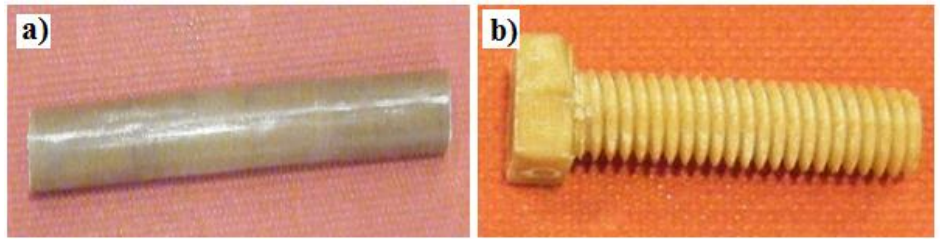

Figure 1.24: Images of a) composite rod and b) composite screw prepared via the forging process. Figure 1.22a) reprinted from reference [186], Copyright (2012), with permission from Springer. Figure 1.22b) reprinted from reference [187], Copyright (2013), with permission from Elsevier.

Polycaprolactone (PCL)-phosphate glass discs (see Figure 1.25a) were investigated in vivo using a rat calvarium model [188]. No clinical complications were observed and the lack of an inflammatory response showed that these composite materials were biocompatible. Additionally, when compared to monolithic PCL discs the PCLphosphate glass discs revealed an increase in the amount of mineralized bone from $20 \%$ to $35 \%$ over time. Extensive bone growth could also be seen after 26 weeks of implantation which was characterized using histological examination (see Figure 1.25b) [188].

(a)

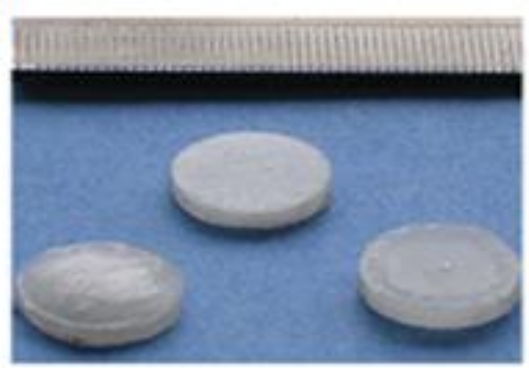

(b)

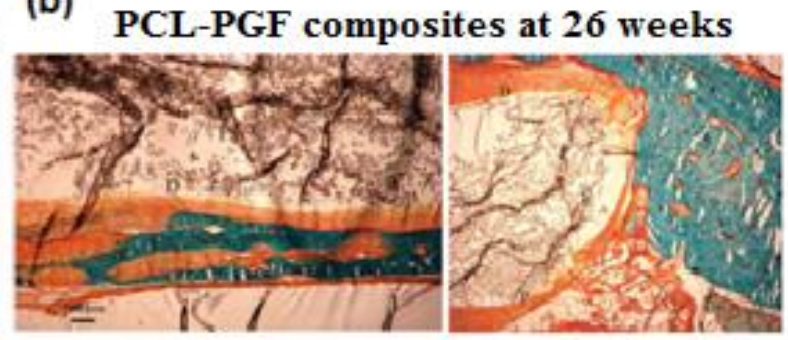

Figure 1.25: (a) PCL-phosphate glass discs before implantation ( $8 \mathrm{~mm}$ diameter), and

(b) examples of bone associated with the dural face of implants after 26 weeks 
implantation. Reprinted from reference [188], Copyright (2010), with permission from John Wiley and Sons.

PCL-phosphate glass composites have also been explored as a root canal filling material which was capable of sealing itself within the root canal within aqueous environments whilst releasing certain ions $\left(\mathrm{Na}^{+}, \mathrm{Ca}^{2+}, \mathrm{PO}_{4}{ }^{3-}, \mathrm{P}_{2} \mathrm{O}_{7}{ }^{4-}, \mathrm{P}_{3} \mathrm{O}_{9}{ }^{3-}, \mathrm{P}_{5} \mathrm{O}_{10}{ }^{5-}\right)$ at controlled rates [189]. Compared to the conventional gutta-percha (GP) filler, these PCLphosphate glass composites exhibited better adaptation in the root canal and were found to be firmly adhered to the canal wall.

Although a considerable amount of research has been undertaken on various compositions of phosphate glasses in various geometries for biomedical applications, there are still many challenges to overcome (for example, industrial-level scale-up fibre manufacture) for commercial exploitation of these unique resorbable materials.

\subsubsection{Electrical Properties}

Phosphate glasses are not highly conducting materials, particularly oxide phosphate glasses, like all other glass systems. However, there is a vast literature concerning basic and applied research on the study of the electrical properties of phosphates, either of the ionic or electronic conductivity type. Furthermore, there are some examples to which phosphate-based glasses play a major role, such as LiPON [30], sulfide-phosphate electrolytes [190], NASICON or NZP glass-ceramics [31,191] and cathode materials [192]. Particularly, since the advent of all solid-state rechargeable batteries, the research on novel glassy materials with high ionic or electronic conductivities has received increasing interest. 
The application of glasses in either bulk or thin-film form may have several important advantages for the practical configuration of the solid state battery. Glasses are constituted by a single homogeneous phase without grain boundaries and the conduction mechanism may take place in a much simpler way than in polycrystalline ceramics. Furthermore, the composition of a glass can be tuned through small to large variations without affecting the network structure and so the conductivity can be enhanced only by adequate combinations of their chemistry. However, despite the wide range of possibilities for the application of phosphate glasses in electrochemical systems, one must always be concerned by the issue of chemical and electrochemical stability under ambient conditions and in combination with the rest of components in the device, and in this respect much remains to be done.

Lithium or sodium phosphate glasses might be thought to be the systems with the highest ionic conductivity due to both alkali ions being very mobile. However, experience has demonstrated that even though the content of alkali oxide may easily reach 50 to $60 \mathrm{~mol} \%$, the room temperature conductivity remains at $10^{-6}{\mathrm{~S} . \mathrm{cm}^{-1}}^{\text {, in the }}$ best case, which is a value well below the conductivity of about $10^{-2}$ to $10^{-1}{\mathrm{~S} . \mathrm{cm}^{-1} \text { of }}^{-1}$ the conventional liquid electrolytes. In a representative work by Martin et al. [193], the conductivity of $\mathrm{Li}_{2} \mathrm{O}-\mathrm{P}_{2} \mathrm{O}_{5}$ glasses was analyzed and compared with equimolar lithium silicate and borate systems, and the authors concluded that the amount of charged nonbridging oxygens in the network allows for, or facilitates, the fast migration of alkali ions throughout a sort of channels of non-bridging oxygens, which in the case of silicates is higher than in phosphates. Actually, this is also at the origin of the interpretation for the increase of electrical conductivity in lithium phosphate glasses after the nitrogen for oxygen substitution, as it will be seen below. The other cation that gives rise to an abnormal very high conductivity is $\mathrm{Ag}^{+}$, and when combined with $\mathrm{I}^{-}$ 
anions in phosphate systems conductivity of up to $10^{-2} \mathrm{~S} . \mathrm{cm}^{-1}$ can be attained, though the stability of these glasses is even worse than that of the pure alkali phosphates and their electrochemical window very narrow, thus finding a very limited use $[194,195]$.

It seems clear that either the mobility of the ionic species or their concentration cannot be increased to the point necessary to reach conductivities at least of $10^{-4}{\mathrm{~S} . \mathrm{cm}^{-1}}^{\text {, which }}$ would be adequate for their application as solid electrolytes; therefore, some other means should be addressed to further increase their room temperature conductivity. One of these approaches concerns the polarizability of the anions that form the glass network and that directly bond the modifier cations.

The two most well-known models that explain the ionic conduction in glasses are the Anderson and Stuart model [196] and the theory of the weak electrolyte [197]. The Anderson and Stuart model considers that the activation energy is composed of an electrostatic term and a strain term and the total activation energy $(F)$ for the conduction of the mobile species may be written by equation (15):

$$
\mathrm{F}=\beta \mathrm{zz}_{0} \mathrm{e}^{2} / \gamma\left(\mathrm{r}+\mathrm{r}_{0}\right)+4 \pi \mathrm{Gr}_{\mathrm{D}}\left(\mathrm{r}-\mathrm{r}_{\mathrm{D}}\right)^{2}
$$

In the first term of the equation, $\beta$ is a factor related to the finite displacement, $\mathrm{z}$ and $\mathrm{z}_{0}$ the valence of the ions, $\gamma$ a covalency parameter and $r$ and $r_{0}$ the interionic radii. This first term is influenced by the covalent character of the bonds between the mobile species, i.e. modifier ions, and the counterion to which cations are bonded. In this sense, substitution of oxygen by a different anion, like $\mathrm{S}^{2-}$, establishing weaker bonds with the modifier cations may reduce the associated electrostatic activation energy term and therefore increase the conductivity of the glass. For instance, phosphate glasses containing sulfide species, e.g. $\mathrm{Li}_{2} \mathrm{~S}$, are known to be highly conducting glasses and have been of great interest in the last years [190]. In the second term, G refers to the shear modulus and $r_{D}$ to a doorway that should allow the passing of an ion of radius $r$. 
On the other hand, the weak electrolyte model assumes that not all modifier ions participate of the conduction process and only a part of all cations will be mobile. In this case, if one maintains the same anionic network, $\mathrm{O}^{2-}$ in an oxide glass, and keeps constant the total amount of modifier, it is possible to alter the number of mobile species through compositional changes that increase the number of cations in the energetic state favorable to take part of the electrical conduction process. This approximation may be evidenced in mixed-former glasses, such boro-phosphate compositions, in which the substitution of $\mathrm{P}_{2} \mathrm{O}_{5}$ by a second former oxide or intermediate like $\mathrm{B}_{2} \mathrm{O}_{3}$ gives rise to a substantial increase of the electrical conductivity of the glasses [53].

Electronic conduction in phosphate glasses has been studied in systems having mainly $\mathrm{Fe}_{2} \mathrm{O}_{3}$ [198] and $\mathrm{V}_{2} \mathrm{O}_{5}$ [199]. Apart from their fundamental interest in understanding the mechanisms of conduction in amorphous conductors, transition metal oxide containing phosphate glasses have recently gained importance for their application as mixed ionicelectronic conducting electrode materials in rechargeable batteries [192]. Nevertheless, their room temperature conductivity remains quite low as compared to crystalline electrode materials, generally below $10^{-10} \mathrm{~S}_{\mathrm{cm}}{ }^{-1}$, and most of the times glasses must be processed in the form of glass-ceramics in order to gain further increase in their conductivity, as shown by Garbarczyk et al. in $\mathrm{V}_{2} \mathrm{O}_{5}-\mathrm{P}_{2} \mathrm{O}_{5}$ glasses [200], or formulated as mixed former glasses and with two or more transition metal oxides [201,202].

An interesting effect was postulated by Bazan et al. in alkali phosphate glasses having tungstate oxide $\mathrm{WO}_{3}$, through which minima in the electrical conductivity are shown when varying the lithium oxide content into a $\mathrm{WO}_{3}-\mathrm{P}_{2} \mathrm{O}_{5}$ glass system [203]. Such glass compositions are able to exhibit both electronic and ionic conductivity, though depending on the alkali content their behavior may be on the electronic dominant side or 
in the ionic one. Furthermore, the reason for the observed minima upon alkali incorporation was proposed to be due to a coupling between the ionic species and the polarons, which for a certain amount of alkali oxide reduce the total conductivity down to a minimum that constitutes a change of regime. The current study of mixed ionicelectronic conducting phosphate glasses has been of importance for the application of glasses in electrochromic devices [204].

Finally, it is worth mentioning that phosphate glasses have also received much attention due to their particular ability for the retention of water and their relatively high proton conductivities at moderate temperatures, an effect firstly observed by Abe et al. [205], which makes them suitable as protonic conducting electrolytes in fuel cell systems where polymeric systems fail under intermediate or high temperature operation conditions [206].

\section{Solid Electrolytes for Battery Applications}

There is no doubt that nowadays the research on new electrochemical systems for the storage and conversion of clean energy is of crucial interest for the development of modern societies both at the small and large scale, and glasses may play a major role in their progress. One of the most productive fields of research among the glass science community has been the search for new solid electrolytes in the form of bulk glasses or glass-ceramics and thin-films.

One of the most well-known commercialized solid state electrolytes with strong links to phosphate glasses is the so-called LiPON, which is an amorphous thin-film material that was developed as solid electrolyte for microbatteries and was firstly studied by J. B. Bates and coworkers [30]. The layers of LiPON are grown by radio-frequency magnetron sputtering techniques under $\mathrm{N}_{2}$ atmosphere, starting from $\mathrm{Li}_{3} \mathrm{PO}_{4}$ targets and 
reaching an approximate composition of $\mathrm{Li}_{3.3} \mathrm{PO}_{3.8} \mathrm{~N}_{0.22}$, depending on the processing conditions. The authors soon realized that the electrochemical properties of the films as well as their chemical and mechanical resistance were much improved with respect to those of the lithium phosphates used before, as it happens after the nitrogen for oxygen substitution in phosphate glasses. Furthermore, the layers of sputtered LiPON may serve not only as single electrolyte layer but also as a means to protect batteries from the deterioration occurring as due to the formation of dendrites at the metallic lithium anodes when liquid electrolytes are employed [207]. Figure 1.26 shows a schematic cross-section photograph of the typical configuration of a lithium microbattery where a LiPON electrolyte is used, as shown by Bates et al. in reference [208].

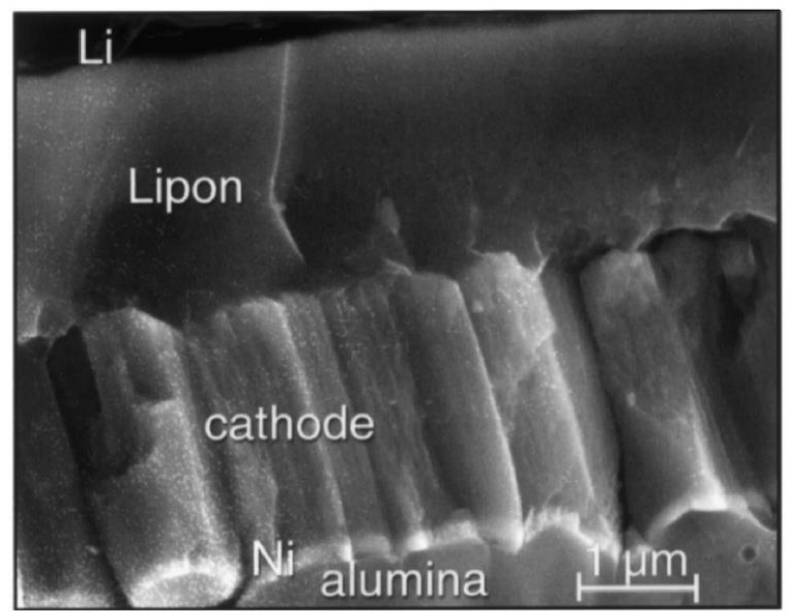

Figure 1.26: Schematic cross-section of a thin-film lithium microbattery where LiPON electrolyte can be seen in between the Li anode and cathode material. Reprinted from reference [208], Copyright (2000), with permission from Elsevier.

In fact, the knowledge of LiPON electrolytes has been mostly based on the previous existing research on nitrided phosphate glasses, and most authors have taken advantage of the structural models in these glass systems for the elucidation of the structure and 
properties changes in LiPON electrolytes. As seen in nitrided lithium metaphosphate glasses, the study the sputtered LiPON layers has also shown to present the dicoordinated $\left(\mathrm{N}_{\mathrm{d}}\right)$ and tricoordinated nitrogen atoms $\left(\mathrm{N}_{\mathrm{t}}\right)$ that were introduced above in section 1.3.1. of Oxynitride Phosphate Glasses, and several authors have found that there is an increase of the ionic conductivity of the films with the increase in the proportion of $\mathrm{N}_{\mathrm{t}}$ species of nitrogen [209]. Here, it should be pointed out that while the conduction mechanisms might be strongly related between the one occurring in the film LiPON electrolytes and that in the oxynitride lithium phosphate glass, the chemical composition of both types of materials can be quite different and so the structural interpretation that was before stated for the bulk glass systems should not be strictly used in the structure-properties relationship in the LiPON films [210]. The ionic conductivity change by N/O substitution in lithium phosphate glasses has been studied thoroughly in the last years by F. Muñoz and coworkers. In a first work, the authors showed that independent of the modifier content in nitrided $\mathrm{Li}_{2} \mathrm{O}-\mathrm{P}_{2} \mathrm{O}_{5}$ glasses, the room temperature conductivity increases with nitrogen up to values of N/P ratio about $0.2-0.3$, then showing a much lower or null variation with further nitrogen addition [211]. In that work, they proposed that the increase in electrical conductivity should be due to the fact that nitridation produces a decrease of the bridging to non-bridging oxygens ratio (BO/NBO) giving rise to a larger net amount of NBOs as the nitrogen content increases, Thus, the nitrogen for oxygen substitution creates conduction paths favorable for the ionic hopping mechanism of lithium and this hypothesis was later evidenced by Mascaraque et al. through the study of the $\mathrm{BO} / \mathrm{NBO}$ ratio of a range of oxynitride glass compositions with varying $\mathrm{Li}_{2} \mathrm{O} / \mathrm{P}_{2} \mathrm{O}_{5}$ ratios [212]. 
Phosphates have also been studied in the form of glass-ceramics trying to reproduce the composition of crystalline compounds based on lithium titanium phosphates with the NASICON (sodium superionic conductor) type structure, or $\mathrm{NZP}$, in $\mathrm{NaZr}_{2} \mathrm{P}_{3} \mathrm{O}_{12}$. The systems studied have a variety of alternatives but most are formulated within $\mathrm{Li}_{2} \mathrm{O}$ $\mathrm{Al}_{2} \mathrm{O}_{3}-\mathrm{MO}_{2}-\mathrm{P}_{2} \mathrm{O}_{5}$, where $\mathrm{M}$ can be $\mathrm{Ge}$ or $\mathrm{Ti}$ and all belong to the ortho-phosphate composition [31]. They are prepared through a melt-quenching method at temperatures from 1400 to $1500^{\circ} \mathrm{C}$, and then heat treated in order to develop the LATP (Lithium Aluminum Titanium Phosphate) crystalline phases, giving rise normally to a fully crystallized material. In fact, the melts have a very high tendency for spontaneous crystallization given the very low amount of $\mathrm{P}_{2} \mathrm{O}_{5}$ from which they are formulated, which in many cases originates in inhomogeneous glass/glass-ceramics. However, they

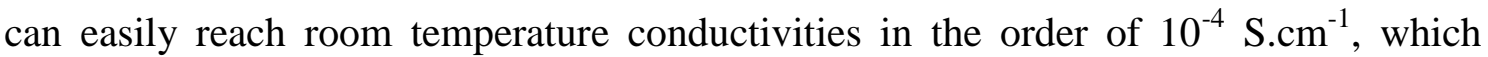
allow them to be used as solid-state electrolytes in their bulk form. Recently, LATP glass-ceramics have been tested into lithium-air secondary batteries as a protecting layer of the lithium metallic electrode or even in combination with LiPON electrolyte $[213,214]$.

\subsubsection{Phosphate Glasses for Waste Storage}

As it has been discussed in previous sections, phosphate glasses usually have a chemical durability which is inferior to that of most silicate and borosilicate glasses. The dissolution rate is very sensitive to phosphate glass compositions, and widely ranges from over $10^{-4}$ to almost $10^{-9}$ g.cm $\mathrm{cm}^{-2} \cdot \mathrm{min}^{-1}$. In order to improve the chemical durability, cations with high electrostatic field, like $\mathrm{Zn}^{2+}$ and $\mathrm{Pb}^{2+}$ are used to increase greatly the covalence of the $\mathrm{P}-\mathrm{O}-\mathrm{M}$ bonds. Trivalent cations $\left(\mathrm{Fe}^{3+}, \mathrm{Al}^{3+}\right)$ have also been successfully introduced to strengthen the glass network reticulation. However, the iron 
phosphate glasses are an exception. Binary and ternary iron phosphate glasses containing more than 25 mol $\% \mathrm{Fe}_{2} \mathrm{O}_{3}$ have an exceedingly good chemical durability. Their dissolution rate at $90^{\circ} \mathrm{C}$ in distilled water or in saline solution is up to 100 times lower than that of window glass [215]. In addition to their excellent chemical durability, iron phosphate glasses can usually be melted between $950^{\circ} \mathrm{C}$ and $1150^{\circ} \mathrm{C}$ in only a few hours [216] since the melts are fluid and rapidly homogenize.

Vitrification of high level nuclear wastes (HLW) has received a great worldwide attention since more than 40 years. The associated technology, which has reached its maturity, presents several relative advantages such as the ease of production, the insensitivity to the waste composition fluctuations and the high resistance to potential alterations due to the combined effects of heat, radiation and aqueous solutions.

Many vitrification processes have been developed and tested. They can be classified in two types: discontinuous and continuous, with a clear tendency in favor of the last one. Each of them includes three temperature dependent phases: drying, calcining and vitrification. HLW can be incorporated directly into the glass network or by glass encapsulation in the form of a composite material. Depending on the process chosen for the large scale vitrification plant, discontinuous pouring of the melt can be achieved to fill a canister, or the molten glass can be separated into droplets allowing the continuous production of beads which are poured in a canister and then embedded in a molten lead matrix (Vitromets). In each case, after filling, the storage containers are welded, cooled down and then transported to a storage facility.

Among several hundred of glass frits described in literature, only a limited number of glass compositions is used on a large scale or considered as reference materials. Table VI illustrates, for most countries, the glass compositions used for HLW incorporation 
and the corresponding waste loading limit. These glass formulations may be subject to slight changes depending on the fluctuations in the waste composition.

Table VI: Compositions of some nuclear waste glasses in wt. \%.

\begin{tabular}{|l|l|l|l|l|l|l|l|l|l|}
\hline Glass/country & \multirow{2}{*}{$\mathrm{SiO}_{2}$} & $\mathrm{P}_{2} \mathrm{O}_{5}$ & $\mathrm{~B}_{2} \mathrm{O}_{3}$ & $\mathrm{Al}_{2} \mathrm{O}_{3}$ & $\mathrm{CaO}$ & $\mathrm{MgO}$ & $\mathrm{Na}_{2} \mathrm{O}$ & Misc. & loading \\
& & & & & & & & & $(\%)$ \\
\hline France & 47.2 & - & 14.9 & 4.4 & 4.1 & - & 10.6 & 18.8 & $\leq 28$ \\
\hline USA & 49.8 & - & 8.0 & 4.0 & 1.0 & 1.4 & 8.7 & 27.1 & $\leq 33$ \\
\hline UK & 47.2 & - & 16.9 & 4.8 & - & 5.3 & 8.4 & 17.4 & $\leq 25$ \\
\hline Germany/ & 52.7 & - & 13.2 & 2.7 & 4.6 & 2.2 & 5.9 & 18.7 & $\leq 30$ \\
\hline Belgium & & & & & & & & & \\
\hline Russia & - & 52 & - & 19.0 & - & - & 21.2 & 7.8 & $\leq 10$ \\
\hline
\end{tabular}

High waste loading are achieved both in borosilicate and alumino-phosphate glasses, however molten phosphate glasses are known to be highly corrosive to refractory liners, contrary to the borosilicate melts. This behavior is probably the main reason why their application has not been envisaged for waste from nuclear fuel reprocessing in most countries excepted in Russia since 1987. Those chemical compositions are the results of a compromise between glass durability and technical feasibility. Attention has to be paid to the processing temperatures and the viscosity of the melt which should be the lowest as possible, $1150^{\circ} \mathrm{C}$ and $10 \mathrm{~Pa}$.s, respectively. Thus, the volatility of fission products, like Cs, could be avoided and a control of the pouring into the canisters could be ensured, minimizing the blending problems. The critical characteristics of the glass waste are the possibility to undergo phase transformations during cooling, thus 
degrading the mechanical integrity, and the radiation effects on any of the properties of the glass and especially on its chemical durability. The reintroduction of radionuclides in the biosphere is considered as fulfilled by water leaching. It is the only conceivable way to transport radioactive materials away from a waste repository. The release rates of radionuclides can be expressed on the basis of normalized dissolution rate (NDR) according to various test protocols such as ISO 6961-1982 and supposing that the evaluation of the long-term performance of glass wastes (i.e. more than 10000 years) can be inferred to laboratory time scale experiments. Typical NDR values of glass wastes are of $10^{-6} \mathrm{~g} \cdot \mathrm{cm}^{-2}$.day ${ }^{-1}$. However, such a value can be dramatically increased, by several orders of magnitude, when the glass has undergone crystallization of water soluble phases during cooling.

The following table summarizes typical data of HLW borosilicate and phosphate glasses [217].

Table VII: Typical properties of HLW glasses

\begin{tabular}{|l|l|l|l|l|}
\hline Glass & Density $\left(\mathrm{g} \cdot \mathrm{cm}^{-3}\right)$ & $\begin{array}{l}\text { Compressive } \\
\text { Strength }(\mathrm{MPa})\end{array}$ & $\begin{array}{l}\text { NDR }\left(28^{\text {th }} \text { day }\right) \\
\left(10^{-6} \cdot \mathrm{g} \cdot \mathrm{cm}^{-2} \cdot \mathrm{day}^{-1}\right)\end{array}$ & Thermal stability \\
\hline Borosilicate & 2.7 & $22-54$ & $0.3(\mathrm{Cs})-0.2(\mathrm{Sr})$ & $\geq 550^{\circ} \mathrm{C}$ \\
\hline Phosphate & 2.6 & $9-14$ & $1.1(\mathrm{Cs})-0.4(\mathrm{Sr})$ & $\geq 450^{\circ} \mathrm{C}$ \\
\hline
\end{tabular}

Depending on their origin, HLW can contain phosphates (up to 15 wt. $\% \mathrm{P}_{2} \mathrm{O}_{5}$ ), iron oxide (up to 25 wt. \%) and other heavy metal oxides such as $\mathrm{Bi}_{2} \mathrm{O}_{3}$ (up to 30 wt. \%) or $\mathrm{UO}_{2}$ (up to 30 wt. \%). As a consequence, the borosilicate glass used for the vitrification of the nuclear wastes can present a phase separation below $\mathrm{T}_{\mathrm{g}}$ resulting from a liquid 
immiscibility above $\mathrm{T}_{\mathrm{g}}$. This is due to a $\mathrm{P}_{2} \mathrm{O}_{5}$ content larger than a critical concentration, which is clearly dependent on the glass composition and vary from 0.5 to 7 wt. \% [216]. This phase separation may also induce a mismatch in the coefficients of thermal expansion that results in local stresses and cracks in the glassy phase increasing the risk of failure of the glass waste form.

To avoid this problem, two possibilities may be considered. The easiest is to dilute such HLW's in order to decrease the $\mathrm{P}_{2} \mathrm{O}_{5}$ content below the phase separation threshold. This unfortunately leads to an increase of the volume of the resulting waste form.

An alternative is to take advantage of the presence of phosphorous and iron oxides in these HLW and to produce a glassy iron phosphate waste form. It has been demonstrated that the melting and fining process of such iron phosphate glasses can be achieved in less than $2 \mathrm{~h}$ at temperatures which are usually lower than those needed for borosilicate glasses. Furthermore, these glasses exhibit chemical durability (DR) values of about $10^{-9} \mathrm{~g} . \mathrm{cm}^{-2}$.day ${ }^{-1}$, evaluated from the weight loss of bulk samples immersed in deionized water at $90^{\circ} \mathrm{C}$. These values are similar to that of a CVS-IS standard borosilicate glass made by Pacific Northwest National Labs [216]. Furthermore, the lowest DR values are obtained for glasses with an $\mathrm{O} / \mathrm{P}$ atomic ratio close to 3.5. From a structural point of view, it corresponds to pyrophosphate $\mathrm{P}_{2} \mathrm{O}_{7}$ groups which are bonded together by iron ions. Assuming that the corrosion of phosphate glasses occurs by the hydration of P-O-P bonds, the excellent chemical durability of these glasses may be attributed to the replacement of the P-O-P bonds by the more hydration resistant $\mathrm{Fe}-\mathrm{O}-\mathrm{P}$ bonds.

Using the same approach, a simulated sodium bearing waste (SBW) was successfully vitrified in iron phosphate glasses at a maximum waste loading of $40 \mathrm{wt}$. \% using both conventional and cold crucible induction melting techniques [218]. No sulfate 
segregation or crystalline phases were detectable. The wasteforms containing $40 \mathrm{wt}$. \% SBW satisfy current requirements for aqueous chemical durability. The fluid wasteforms can be melted at a relatively low temperature $\left(1000^{\circ} \mathrm{C}\right)$ and for short times $(<6 \mathrm{~h})$. These properties combined with a significantly higher waste loading and the feasibility of cold crucible induction melting, offer considerable savings in time, energy, and cost for vitrifying the SBW.

Finally, before 1990, the nuclear waste management community considered borosilicate glasses as the "one size fits all" host matrix. As the diversity and chemical complexity of the nuclear wastes became more apparent and as the range of nuclear wastes tested in borosilicate glasses widened, the potential problems of the incompatibility of certain wastes with borosilicate glasses became more evident. A logical solution to this problem is to have alternative host matrices that are better suited for vitrifying such problematic wastes and match the glass to the waste.

Conclusions and perspectives

Phosphate based glasses have been investigated as one of the most versatile systems which have found application in many different technological fields, from ionic conductors to laser host materials, sealing glasses, biomaterials and even as matrices for immobilization of toxic wastes. Their particular thermal characteristics make them unique for certain applications where other glass types would not be appropriate, and despite their relatively low chemical durability, normally associated due to their hygroscopic character, several methods have successfully been applied to address this drawback. Furthermore, their ability to incorporate transition metal elements, rare-earths or heavy metals, as well as for the substitution of oxygen by a number of different 
elements $(\mathrm{N}, \mathrm{S}, \mathrm{F}, \mathrm{I}, \ldots)$, significantly increases the applicability of phosphate glass systems, giving rise to new, improved and enhanced properties constantly.

Furthermore, structural studies of phosphate glasses have provided very precise representations of their atomic arrangements, not only at the local scale but also at longer range orders, enabling further insight into their structure-property relationships. Therefore, phosphate glasses have a very bright future ahead with further new developments transpiring into further new applications. As these new developments come to the fore, their formulations will inevitably become more complex and elucidation of their properties based on their structure will remain of key importance, for which novel modelling techniques of amorphous systems may well be required and become a central issue.

\section{Acknowledgements}

F. Muñoz thanks funding from projects MAT2013-48246-C2-1-P from MINECO of Spain and I-link+0959 from CSIC. I. Ahmed would like to acknowledge the Faculty of Engineering, Advanced Materials Research Group, University of Nottingham, for provision of studentship funds. 


\section{References}

[1] W. Vogel: Glass Chemistry (Springer-Verlag, Berlin, Heidelberg 1994).

[2] N.N. Greenwood, A. Earnshaw: Chemistry of the Elements (Pergamon Press, Oxford 1984).

[3] V.M. Goldschmidt: Geochemische Verteilungsgesetze der Elemente, Skr. Nor. Vidensk Akad. K1, 1; Mat. Naturvidensk. K1 8, 7-156 (1926).

[4] W.J. Zachariasen: The atomic arrangement in Glass, J. Am. Ceram. Soc. 54, 38413851 (1932).

[5] A. Dietzel: Die kationenfeldstärken und irhe beziehungen zu entglasungsvorgängen, zur berbindungsbildung und zu den schmelzpunkten von silicaten, Z. Elektrochem. 48, 9-23 (1942).

[6] E. Thilo: Die Kondensierten Phosphate, Die Naturwissenschaften 46(11), 367-373 (1959).

[7] J.R. Van Wazer: Phosphorus and its compounds vol. I (Interscience, New York 1958).

[8] R.K. Brow, D.R. Tallant, J.J. Hudgens, S.W. Martin, A.D. Irwin: The short-range structure of sodium ultraphosphate glasses, J. Non-Cryst. Solids 177, 221-228 (1994).

[9] U.W. Hoppe: A structural model for phosphate glasses, J. Non-Cryst. Solids 195, 138-147 (1996).

[10] J.R. Jones, A.G. Clare: Bio-Glasses: An Introduction (John Wiley \& Sons, United Kingdom 2012).

[11] M. Ren, S. Cai, W. Zhang, T. Liu, X. Wu, P. Xu, D. Wang: Preparation and chemical stability of $\mathrm{CaO}-\mathrm{P}_{2} \mathrm{O}_{5}-\mathrm{Na}_{2} \mathrm{O}-\mathrm{B}_{2} \mathrm{O}_{3}$ porous glass-ceramics, J. Non-Cryst. Solids 380, 78-85 (2013). 
[12] J.H. Campbell, J.S. Hayden, A. Marker: High Power Solid-State Lasers: a Laser Glass Perspective, Int. J. App. Glass Sci. 2 [1], 3-29 (2011).

[13] I. Ahmed, A.J. Parsons, G. Palmer, J.C. Knowles, G.S. Walker, C.D. Rudd: Weight loss, ion release and initial mechanical properties of a binary calcium phosphate glass fibre/PCL composite, Acta Biomaterialia 4, 1307-1314 (2008).

[14] J.C. Knowles: Phosphate based glasses for biomedical applications, Journal of Materials Chemistry 13, 2395-2401 (2003).

[15] I. Ahmed, M. Lewis, I. Olsen, J.C. Knowles: Phosphate glasses for tissue engineering: Part 2. Processing and characterisation of a ternary-based $\mathrm{P}_{2} \mathrm{O}_{5}-\mathrm{CaO}-\mathrm{Na}_{2} \mathrm{O}$ glass fibre system, Biomaterials 25, 501-7 (2004).

[16] I. Ahmed, M. Lewis, I. Olsen, J.C. Knowles: Phosphate glasses for tissue engineering: Part 1. Processing and characterisation of a ternary-based $\mathrm{P}_{2} \mathrm{O}_{5}-\mathrm{CaO}-\mathrm{Na}_{2} \mathrm{O}$ glass system, Biomaterials 25, 491-499 (2004).

[17] K.M.Z. Hossain, M.S. Hassan, R. Felfel, If. Ahmed: Development of phosphatebased glass fibers for biomedical applications, in Hot Topics in Biomaterials, 104-115 (Future Science Ltd., London 2014).

[18] M.J. Weber: Science and technology of laser glass, J. Non-Cryst. Solids 123, 208$222(1990)$.

[19] J.H. Campbell, T.I. Suratwala: Nd-doped phosphate glasses for high-energy/highpeak-power lasers, J. Non-Cryst. Solids 263\&264, 318-341 (2000).

[20] T.T. Fernandez, P. Haro-González, B. Sotillo, M. Hernandez, D. Jaque, P. Fernandez, C. Domingo, J. Siegel, J. Solis: Ion migration assisted inscription of high refractive index contrast waveguides by femtosecond laser pulses in phosphate glass, Optics Letters 38, 5248-5251 (2013). 
[21] J. del Hoyo, R. Martinez Vazquez, B. Sotillo, T.T. Fernandez, J. Siegel, P. Fernández, R. Osellame, J. Solis: Control of waveguide properties by tuning femtosecond laser induced compositional changes, App. Phys. Lett. 105, 131101 (2014).

[22] N. Marquestaut, Y. Petit, A. Royon, P. Mounaix, T. Cardinal, L. Canioni: ThreeDimensional Silver Nanoparticle Formation Using Femtosecond Laser Irradiation in Phosphate Glasses: Analogy with Photography, Adv. Funct. Mater. 24, 5824-5832 (2014)

[23] J.E. Shelby: Introduction of Glass Science and Technology $2^{\text {nd }}$ Ed. (The Royal Society of Chemistry, Cambridge 2005).

[24] R. Morena: Phosphate glasses as alternatives to Pb-based sealing frits, J. NonCryst. Solids 263\&264, 382-387 (2000).

[25] M. Rajaram, D.E. Day: Preparation and properties of oxynitride phosphate glasses made from $27 \mathrm{R}_{2} \mathrm{O} \cdot 20 \mathrm{BaO} \cdot 3 \mathrm{Al}_{2} \mathrm{O}_{3} \cdot 50 \mathrm{P}_{2} \mathrm{O}_{5}$, J. Non-Cryst. Solids 102, 173-180 (1988).

[26] M. Duclot, J.-L. Souquet: Glassy materials for lithium batteries: electrochemical properties and devices performances, J. Power Sources 97-98, 610-615 (2001).

[27] T. Ishiyama, S. Suzuki, J. Nishii, T. Yamashita, H. Kawazoe, T. Omata: Proton conducting tungsten phosphate glass and its application in intermediate temperature fuel cells, Solid State Ionics 262, 856-859 (2014).

[28] T. Ishiyama, J. Nishii, T. Yamashita, H. Kawazoe and T. Omata: Electrochemical substitution of sodium ions with protons in phosphate glass to fabricate pure proton conducting glass at intermediate temperatures, J. Mater. Chem. A 2, 3940-3947 (2014). [29] Satoshi Nakata, Takuya Togashi, Tsuyoshi Honma, Takayuki Komatsu: Cathode properties of sodium iron phosphate glass for sodium ion batteries, Journal of NonCrystalline Solids 450, 109-115 (2016). 
[30] X. Yu, J.B. Bates, G.E. Jellison Jr., F.X. Hart: A Stable Thin-Film Lithium

Electrolyte: Lithium Phosphorus Oxynitride, J. Electrochem. Soc. 144 [2], 524-532 (1997).

[31] X. Xu, Z. Wen, Z. Gu, X. Xu, Z. Lin: Lithium ion conductive glass-ceramics in the system $\mathrm{Li}_{1.4} \mathrm{Al}_{0.4}\left(\mathrm{Ge}_{1-\mathrm{x}} \mathrm{Ti}_{\mathrm{x}}\right)_{1.6}\left(\mathrm{PO}_{4}\right)_{3}(\mathrm{x}=0-1.0)$, Solid State Ionics 171, 207-213 (2004).

[32] S.T. Reis, M. Karabulut, D.E. Day: Structural features and properties of lead-ironphosphate nuclear wasteforms, J. Nucl. Mat. 304, 87-95 (2002).

[33] J.R. Van Wazer: Structure and Properties of the Condensed Phosphates. II. A Theory of the Molecular Structure of Sodium Phosphate Glasses, J. Am. Chem. Soc. 72, 644-647 (1950).

[34] E. Lippmaa, M. Maegi, A. Samoson, G. Engelhardt, A. Grimmer: Structural studies of silicates by solid-state high-resolution silicon-29 NMR, J. Am. Chem. Soc. 102 (15), 4889-4893 (1980).

[35] R.K. Brow, Review: the structure of simple phosphate glasses, J. Non-Cryst. Solids 263\&264, 1-28 (2000).

[36] B.H. Jung, D.N. Kim, H.-S. Kim: Properties and structure of (50-x)BaO-xZnO50 $\mathrm{P}_{2} \mathrm{O}_{5}$ glasses, J. Non-Cryst. Solids 351, 3356-3360 (2005).

[37] L. Muñoz-Senovilla, F. Muñoz: Behaviour of viscosity in metaphosphate glasses, J. Non-Cryst. Solids 385, 9-16 (2014).

[38] S. Mamedov, D. Stachel, M. Soltwitsch, D. Quitmann: Local environment and dynamics of $\mathrm{PO}_{4}$ tetrahedra in Na-Al- $\mathrm{PO}_{3}$ glasses and melts, J. Chem. Phys. 123, 124515-124527 (2005).

[39] R.J. Kirkpatrick, R.K. Brow: Nuclear magnetic resonance investigation of the structures of phosphate and phosphate-containing glasses: a review, Solid State Nucl. Magn. Res. 5, 9-21 (1995). 
[40] R.K. Brow, D.R. Tallant, S.T. Myers, C.C. Phifer: The short-range structure of zinc polyphosphate glass, J. Non-Cryst. Solids 191, 45-55 (1995).

[41] F. Muñoz, F. Agulló-Rueda, L. Montagne, R. Marchand, A. Durán, L. Pascual: Structure and properties of $(25-\mathrm{x} / 2) \mathrm{Li}_{2} \mathrm{O}-(25-\mathrm{x} / 2) \mathrm{Na}_{2} \mathrm{O}-\mathrm{xPbO}-50 \mathrm{P}_{2} \mathrm{O}_{5}$ metaphosphate glasses, J. Non-Cryst. Solids 347, 153-158 (2004).

[42] T.M. Duncan, D.C. Douglass: On the ${ }^{31} \mathrm{P}$ chemical shift anisotropy of condensed phosphates, Chemical Physics 87, 339-349 (1984).

[43] M. Feike, R. Graf, I. Schnell, C. Jäger, C.W. Spiess: Structure of crystalline phosphates from 31P Double-Quantum NMR spectroscopy, J. Am. Chem. Soc. 118, 9631-9634 (1996).

[44] P. Rajbhandari, Y. Chen, B. Doumert, L. Montagne, G. Tricot: Investigation of zinc alkali pyrophosphate glasses. Part II : Local and medium range orders analysed by 1D/2D NMR, Mat. Chem. Phys. 155, 23-29 (2015).

[45] R. Witter, P. Hartmann, J. Vögel, C. Jäger: Measurements of chain length distributions in calcium phosphate glasses using $2 \mathrm{D}{ }^{31} \mathrm{P}$ double quantum NMR, Solid State Nucl. Magn. Res. 13, 189-200 (1998).

[46] F. Fayon, G. Le Saout, L. Emsley, D. Massiot: Through-bond phosphorusphosphorus connectivities in crystalline and disordered phosphates by solid-state NMR, Chem. Comm. 1702-1703 (2002).

[47] F. Fayon, I.J. King, R.K. Harris, J.S.O. Evans, D. Massiot: Application of the through-bond correlation NMR experiment to the characterization of crystalline and disordered phosphates, C. R. Chimie 7, 351-361 (2004).

[48] J. Ren, H. Eckert: Applications of DQ-DRENAR for the structural analysis of phosphate glasses, Solid State Nucl. Magn. Res. 72, 140-147 (2015). 
[49] P. Guerry, M. E. Smith, S.P. Brown: ${ }^{31}$ P MAS Refocused INADEQUATE SpinEcho (REINE) NMR Spectroscopy: Revealing $J$ Coupling and Chemical Shift TwoDimensional Correlations in Disordered Solids, J. Am. Chem. Soc. 131, 11861-11874 (2009).

[50] M. Lahaye, B. Doumert, B. Revel, K. Ben Tayeb, H. Vezin, G. Tricot : Application of Magnetic Resonance Spectroscopies to the $\mathrm{xZnO}-(100-\mathrm{x}) \mathrm{NaPO}_{3}$ Glass System : Glass Network Organization and Effect of Co2+ doping, J. Phys. Chem. C 119, 17288$17297(2015)$.

[51] F. Moreau, A. Durán, F. Muñoz : Structure and properties of high $\mathrm{Li}_{2} \mathrm{O}$-containing aluminophosphate glasses, J. Eur. Ceram. Soc. 29, 1895-1902 (2009).

[52] L. Van Wüllen, G. Tricot, S. Wegner: An advanced NMR protocol for the structural characterization of aluminophosphate glasses, Solid State Nucl. Mag. Res. 32, 44-52 (2007).

[53] F. Muñoz, L. Montagne, L. Pascual, A. Durán : Composition and structure effects on the properties of lithium borophosphate glasses showing boron anomaly, J. NonCryst. Solids, 355, 2571-2577 (2009).

[54] M. Zeyer, L. Montagne, V. Kostoj, G. Palavit, D. Prochnow, C. Jaeger : ${ }^{17} \mathrm{O}$ nuclear magnetic resonance study of $\mathrm{Na}_{2} \mathrm{O}-\mathrm{P}_{2} \mathrm{O}_{5}$ glasses, 311, 223-232 (2002).

[55] A. Flambard, L. Montagne, L. Delevoye : A new ${ }^{17}$ O-isotopic enrichment method for the NMR characterisation of phosphate compounds, Chemm. Commun. 3426-3428 (2006).

[56] A. Flambard, L. Montagne, L. Delevoye, G. Palavit, J.-P. Amoreaux, J.-J. Videau : Solid-state NMR study of mixed-network sodium-niobium phosphate glasses, 345\&346, 75-79 (2004). 
[57] R.E. Dinnebier, S.J.L. Billingue (Eds.): Powder diffraction: theory and practice (RSC publishing, Cambridge 2008).

[58] U. Hoppe, G. Walter, R. Kranold, D. Stachel: Structural specifics of phosphate glasses probed by diffraction methods: a review, J. Non-Cryst. Solids 263\&264, 29-47 (2000).

[59] J. Biscoe, A.G. Pincus, C.S. Smith, B.E. Warren: X-ray study of lime-phosphate and lime-borate glass, J. Am. Ceram. Soc. 24, 116-119 (1941).

[60] Y. Waseda: The Structure of Non-Crystalline Materials (McGraw-Hill, New York, 1980).

[61] U. Hoppe, D. Stachel, D. Beyer : Oxygen coordination of metal ions in phosphate and silicate glasses studied by a combination of x-ray and neutron diffraction, Phys. Scripta T57, 122-126 (1995).

[62] E. Matsubara, K. Sugiyama, Y. Waseda, M. Ashizuka, E. Ishida: Structural analysis of zinc metaphosphate glass by anomalous X-ray scattering, J. Mater. Sci. Lett. 9, 14-16 (1990).

[63] A. Balerna, M. Bionducci, A. Falqui, G. Licheri, C. Meneghini, G. Navarra, M. Bettinelli : A structural study of Sr metaphosphate glass by anomalous X-ray scattering and EXAFS spectroscopy, J. Non-Cryst. Solids 232\&234, 607-612 (1998).

[64] P.H. Gaskell, J. Zhao, P. Boden, P. Chieux: Structure of a copper sodium phosphate glass by neutron scattering with isotopic substitution, J. Non-Cryst. Solids 150, 80-86 (1992).

[65] U. Hoppe, E. Metwalli, R. K. Brow, J. Neuefeind: High-energy X-ray diffraction study of La co-ordination in lanthanum phosphate glasses, J. Non-Cryst. Solids 297, 263-274 (2002). 
[66] U. Hoppe, D. Ilieva, J. Neuefeind: The structure of gallium phosphate glasses by high-energy X-ray diffraction, Zeitschrift fur Naturforschung A 57, 709-715 (2002).

[67] U. Hoppe, M. Karabulut, E. Metwalli, R. K. Brow, P. Jovari: The Fe-O coordination in iron phosphate glasses by X-ray diffraction with high energy photons, J. Phys. Condensed Matt. 15, 6143-6153 (2003).

[68] U. Hoppe, R. Kranold, A. Ghosh, C. Landron, J. Neuefeind, P. Jovari; Environments of lead cations in oxide glasses probed by X-ray diffraction, J. NonCryst. Solids 328, 146-156 (2003).

[69] U. Hoppe, Y. Dimitriev, P. Jovari: Structure of zinc phosphate glasses of 75 and 80 mol \% $\mathrm{ZnO}$ content studied by X-ray diffraction and reverse Monte Carlo simulations, Zeitschrift fur Naturforschung A 60, 517-526 (2005).

[70] U. Hoppe, R. K. Brow, B. C. Tischendorf, A. Kriltz, P. Jóvári, A. Schöps, A.C. Hannon: Structure of titanophosphate glasses studied by X-ray and neutron diffraction, J. Non-Cryst. Solids 353, 1802-1807 (2007).

[71] U. Hoppe, G. Walter, A. Barz, D. Stachel, A.C. Hannon: The P-O bond lengths in vitreous $\mathrm{P}_{2} \mathrm{O}_{5}$ probed by neutron diffraction with high real-space resolution, J. Phys.: Condens. Matt. 10, 261-270 (1998).

[72] K. Suzuki, M. Ueno: Experimental discrimination between bridging and nonbridging oxygen phosphorus bonds in $\mathrm{P}_{2} \mathrm{O}_{5}-\mathrm{Na}_{2} \mathrm{O}$ glass by pulsed neutron total scattering, Journal de Physique 46 (C8), 261-265 (1985).

[73] U. Hoppe, G. Walter, R. Kranold, D. Stachel: An X-ray diffraction study of the structure of vitreous $\mathrm{P}_{2} \mathrm{O}_{5}$, Z. Naturforsch. A53, 93-04 (1998).

[74] R. Gresch, W. Müller-Warmuth, H. Dutz: X-ray photoelectron spectroscopy of sodium phosphate glasses, J. Non-Cryst. Solids 34, 127-136 (1979). 
[75] P. Losso, B. Schnabel, C. Jäger, U. Sternberg, D. Stachel, D.O. Smith: ${ }^{31}$ P NMR investigations of binary alkaline earth phosphate glasses of ultraphosphate composition, J. Non-Cryst. Solids 143, 265-273 (1992).

[76] R.K. Brow, C.C. Phifer, G.L. Turner, R.J. Kirkpatrick: Cation effects on ${ }^{31}$ P MAS NMR chemical shifts of metaphosphate glasses, J. Am. Ceram. Soc. 74, 1287-1290 (1991).

[77] G.N. Greaves, S.J. Gurman, L.F. Gladden, C.A. Spence, B.C. Sales, L.A. Boatner, R.N. Jenkins: A structural basis for the corrosion resistance of lead-iron-phosphate glasses: An X-ray absorption spectroscopy study, Philos. Mag. B 58, 271-283 (1988).

[78] U. Hoppe, G. Walter, D. Stachel, A.C. Hannon: Short-range order details of metaphosphate glasses studied by pulsed neutron scattering, Z. Naturforsch. A50, 684$692(1995)$

[79] U. Hoppe, G. Walter, D. Stachel, A.C. Hannon. Short-range order in $\mathrm{KPO}_{3}$ glass studied by neutron and X-ray diffraction, Z. Naturforsch. A51, 179-186 (1996).

[80] T. Uchino, Y. Ogata: Ab-initio molecular orbital calculations on the electronic structure of phosphate glasses. Binary alkali metaphosphate glasses, J. Non-Cryst. Solids 191, 56-70 (1995).

[81] U. Hoppe, G. Walter, D. Stachel: The short range order of metaphosphate glasses investigated by X-ray diffraction, Phys. Chem. Glasses, 33, 216-221 (1992).

[82] U. Hoppe, G. Walter, R. Kranold, D. Stachel, A. Barz: The dependence of structural peculiarities in binary phosphate glasses on their network modifier content, J. Non-Cryst. Solids 192\&193, 28-31 (1995).

[83] J.J. Hudgens, S.W. Martin: Glass transition and infrared spectra of low alkali, anhydrous lithium phosphate glasses, J. Am. Ceram. Soc. 76, 1691-1696 (1993). 
[84] J.J. Hudgens: The structure and properties of anhydrous alkali ultra-phosphate glasses, (PhD Thesis, Iowa State University, Ames 1994).

[85] U. Hoppe, R. Kranold, D. Stachel, A. Barz, A.C. Hannon: A neutron and X-ray diffraction study of the structure of the $\mathrm{LaP}_{3} \mathrm{O}_{9}$ glass, J. Non-Cryst. Solids 232\&234, 44-50 (1998).

[86] U. Hoppe, R. Kranold, D. Stachel, J. Neuefeind: Oxygen coordination of modifier cations in metaphosphate glasses probed by high energy X-ray diffraction, Phosphorus Res. Bull. 10, 546-551 (1999).

[87] A. Musinu, G. Paschina, G. Piccaluga, G. Pinna: Short range order of metaphosphate glasses by X-ray diffraction, J. Non-Cryst. Solids 177, 97-102 (1994).

[88] S.C. Moss, D.L. Price, in: D. Adler, H. Fritzsche, S.R. Ovshinsky (Eds.), Physics of Disordered Materials, (Plenum, New York 1985).

[89] S.R. Elliott : Extended-range order, interstitial voids and the first sharp diffraction peak of network glasses, J. Non-Cryst. Solids 182, 40-48 (1995).

[90] P.H. Gaskell, D.J. Wallis: Medium-range order in silica, the canonical network glass, Phys. Rev. Lett. 76, 66-69 (1996).

[91] G. Walter, U. Hoppe, T. Baade, R. Kranold, D. Stachel: Intermediate-range order in $\mathrm{MeO}-\mathrm{P}_{2} \mathrm{O}_{5}$ glasses, J. Non-Cryst. Solids 217, 299-307 (1997).

[92] K. Suzuya, D.L. Price, C.-K. Loong, S.W. Martin: Structure of vitreous $\mathrm{P}_{2} \mathrm{O}_{5}$ and alkali phosphate glasses, J. Non-Cryst. Solids 232\&234, 650-657 (1998).

[93] K. Suzuya, D.L. Price, C.-K. Loong, S. Kohara: The structure of magnesium phosphate glasses, J. Phys. Chem. Solids 60, 1457-1460 (1999).

[94] K. Suzuya, K. Itoh, A. Kajinami, C.-K. Loong: The structure of binary zinc phosphate glasses, J. Non-Cryst. Solids 345\&346, 80-87 (2004). 
[95] H. Rietveld: A profile refinement method for nuclear and magnetic structures, J. Appl. Crystallogr. 2, 65-71 (1969).

[96] R. L. McGreevy and L. Pusztai: Reverse Monte Carlo simulation: A new technique for the determination of disordered structures, Mol. Simul. 1, 359-367 (1988).

[97] R. L. McGreevy: Reverse Monte Carlo modelling, J. Phys.: Condens. Matter 13, R877-R914 (2001).

[98] B. J. Alder and T. E. Wainwright: Studies in molecular dynamics. I. General method, J. Chem. Phys. 31, 459-466 (1959).

[99] A. N. Cormack and Y. Cao: Molecular dynamics simulation of silicate glasses, Molecular Engineering 6, 183-227 (1996).

[100] A. K. Soper: Test of the empirical potential structure refinement method and a new method of application to neutron diffraction data on water, Mol. Phys. 99, 1503$1516(2001)$.

[101] A. K. Soper: Partial structure factors from disordered materials diffraction data: an approach using empirical potential structure refinement, Phys. Rev. B 72, 104204$104216(2005)$.

[102] K. M. Wetherall, D. M. Pickup, R. J. Newport and G. Mountjoy: The structure of calcium metaphosphate glass obtained from x-ray and neutron diffraction and reverse Monte Carlo modelling, J. Phys.: Condens. Matter 21, 035109 (2009).

[103] A. Tilocca, Models of structure, dynamics and reactivity of bioglasses: a review, J. Mater. Chem. 20, 6848-6858 (2010).

[104] Y. Shaharyar, E. Wein, J.-J. Kim, R. E. Youngman, F. Muñoz, H.-W. Kim, A. Tiloccah, A. Goel, Structure-solubility relationships in fluoride-containing phosphate based bioactive glasses, J. Mater. Chem. B 3, 9360-9373 (2015). 
[105] J.K. Christie, R.I. Ainsworth, N.H. de Leeuw, Ab initio molecular dynamics simulations of structural changes associated with the incorporation of fluorine in bioactive phosphate glasses, Biomaterials 35, 6164-6171 (2014).

[106] E.A. Ruben, M.S. Chapman, J.D. Evanseck: Hydrogen Bonding Mediated by Chemical Interactions Determines Hydration Enthalpy Differences of Phosphate Water Clusters, J. Phys. Chem. A 111, 10804-10814 (2007).

[107] F. Delahaye, L. Montagne, G. Palavit, J.C. Touray, P. Baillif: Acid dissolution of sodium-calcium metaphosphate glasses, J. Non-Cryst. Solids 242, 25-32 (1998).

[108] D.E. Day, Z. Wu, C.S. Ray, P. Hrma: Chemically durable iron phosphate glass wasteforms, J. Non-Cryst. Solids 241, 1-12 (1998).

[109] B.C. Bunker, G.W. Arnold, J.A. Wilder: Phosphate glass dissolution in aqueous solutions, J. Non-Cryst. Solids 64, 291-316 (1984).

[110] H. Gao, T. Tan, D. Wang: Dissolution mechanism and release kinetics of phosphate controlled release glasses in aqueous medium, J. Controlled Release 96, 2936 (2004).

[111] F. Döhler, A. Mandlule, L. Van Wüllen, M. Friedrich, D.S. Brauer: ${ }^{31}$ P NMR characterization of phosphate fragments during dissolution of calcium sodium phosphate glasses, J. Mat. Chem. B 3, 1125-1134 (2015).

[112] P.E. Gray, L.C. Klein: The chemical durability of sodium ultraphosphate glasses, Glass Technology 24 [4], 202-206 (1983).

[113] N. Mascaraque, A. Durán, F. Muñoz: Effect of fluorine and nitrogen on the chemical durability of lithium phosphate glasses, J. Non-Cryst. Solids 417-418, 60-65 (2015).

[114] H. Takebe, Y. Baba, M. Kuwabara: Dissolution behavior of ZnO-P2O5 glasses in water, J. Non-Cryst. Solids 352, 3088-3094 (2006). 
[115] R. Marchand: Mise en évidence de verres de phosphates contenant de l'azote, C.R. Acad. Sc. Paris 294, 91-94 (1982).

[116] S. Hampshire, M.J. Pomeroy: Grain boundary glasses in silicon nitride : A review of chemistry, properties and crystallisation, J. Eur. Ceram. Soc. 32, 1925-1932 (2012).

[117] F. Muñoz, A. Durán, L. Pascual, R. Marchand: Compositional and viscosity influence on the nitrogen/oxygen substitution reactions in phosphate melts, Phys. Chem. Glasses 46 [1], 39-45 (2005).

[118] R. Marchand, D. Agliz, L. Boukbir, A. Quemerais: Characterization of nitrogen containing phosphate glasses by X-ray photoelectron spectroscopy, J. Non-Cryst. Solids 103, 35-44 (1988).

[119] B.C. Bunker, G.W. Arnold, M. Rajaram, D.E. Day: Corrosion of phosphorus oxynitride glasses in water and Humid air, J. Am. Ceram. Soc. 70, 425-430 (1987).

[120] L. Pascual, A. Durán: Preparation and properties of nitride phosphate glasses, Glastech. Ber. 64 [2], 43-48 (1991).

[121] M.R. Reidmeyer, D.E. Day: Phosphorus oxynitride glasses, J. Non-Cryst. Solids 181, 201-214 (1995).

[122] A. Le Sauze, R. Marchand: Chemically durable nitride phosphate glasses resulting from nitrogen/oxygen substitution within $\mathrm{PO}_{4}$ tetrahedra, J. Non-Cryst. Solids 263\&264, 285-292 (2000).

[123] G.L. Paraschiv, F. Muñoz, L.R. Jensen, Y. Yue, M. Smedskjaer: Impact of nitridation of metaphosphate glasses on liquid fragility, J. Non-Cryst. Solids 441, 22-28 (2016).

[124] M.R. Reidmeyer, D.E. Day: Preparation and properties of nitrogen-doped phosphate glasses, J. Am. Ceram. Soc. 68 [8] C-188-C-190 (1985). 
[125] R.K. Brow, M.R. Reidmeyer, D.E. Day: Oxygen bonding in nitrided sodium- and lithium-metaphosphate glasses, J. Non-Cryst. Solids 99, 178-189 (1988).

[126] A. Le Sauze, L. Montagne, G. Palavit, F. Fayon, R. Marchand: X-ray photoelectron spectroscopy and nuclear magnetic resonance structural study of phosphorus oxynitride glasses 'LiNaPON', J. Non-Cryst. Solids 263\&264, 139-145 (2000).

[127] F. Muñoz, L. Pascual, A. Durán, J. Rocherullé, R. Marchand : Alkali and alkalilead oxynitride phosphate glasses : a comparative structural study by NMR and XPS, C.R. Chimie 5, 731-738 (2002).

[128] F. Muñoz, L. Pascual, A. Durán, L. Montagne, G. Palavit, R. Berjoan, R. Marchand: Structural of phosphorus oxynitride glasses LiNaPbPON by nuclear magnetic resonance and X-ray photoelectron spectroscopy, J. Non-Cryst. Solids 324, $142-149(2003)$.

[129] F. Muñoz, L. Pascual, A. Durán, R. Berjoan, R. Marchand : Validation of the mechanism of nitrogen/oxygen substitution in Li-Na-Pb-P-O-N oxynitride phosphate glasses, J. Non-Cryst. Solids 352, 3947-3951 (2006).

[130] F. Muñoz: Kinetic analysis of the substitution of nitrogen for oxygen in phosphate glasses, Phys. Chem. Glasses: Eur. J. Glass Sci. Technol. B 52 [4], 181-186 (2011).

[131] F. Muñoz, L. Delevoye, L. Montagne, T. Charpentier: New insights into the structure of oxynitride NaPON phosphate glasses by 17-oxygen NMR, J. Non-Cryst. Solids 363, 134-139 (2013).

[132] F. Muñoz, A. Durán, L. Pascual: Synthesis and properties of nitrided phosphate glasses in the system $\mathrm{R}_{2} \mathrm{O}-\mathrm{R}^{\prime} \mathrm{O}-\mathrm{PbO}-\mathrm{P}_{2} \mathrm{O}_{5}\left(\mathrm{R}, \mathrm{R}^{\prime}=\mathrm{Li}, \mathrm{Na}\right)$, Phys. Chem. Glasses $43 \mathrm{C}$, $113-118(2002)$. 
[133] Q. Riguidel, F. Muñoz: Effect of nitridation on the aqueous dissolution of $\mathrm{Na}_{2} \mathrm{O}-$ $\mathrm{K}_{2} \mathrm{O}-\mathrm{CaO}-\mathrm{P}_{2} \mathrm{O}_{5}$ metaphosphate glasses, Acta Biomaterialia 7, 2631-2636 (2011).

[134] B. Wang, B.S. Kwak, B.C. Sales, J.B. Bates: Ionic conductivities and structure of lithium phosphorus oxynitride glasses, J. Non-Cryst. Solids, 183, 297-306 (1995).

[135] R.K. Brow, D.R. Tallant: Structural design of sealing glasses, J. Non-Cryst. Solids 222, 396-406 (1997).

[136] J. Rocherullé, J. Massera, H. Oudadesse, L. Calvet, J. Trolès, X.H. Zhang : Heat capacities of crystalline and glassy lithium metaphosphate up to the transition region, J. Therm. Anal. Calorim. 123, 401-407 (2016).

[137] S. Inaba, S. Oda, K. Morinaga : Heat capacity of oxide glasses measured by AC calorimetry, J. Non-Cryst. Solids 306, 42-49 (2002).

[138] J.J. Hudgens, R.K. Brow: Raman spectroscopy study of the structure of lithium and sodium ultraphosphate glasses, J. Non-Cryst. Solids 223, 21-31 (1998).

[139] T.M. Alam, S. Conzone, R.K. Brow, T.J. Boyle: ${ }^{6} \mathrm{Li},{ }^{7} \mathrm{Li}$ nuclear magnetic resonance investigation of lithium coordination in binary phosphate glasses, J. NonCryst. Solids 258, 140-154 (1999).

[140] R.G. Frieser: A review of solder glasses, Electrocomponent Sci. Technol. 2, 163199 (1975).

[141] I.W. Donald: Preparation, properties and chemistry of glass and glass-ceramic-tometal seals and coatings, J. Mater. Sci. 28, 2841-2886 (1993)

[142] J. A. Wilder, J. T. Healey, B. C. Bunker, in "Advances in Ceramics" Vol. 4, edited by J. H. Simmons (American Ceramic Society, Columbus OH) 313-326 (1982).

[143] T.H. Wang, P. F. James, in "Proceedings of the $2^{\text {nd }}$ International Conference on New Materials and their Applications", University of Warwick, UK, 10-12 April 1990, 
Institute of Physics Conference Series no. 111, edited by D. Holland (IOP, Bristol) 401410 (1990).

[144] I. W. Donald, P. M. Mallinson, B. L. Metcalfe, L. A. Gerrard, J. A. Fernie: Recent developments in the preparation, characterization and applications of glass and glassceramic-to-metal seals and coatings, J. Mater. Sci. 46, 1975-2000 (2011).

[145] A.E. Marino, S.R. Arrasmith, L.L. Gregg, S.D. Jacobs, G. Chen, Y. Duc: Durable phosphate glasses with lower transition temperatures, J. Non-Cryst. Solids 289, 37-41 (2001).

[146] D. Ehrt: Phosphate and Fluoride-phosphate Optical Glasses -Properties, Structure and Applications, Phys. Chem. Glasses: Eur. J. Glass Sci. Technol. B 56 [6], 217-234 (2015).

[147] E.T.Y. Lee, E.R.M. Taylor: Thermo-optic coefficients of potassium aluminometaphosphate glasses, J. Non-Cryst.Solids 65 1187-1192 (2004).

[148] A.K. Varshneya: Fundamentals of Inorganic Glasses (Academic Press, INC., London 1994).

[149] P.R. Ehrmann, K. Carlson, J.H. Campbell, C.A. Click, R.K. Brow: Neodymium fluorescence quenching by hydroxyl groups in phosphate laser glasses, J. Non-Cryst. Solids 349, 105-114 (2004).

[150] J.S. Hayden, M.K. Aston, S.A. Payne, M.L. Elder, J.H. Campbell: Laser and thermo-physical properties of Nd-doped phosphate glasses, Proceedings of SPIE 1761, $162-173(1992)$.

[151] G. Ofelt: Intensities of Crystal Spectra of Rare-Earth Ions, J. Chem. Phys. 37, $511-520(1962)$.

[152] B. Judd: Optical absorption intensities of rare-earth ions, Phys. Rev. 127, 750-761 (1962). 
[153] W.F. Krupke: Induced-emission cross sections in neodymium laser glasses, IEEE Journal of Quantum Electronics 10, 450-457 (1974).

[154] C. Thorsness, T.I. Suratwala, R.A. Steele, J.H. Campbell, J.S. Hayden, S. Pucilowski, K. Suzuki: Dehydroxylation of phosphate laser glass, International Symposium on Optical Science and Technology, International Society for Optics and Photonics, 175-194 (2000).

[155] P. Ehrmann, J. Campbell, T. Suratwala, J. Hayden, D. Krashkevich, K. Takeuchi: Optical loss and $\mathrm{Nd}^{3+}$ non-radiative relaxation by $\mathrm{Cu}, \mathrm{Fe}$ and several rare-earth impurities in phosphate laser glasses, J. Non-Cryst. Solids 263, 251-262 (2000).

[156] V. Arbuzov, Y.K. Fyodorov, S. Kramarev, S. Lunter, S. Nikitina, A. Pozharskii, A. Shashkin, A. Semyonov, V. Ter-Nersesyants, A. Charukhchev: Neodymium phosphate glasses for the active elements of a 128 channel laser facility, Glass Technology 46, 6770 (2005).

[157] L. Hu, S. chen, J. Tang, B. Wang, T. Meng, W. Chen, L. Wen, J. Hu, S. Li, Y. Xu, Y. Jiang, J. Zhang, Z. Jiang: Large aperture N31 neodymium phosphate laser glass for use in a high power laser facility, High Power Laser Science and Engineering 2, 1-6 (2014).

[158] E.A. Abou Neel, W. Chrzanowski, D.M. Pickup, L.A. O'Dell, N.J. Mordan, R.J. Newport, M.E. Smith, J.C. Knowles: Structure and properties of strontium-doped phosphate-based glasses, Journal of The Royal Society Interface 6, 435-446 (2009).

[159] E.A. Abou Neel, I. Ahmed, J.J. Blaker, A. Bismarck, A.R. Boccaccini, M.P. Lewis, S.N. Nazhat, J.C. Knowles: Effect of iron on the surface, degradation and ion release properties of phosphate-based glass fibres, Acta Biomaterialia 1, 553-563 (2005). 
[160] E.A. Abou Neel, W. Chrzanowski, J.C. Knowles: Effect of increasing titanium dioxide content on bulk and surface properties of phosphate-based glasses, Acta Biomaterialia 4, 523-534 (2008).

[161] M. Navarro, M.P. Ginebra, J.A. Planell: Cellular response to calcium phosphate glasses with controlled solubility, J Biomed Mater Res A 67, 1009-15 (2003).

[162] D. Furniss, A.B. Seddon: Towards monomode proportioned fibreoptic preforms by extrusion, Journal of Non-Crystalline Solids 256-257, 232-236 (1999).

[163] F.T. Wallenberger, N.E. Weston: Glass Fibers from High and Low Viscosity Melts, Mat Res Soc Symposium Proc. 702, 165-172 (2002).

[164] J. Choueka, J.L. Charvet, H. Alexander, Y.O. Oh, G. Joseph, N.C. Blumenthal, W.C. LaCourse: Effect of annealing temperature on the degradation of reinforcing fibers for absorbable implants, J Biomed Mater Res. 29, 1309-1315 (1995).

[165] I. Ahmed, C.A. Collins, M.P. Lewis, I. Olsen, J.C. Knowles: Processing, characterisation and biocompatibility of iron-phosphate glass fibres for tissue engineering, Biomaterials 25, 3223-3232 (2004).

[166] I. Ahmed, S.S. Shaharuddin, N. Sharmin, D. Furniss, C. Rudd, Core/Clad Phosphate Glass Fibres Containing Iron and/or Titanium, Biomedical glasses 1, 20-30 (2015).

[167] F. Ungaro, R. d'Emmanuele di Villa Bianca, C. Giovino, A. Miro, R. Sorrentino, F. Quaglia, M.I. La Rotonda: Insulin-loaded PLGA/cyclodextrin large porous particles with improved aerosolization properties: In vivo deposition and hypoglycaemic activity after delivery to rat lungs, Journal of Controlled Release 135, 25-34 (2009).

[168] T. Rouxel: Elastic properties of glasses: a multiscale approach, Comptes Rendus Mécanique 334, 743-753 (2006). 
[169] M. Goldstein, T.H. Davies: Glass Fibers with Oriented Chain Molecules, Journal of the American Ceramic Society 38, 223-226 (1955).

[170] S. Inaba, H. Hosono, S. Ito: Entropic shrinkage of an oxide glass, Nat Mater. 14, 312-317 (2015).

[171] I. Ahmed, P.S. Cronin, E.A. Abou Neel, A.J. Parsons, J.C. Knowles, C.D. Rudd: Retention of mechanical properties and cytocompatibility of a phosphate-based glass fiber/polylactic acid composite, J Biomed Mater Res B Appl Biomater. 89, 18-27 (2009).

[172] I. Ahmed, I. Jones, A. Parsons, J. Bernard, J. Farmer, C. Scotchford, G. Walker, C. Rudd: Composites for bone repair: phosphate glass fibre reinforced PLA with varying fibre architecture, Journal of Materials Science: Materials in Medicine 22, 1825-1834 (2011).

[173] A.Z. Kharazi, M.H. Fathi, F. Bahmany: Design of a textile composite bone plate using 3D-finite element method, Materials \& Design 31, 1468-1474 (2010).

[174] S.L. Evans, P.J. Gregson: Composite technology in load-bearing orthopaedic implants, Biomaterials 19, 1329-1342 (1998).

[175] N. Sharmin, A.J. Parsons, C.D. Rudd, I. Ahmed: Effect of boron oxide addition on fibre drawing, mechanical properties and dissolution behaviour of phosphate-based glass fibres with fixed 40,45 and $50 \mathrm{~mol} \% \mathrm{P}(2) \mathrm{O}(5)$, Journal of Biomaterials Applications 29, 639-653 (2014).

[176] R.M. Felfel, I. Ahmed, A.J. Parsons, P. Haque, G.S. Walker, C.D. Rudd: Investigation of Crystallinity, Molecular Weight Change, and Mechanical Properties of PLA/PBG Bioresorbable Composites as Bone Fracture Fixation Plates, Journal of Biomaterials Applications 26, 765-789 (2012). 
[177] R. Shah, A.C.M. Sinanan, J.C. Knowles, N.P. Hunt, M.P. Lewis: Craniofacial muscle engineering using a 3-dimensional phosphate glass fibre construct, Biomaterials 26, 1497-1505 (2005).

[178] E.A. Abou Neel, I. Ahmed, J. Pratten, S.N. Nazhat, J.C. Knowles: Characterisation of antibacterial copper releasing degradable phosphate glass fibres, Biomaterials 26, 2247-2254 (2005).

[179] M. Yamaguchi, H. Oishi, Y. Suketa: Stimulatory effect of zinc on bone formation in tissue culture, Biochemical Pharmacology 36, 4007-4012 (1987).

[180] C. Gérard, L.-J. Bordeleau, J. Barralet, C.J. Doillon: The stimulation of angiogenesis and collagen deposition by copper, Biomaterials 31, 824-831 (2010).

[181] C. Vitale-Brovarone, G. Novajra, J. Lousteau, D. Milanese, S. Raimondo, M. Fornaro: Phosphate glass fibres and their role in neuronal polarization and axonal growth direction, Acta Biomaterialia 8, 1125-1136 (2012).

[182] S.N. Nazhat, E.A. Abou Neel, A. Kidane, I. Ahmed, C. Hope, M. Kershaw, P.D. Lee, E. Stride, N. Saffari, J.C. Knowles, R.A. Brown: Controlled Microchannelling in Dense Collagen Scaffolds by Soluble Phosphate Glass Fibers, Biomacromolecules 8, 543-551 (2006).

[183] N.-Y. Joo, J.C. Knowles, G.-S. Lee, J.-W. Kim, H.-W. Kim, Y.-J. Son, J.K. Hyun: Effects of phosphate glass fiber-collagen scaffolds on functional recovery of completely transected rat spinal cords, Acta Biomaterialia 8, 1802-1812 (2012).

[184] R. Kayacan: The effect of staining on the monotonic tensile mechanical properties of human cortical bone, Journal of Anatomy 211, 654-661 (2007).

[185] F.G. Evans: Mechanical properties and histology of cortical bone from younger and older men, The Anatomical Record 185, 1-11 (1976). 
[186] R. Felfel, I. Ahmed, A. Parsons, L. Harper, C. Rudd: Initial mechanical properties of phosphate-glass fibre-reinforced rods for use as resorbable intramedullary nails, Journal of Materials Science 47, 4884-4894 (2012).

[187] R.M. Felfel, I. Ahmed, A.J. Parsons, C.D. Rudd: Bioresorbable screws reinforced with phosphate glass fibre: Manufacturing and mechanical property characterisation, Journal of the Mechanical Behavior of Biomedical Materials 17, 76-88 (2013).

[188] C.A. Scotchford, M. Shataheri, P.S. Chen, M. Evans, A.J. Parsons, G.A. Aitchison, C. Efeoglu, J.L. Burke, A. Vikram, S.E. Fisher, C.D. Rudd: Repair of calvarial defects in rats by prefabricated, degradable, long fibre composite implants, J. Biomed. Mater. Res. A. 96, 230-238 (2010).

[189] A. Alani, J.C. Knowles, W. Chrzanowski, Y.L. Ng, K. Gulabivala: Ion release characteristics, precipitate formation and sealing ability of a phosphate glasspolycaprolactone-based composite for use as a root canal obturation material, Dent Mater. 25, 400-410 (2009).

[190] T. Ohtomo, F. Mizuno, A. Hayashi, K. Tadanaga, M. Tatsumisago: Electrical and electrochemical properties of $\mathrm{Li}_{2} \mathrm{~S}-\mathrm{P}_{2} \mathrm{~S}_{5}-\mathrm{P}_{2} \mathrm{O}_{5}$ glass-ceramic electrolytes, J. Power Sources 146, 715-718 (2005).

[191] S. Chenu, R. Lebullenger, P. Bérnard-Rocherullé, G. Calvez, O. Guillou, J. Rocherullé, A. Kidari, M.J. Pomeroy, S. Hampshire: Glass reactive sintering as an alternative route for the synthesis of NZP glass-ceramics, J. Mat. Sci. 47, 486-492 (2012).

[192] G. Delaizir, V. Seznec, P. Rozier, C. Surcin, P. Salles, M. Dollé : Electrochemical performances of vitreous materials in the system $\mathrm{Li}_{2} \mathrm{O}-\mathrm{V}_{2} \mathrm{O}_{5}-\mathrm{P}_{2} \mathrm{O}_{5}$ as electrode for lithium batteries, Solid State Ionics 237, 22-27 (2013). 
[193] S.W. Martin, C.A. Angell: Dc and Ac conductivity in wide composition range $\mathrm{Li}_{2} \mathrm{O}-\mathrm{P}_{2} \mathrm{O}_{5}$ glasses, J. Non-Cryst. Solids 83, 185-207 (1986).

[194] H. Takahashi, H. Nakanii, T. Sakuma, Y. Onoda: Sodium ion motion in NaI$\mathrm{AgPO}_{3}$ glasses, Solid State Ionics 179, 2137-2141 (2008).

[195] A.C.M. Rodrigues, M.L.F. Nascimento, C.B. Bragatto, J.-L. Souquet: Charge carrier mobility and concentration as a function of composition in $\mathrm{AgPO}_{3}-\mathrm{AgI}$ glasses, J. Chem. Phys. 135, 234504 (2011).

[196] O.L. Anderson, D.A. Stuart: Calculation of activation energy of ionic conductivity in silica glasses by classical methods, J. Am. Ceram. Soc. 37 [12], 573-580 (1954).

[197] M.D. Ingram, C.T. Moynihan, A.V. Lesikar: Ionic conductivity and the weak electrolyte theory of glass, J. Non-Cryst. Solids, 38\&39, 371-376 (1980).

[198] B. Santic, A. Mogus-Milankovic, D.E. Day: The dc electrical conductivity of iron phosphate glasses, J. Non-Cryst. Solids 296, 65-73 (2001).

[199] M. Wasiucionek, J.E. Garbarczyk, P. Kurek, J. Jakubowski: Electrical properties of glasses of the $\mathrm{Na}_{2} \mathrm{O}-\mathrm{V}_{2} \mathrm{O}_{5}-\mathrm{P}_{2} \mathrm{O}_{5}$ system, Solid State Ionics 70\&71, 346-349 (1994).

[200] J.E. Garbarczyk, P. Jozwiak, M. Wasiucionek, J.L. Nowinski: Effect of nanocrystallization on the electronic conductivity of vanadate-phosphate glasses, Solid State Ionics 177, 2585-2588 (2006).

[201] A.K. Kercher, J.O. Ramey, K.J. Carroll, J.O. Kiggans, N.J. Dudney, R.A. Meisner, L.A. Boatner, G.M. Weith: Mixed polyanion glass cathodes: iron phosphate vanadate glasses, J. Electrochem. Soc. 161 [14], A2210-A2215 (2014).

[202] A.K. Kercher, J.A. Kolopus, K.J. Carroll, R.R. Unocic, S. Kirklin, C. Wolverton, S.L. Stooksbury, L.A. Boatner, N.J. Dudney: Mixed polyanion glass cathodes: glassstate conversion reactions, J. Electrochem. Soc. 163 [2], A131-A137 (2016). 
[203] J.C. Bazan, J.A. Duffy, M.D. Ingram, M.R. Mallace: Conductivity anomalies in tungstate-phosphate glasses: evidence for an ion-polaron interaction?, Solid State Ionics 86-88, 497-501 (1996).

[204] I. Oliva, A. Masuno, H. Inoue, H. Tawarayama, H. Kawazoe: Mixed conduction in alkali niobium tungsten phosphate glasses, Solid State Ionics, 206, 405-409 (2012).

[205] Y. Abe, H. Shimakawa: Protonic conduction in alkaline earth metaphosphate glasses containing, J. Non-Cryst. Solids 51, 357-365 (1982).

[206] H. Sumi, Y. Nakano, Y. Fujishiro, T. Kasuga: Proton conduction of MO-P $\mathrm{P}_{5}$ glasses $(\mathrm{M}=\mathrm{Zn}, \mathrm{Ba})$ containing a large amount of water, Solid State Sciences 45, 5-8 (2015).

[207] N.J. Dudney: Addition of a thin-film inorganic electrolyte (Lipon) as a protective film in lithium batteries with a liquid electrolyte, J. Power Sources 89, 176-179 (2000).

[208] J.B. Bates, N.J. Dudney, B. Neudecker, A. Ueda, C.D. Evans: Thin-film lithium and lithium-ion batteries, Solid State Ionics 135, 33-45 (2000).

[209] S. Jacke, J. Song, L. Dimesso, J. Brötz, D. Becker, W. Jaegermann: Temperature dependent phosphorus oxynitride growth for all-solid-state batteries, J. Power Sources 196, 6911-6914 (2011).

[210] F. Muñoz: Comments on the structure of LiPON thin-film electrolytes, J. Power Sources 198, 432-433 (2012).

[211] F. Muñoz, A. Durán, L. Pascual, L. Montagne, B. Revel, A.C.M. Rodrigues: Increased electrical conductivity of LiPON glasses produced by ammonolysis, Solid State Ionics 179, 574-579 (2008).

[212] N. Mascaraque, J.L.G. Fierro, A. Durán, F. Muñoz: An interpretation for the increase of ionic conductivity by nitrogen incorporation in LiPON oxynitride glasses, Solid State Ionics 233, 73-79 (2013). 
[213] Y. Shimonishi, T. Zhang, N. Imanishi, D. Im, D.J. Lee, A. Hirano, Y. Takeda, O. Yamamoto, N. Sammes: A study on lithium/air secondary batteries-Stability of the NASICON-type lithium ion conducting solid electrolyte in alkaline aqueous solutions, J. Power Sources 196, 5128-5132 (2011).

[214] S. Hasegawa, N. Imanishi, T. Zhang, J. Xie, A. Hirano, Y. Takeda, O. Yamamoto: Study on lithium/air secondary batteries-Stability of NASICON-type lithium ion conducting glass-ceramics with water, J. Power Sources 189, 371-377 (2009).

[215] X. Yu, D.E. Day, G.J. Long, R.K. Brow: Properties and structure of sodium-iron phosphate glasses, J. Non-Cryst. Solids 215, 21-31 (1997).

[216] D.E. Day, Z. Wu, C.S. Ray, P. Hrma: Chemically durable iron phosphate glass wasteforms, J. Non-Cryst. Solids 241, 1-12 (1998).

[217] M.I. Ojovan, W.E. Lee: An introduction to nuclear waste immobilization (Elsevier Science Publishers B.V., Amsterdam 2005).

[218] C.W. Kim, C.S. Ray, D. Zhu, D.E. Day, D. Gombert, A. Aloy, A. MogusMilankovi, M. Karabulut: Chemically durable iron phosphate glasses for vitrifying sodium bearing waste (SBW) using conventional and cold crucible induction melting (CCIM) techniques, Journal of Nuclear Materials 322, 152-164 (2003). 